\title{
Analysis of the Hydrologic Response Associated with Shutdown and Restart of the 200-ZP-1 Pump-and-Treat System
}

F. A. Spane, Jr.

P. D. Thorne

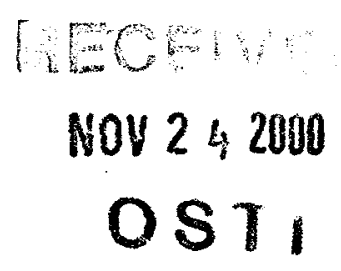

September 2000

Prepared for

the U.S. Department of Energy

under Contract DE-AC06-76RL01830

Pacific Northwest National Laboratory

Richland, Washington 99352 



\section{DISCLAIMER}

This report was prepared as an account of work sponsored by an agency of the United States Government. Neither the United States Government nor any agency thereof, nor any of their employees, make any warranty, express or implied, or assumes any legal liability or responsibility for the accuracy, completeness, or usefulness of any information, apparatus, product, or process disclosed, or represents that its use would not infringe privately owned rights. Reference herein to any specific commercial product, process, or service by trade name, trademark, manufacturer, or otherwise does not necessarily constitute or imply its endorsement, recommendation, or favoring by the United States Government or any agency thereof. The views and opinions of authors expressed herein do not necessarily state or reflect those of the United States Government or any agency thereof. 


\section{DISCLAIMER}

Portions of this document may be illegible in electronic image products. Images are produced from the best available original document. 


\begin{abstract}
A program has been implemented on the Hanford Site that uses the pumping and treatment of contaminated groundwater as part of their remediation strategy. Often, the treated water is reinjected into the aquifer at injection well sites. The implementation of remedial pump-and-treat systems, however, results in hydraulic pressure responses both areally and vertically (i.e., with depth) within the pumped aquifer. The hydraulic responses in the aquifer that result from the operation of the pump-and-treat system can be analyzed to determine large-scale hydraulic properties of the aquifer. In addition, the area within the aquifer affected by the pump-and-treat system (i.e., radius of influence) is commonly estimated based on detecting associated water-level responses within surrounding monitor wells. Natural external stresses such as barometric pressure fluctuations, however, can have a discernible impact on well waterlevel measurements. These temporal barometric effects may significantly mask water-level responses within more distant wells that are only slightly affected $(\leq 0.10 \mathrm{~m})$ by the test system. External stress effects, therefore, can lead to erroneous indications of the radius of influence of the imposed pump-andtreat system remediation activities and can greatly diminish the ability to analyze the associated well responses for hydraulic property characterization. When these extraneous influences are significant, adjustments or removal of the barometric effects from the test-response record may be required for quantitative hydrologic assessment.
\end{abstract}

This report examines possible hydrologic effects of pump-and-treat remediation actions and provides a detailed analysis of water-level measurements for selected 200-ZP-1 pump-and-treat system monitor wells during the recent Y2K shutdown (December 1999) and restart activity (January 2000). Specifically, this report 1) applies recently developed methods for removing barometric pressure fluctuations from well water-level measurements to enhance detection of pump-and-treat system effects at selected monitor wells, 2) analyzes the barometric corrected well water-level responses for determination of large-scale hydraulic properties, and 3) assesses characteristics and conditions that influence hydrologic responses (both laterally and vertically) associated with pump-and-treat systems. The general findings presented in this report have universal application for unconfined and confined aquifer systems. 



\section{Summary}

The use of remedial pump-and-treat systems imposes variable hydrologic pressure responses both areally and vertically (i.e., with depth) within the aquifer. The area within the aquifer affected by the pump-and-treat system (i.e., radius of influence) is commonly determined by detecting associated waterlevel responses within surrounding monitor wells. Discernible hydrologic responses can also be analyzed under favorable conditions to provide estimates of aquifer hydraulic properties. Characterization of hydraulic properties is important for evaluating groundwater-flow and transport characteristics of the aquifer system. An inherent assumption in hydraulic test analysis is that the well water-level responses analyzed are due solely to the imposed hydrologic stress. Natural external stresses such as barometric pressure fluctuations, however, can have a discernible impact on well water-level measurements. These temporal barometric effects may significantly mask water-level responses within more distant wells that are only slightly affected $(\leq 0.10 \mathrm{~m})$ by the pump-and-treat system. External stress effects, therefore, can greatly diminish the ability to analyze the associated well responses for hydraulic property characterization and possibly lead to erroneous indications of the radius of influence of the imposed pump-and-treat system. If they are significant, then removal of these barometric effects from the test-response record may be required to quantify hydraulic properties and assess the area of influence of the pump-and-treat system.

Results indicate that barometric pressure fluctuations can be effectively removed using the multipleregression deconvolution technique, which significantly improves detection and analysis of hydrologic stresses imposed by the 200-ZP-1 pump-and-treat system at surrounding monitor well locations. Use of the barometric pressure-removal method can be used to detect more accurately the hydrologic area of influence (e.g., a response of $0.01 \mathrm{~m}$ ) of the pump-and-treat system in more distant monitor wells.

Analysis of the 200-ZP-1 pump-and-treat system during the $\mathrm{Y} 2 \mathrm{~K}$ restart period provided hydraulic property estimates for transmissivity that ranged between 230 and $430 \mathrm{~m}^{2} / \mathrm{d}$ (average $325 \mathrm{~m}^{2} / \mathrm{d}$ ). The calculated average value compares closely with large-scale values of 300 and $327 \mathrm{~m}^{2} / \mathrm{d}$ previously reported for the unconfined aquifer within the 200-West Area of the Hanford Site. These previously reported values were based on analyzing the areal growth and decline of the groundwater mound that developed in this area as a result of wastewater-disposal activities.

Analysis of the well water-level responses during the $\mathrm{Y} 2 \mathrm{~K}$ restart period also provided estimates for hydraulic conductivity that ranged between 3.5 and $6.6 \mathrm{~m} / \mathrm{d}$ (average $5.0 \mathrm{~m} / \mathrm{d}$ ). The calculated average value is similar to the baseline value of $5.2 \mathrm{~m} / \mathrm{d}$ previously used to simulate large-scale, groundwater-flow conditions for the unconfined aquifer within the 200-West Area. Estimates obtained for specific yield, however, $(\approx 0.03)$ appear to be lower than expected (i.e., between 0.05 to 0.25$)$ for this hydrogeologic unit. The reason for this apparent discrepancy is not completely understood; however, the lower value is consistent with patterns reported for other unconfined aquifer sites using type-curve analysis methods. A more controlled hydrologic test in the future at the 200-ZP-1 pump-and-treat facility may provide more definitive information pertaining to this important hydrologic parameter. 
Operation of the pump-and-treat system induces both horizontal and vertical groundwater-flow components within the aquifer. Based on the investigation performed, it is likely that the pump-andtreat system imposes a discernible hydrologic response over a significant area surrounding the remediation facility (i.e., $>500 \mathrm{~m}$ for pumping times of 1 month or more). The distance, or radius of influence, is a function of a number of physical factors and test facility operation characteristics. Important physical factors include aquifer properties (i.e., hydraulic conductivity, vertical anisotropy, specific yield, aquifer thickness) and well/aquifer completion relationships (i.e., partial penetration aspect). Test facility operation characteristics include the location, duration, magnitude, and variability of groundwater extraction and injection within the aquifer.

Vertical flow conditions imposed by the pump-and-treat system result from the downward movement of water that is released as the water table declines. This is associated with the delayed-yield phenomenon, which is characteristic of unconfined aquifers. The magnitude of the vertical flow component is primarily a function of the depth location within the aquifer (proximity to the water table), vertical anisotropy, aquifer thickness, and radial distance from the pumping well site(s). These factors collectively define hydrologic response (drawdown) at a point within the aquifer. The examples indicate that a downward groundwater-flow component occurs within the upper part of the aquifer during early and intermediate time periods of pumping. Vertical flow, though persistent with distance, diminishes with time, becoming negligible for protracted periods of pump-and-treat system operation. For the theoretical example, small, vertical flow components (i.e., based on drawdown differences $\leq 0.004 \mathrm{~m}$ ) were still evident after 1 year of pumping for radial distances $>100 \mathrm{~m}$ from the pumping well. Pumping wells that partially penetrate the upper part of the aquifer do not preclude vertical downward flow within the upper part of the aquifer but likely diminish the persistence of this effect with time. Additionally, upward vertical flow from the lower part of the aquifer is induced, particularly for areas in proximity to the pumping well.

The hydrologic impact of the pump-and-treat system on the underlying confined aquifer system below the Ringold Lower Mud Unit is largely unknown. However, removal of barometric pressure and earthtide-stress effects from the well 299-W14-9 water-level record, which monitors this underlying confined aquifer system, reveals a hydrologic response that appears associated with the pump-and-treat shutdown and startup activities. This apparent association was not evident in the uncorrected waterlevel response. Possible hydrologic conceptual models responsible for this associated confined aquifer response include pervasive confining layer leakage through the intervening lower mud unit, loading phenomena (i.e., increases and decreases in the overlying unconfined aquifer saturated thickness), direct hydrogeologic communication (in distant areas where the mud unit is absent), or local communication attributed to possible deficient monitor well-completion conditions. With additional study, it may be possible to distinguish between which of the conceptual models is responsible for the imposed response evident at well 299-W14-9.

The analysis of areal water-level responses imposed by the pump-and-treat system provide an opportunity for obtaining detailed, large-scale information for a wide range of hydrologic properties, including transmissivity, hydraulic conductivity, vertical and horizontal anisotropy, storativity, and specific yield. Many of these properties cannot be reliably estimated using standard single-well tests or hydrologic tests of short duration. This large-scale, hydrologic characterization information can 
provide valuable input for assessing the performance of the pump-and-treat facility and for predicting contaminant movement in the 200 -West Area. The wide variability in pumping and injection rates, while acceptable for normal operation of the pump-and-treat facility, greatly complicates this hydrologic characterization opportunity. Operating the pump-and-treat system in a more controlled manner over a 2 - or 3-month period would likely provide the best opportunity for obtaining more accurate, large-scale, hydrologic characterization information. 



\section{Acknowledgments}

Several Pacific Northwest National Laboratory (PNNL) staff provided significant contributions to this report's preparation. Technical peer review and editorial comments were provided by T. J Gilmore and B. V. Johnston, respectively. Graphics support given by D. R. Newcomer, T. J Gilmore, and W. D. Webber is also acknowledged. Thanks are also extended to $\mathrm{S}$. K. Wurstner for providing program software modifications.

A number of people in addition to PNNL staff also contributed to the development of this report. In particular, test data and discussions pertaining to the operation of the 200-ZP-1 pump-and-treat system were provided by L. C. Swanson, G. L. Scheidegger, W. J. McMahon, and C. C. Koerner of CH2M-Hill. In addition, L. C. Swanson of CH2M-Hill, and R. D. Hildebrand and A. C. Tortoso of the U.S. Department of Energy, Richland Operations Office, also provided technical peer review comments. 



\section{Nomenclature}

$\mathrm{b}=$ aquifer thickness; $\mathrm{L}$

$\mathrm{BE}=$ barometric efficiency, equal to $-\gamma_{\mathrm{fc}}\left(\Delta \mathrm{h}_{\mathrm{w}} / \Delta \mathrm{P}_{\mathrm{a}}\right)$; dimensionless

$\mathrm{BE}_{\text {long }}=$ barometric efficiency calculated by simple linear regression; dimensionless

$\mathrm{BE}_{\text {short }}=$ barometric efficiency calculated by Clark method (1967); dimensionless

$D_{a}=$ vertical pneumatic diffusivity of the vadose zone; $L^{2} / T$

$\Delta \mathrm{h}_{\mathrm{w}}=$ change in well water-level elevation as a result of atmospheric pressure change; $\mathrm{L}$

$\mathrm{K}_{\mathrm{D}}=$ vertical anisotropy $\left(\mathrm{K}_{\mathrm{v}} / \mathrm{K}_{\mathrm{h}}\right)$; dimensionless

$\mathrm{K}_{\mathrm{h}}=$ hydraulic conductivity in the horizontal direction; $\mathrm{L} / \mathrm{T}$

$\mathrm{K}_{\mathrm{v}}=$ hydraulic conductivity in the vertical direction; $\mathrm{L} / \mathrm{T}$

$\Delta \mathrm{P}_{\mathrm{a}}=$ change in atmospheric pressure; $\mathrm{F} / \mathrm{L}^{2}$

$\mathrm{Q}=$ pumping rate; $\mathrm{L}^{3} / \mathrm{T}$

$r=$ radial distance from pumped well to monitor well location; $\mathrm{L}$

$\mathrm{r}_{\mathrm{w}}=$ radius of pumping well; $\mathrm{L}$

$\mathrm{s}=$ drawdown; $\mathrm{L}$

$\mathrm{s}_{\mathrm{D}}=$ dimensionless drawdown

$\mathrm{S}=$ storativity; dimensionless

$\mathrm{S}_{\mathrm{y}}=$ specific yield; dimensionless

$\mathrm{T}=$ transmissivity; $\mathrm{L}^{2} / \mathrm{T}$

$\mathrm{t}=$ time; $\mathrm{T}$

$t_{s}=$ dimensionless time with respect to $S$

$t_{y}=$ dimensionless time with respect to $S_{y}$

$Z_{D}=$ dimensionless depth within the aquifer, equal to $\mathrm{z} / \mathrm{b}$

$Z=$ aquifer depth below water table; $\mathrm{L}$

$\beta=$ dimensionless unconfined aquifer parameter, equal to $K_{D} r^{2} / b^{2}$

$\sigma=$ dimensionless unconfined aquifer parameter, equal to $S / S_{y}$

$\gamma_{\mathrm{fc}}=$ average specific weight of the fluid column within the well; F/L3 



\section{Contents}

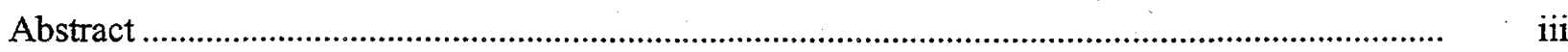

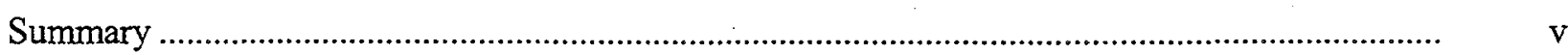

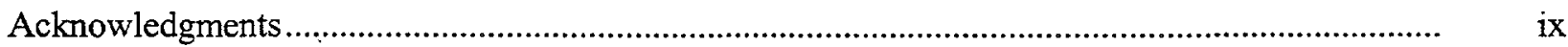

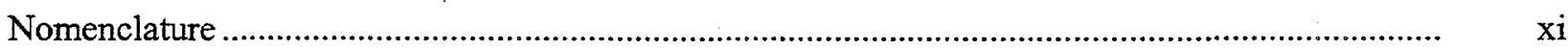

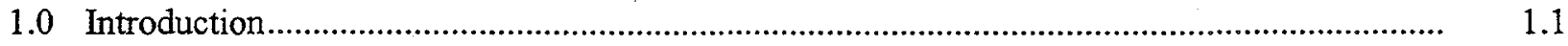

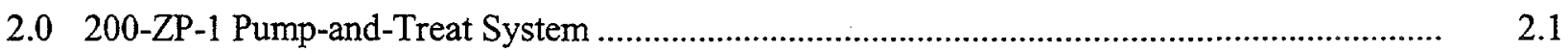

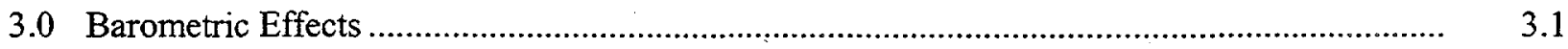

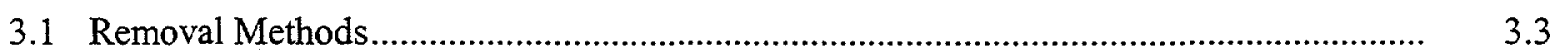

3.1.1 Multiple-Regression Techniques.................................................................. $\quad 3.4$

3.1.2 Vadose Zone Model....................................................................................... $\quad 3.10$

3.1.3 Removal Method Comparison ....................................................................... 3.12

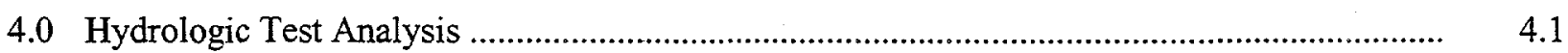

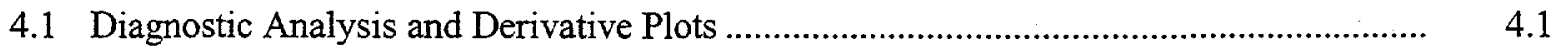

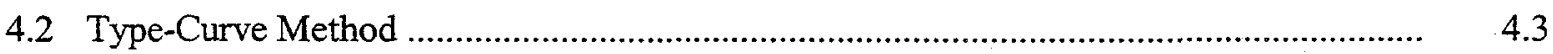

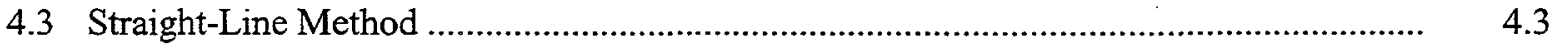

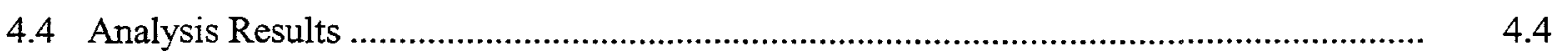

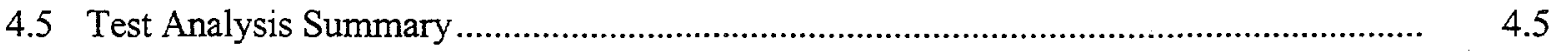

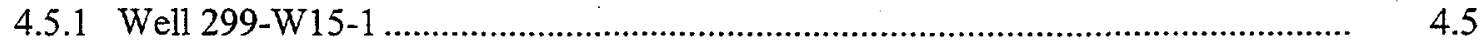

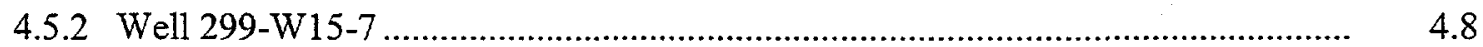

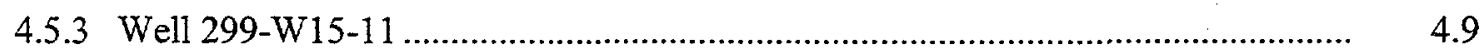

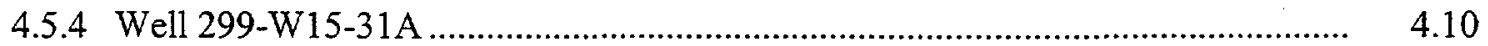

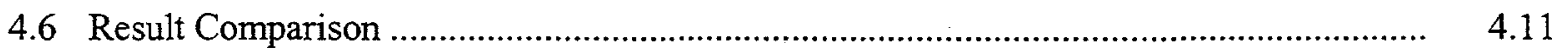

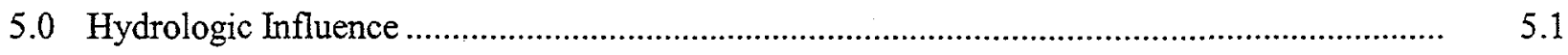

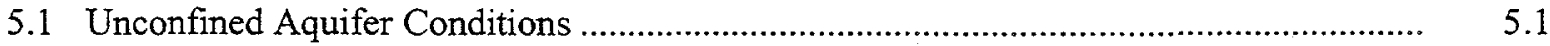

5.1.1 Aquifer Depth ........................................................................................ 5.3 
5.1.2 Vertical Anisotropy ................................................................................. 5.4

5.1.3 Well Partial Penetration ........................................................................... 5.5

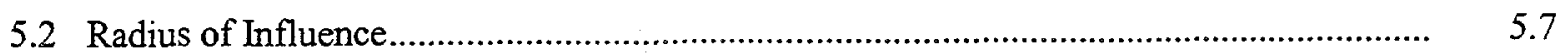

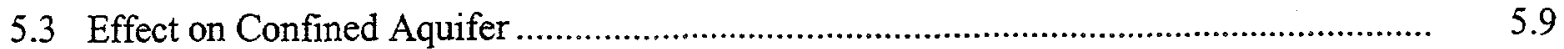

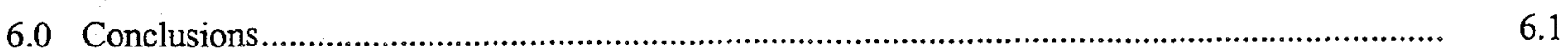

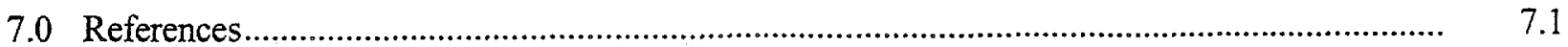

Appendix - Multiple-Regression, Model-Predicted, and Barometric Corrected Water-Level Elevation Responses for Monitor Wells 299-W15-7, -11, and 31A............................. A.1 


\section{Figures}

2.1 Location Map of Wells Within the 200-ZP-1 Operable Unit

2.2 Generalized Geologic Cross Section in the Vicinity of the 200-ZP-1 Pump-and-

Treat System

2.3 Baseline Water-Level Elevation and Atmospheric Pressure Measurements for Monitor Wells 299-W15-1, -7, -11, and -31A.

2.4 Daily Pumping History for Extraction Wells 299-W15-33, -34, and -35 and Associated Water-Level Responses for Monitor Well 299-W15-11

3.1 Well Barometric Pressure-Response Models

3.2 Composite Diagnostic Response Function for Wellbore-Storage/Unconfined Aquifer Model.

3.3 Water-Level Barometric Response Patterns for Monitor Wells 299-W15-1, -7, -11, and $-31 \mathrm{~A}$.

3.4 Multiple-Regression, Model-Predicted, and Barometric Corrected Water-Level Elevation Responses for Monitor Well 299-W15-1, October 27 to November 15, 1999.

3.5 Multiple-Regression, Model-Predicted, and Barometric Corrected Water-Level Elevation Responses for Monitor Well 299-W15-1, December 6, 1999 to February 14, 2000.

3.6 Vadose Zone, Model-Predicted, and Barometric Corrected Water-Level Elevation Responses for Monitor Well 299-W15-1, October 27 to November 15, 1999

4.1 Characteristic Log-Log Drawdown and Drawdown Derivative Plots for Various Hydrogeologic Formation and Boundary Conditions.

4.2 Composite Type-Curve and Derivative Plot Analysis of Drawdown Test Data for Monitor Well 299-W15-1

4.3 Calculated Drawdown Curves for Selected $\mathrm{K}_{\mathrm{D}}$ Values.

4.4 Predicted Responses at Monitor Well 299-W15-1 for the Four 200-ZP-1 Stress Wells.

4.5 Composite Type-Curve and Derivative Plot Analysis of Drawdown Test Data for. Monitor Well 299-W15-7. 
4.6 Composite Type-Curve and Derivative Plot Analysis of Drawdown Test Data for Monitor Well 299-W15-11

4.7 Composite Type-Curve and Derivative Plot Analysis of Drawdown Test Data for Monitor Well 299-W15-31A

5.1 Dimensionless Type-Curve Responses for Fully Penetrating Wells Within Unconfined Aquifers

5.2 Dimensionless Type-Curve Responses as a Function of Aquifer Depth

5.3 Dimensionless Type-Curve Responses as a Function of Aquifer Depth and Vertical Anisotropy

5.4 Dimensionless Flow Pattern Around Pumping Well that Penetrates the Upper $20 \%$ of an Isotropic Unconfined Aquifer

5.5 Predicted Average Aquifer Drawdown Versus Distance After 1 Week, 1 Month, and 1 Year

5.6 Predicted Aquifer Drawdown After 1 Week as a Function of Aquifer Depth

5.7 Baseline Water-Level Elevation and Atmospheric Pressure Measurements for Monitor Well 299-W14-9, December 16, 1999 to February 14, 2000

5.8 Water-Level Barometric Response Pattern for Monitor Well 299-W14-9

5.9 Multiple-Regression, Model-Predicted, and Barometric Corrected Water-Level Elevation Responses for Monitor Well 299-W14-9, January 25 to February 13, 2000.

5.10 Earthtide Potential and Barometric and Earthtide-Corrected Water-Level Elevation Responses for Monitor Well 299-W14-9, December 16 to December 31, 1999.

5.11 Barometric and Earthtide-Corrected Water-Level Elevation Responses for Monitor Well 299-W14-9, December 16, 1999 to February 14, 2000 


\section{Tables}

2.1 Distance Relationships Between Selected Wells Within the 200-ZP-1 Remedial Action Assessment Well Network.

2.2 As-Built Relationships for Selected Wells Within the 200-ZP-1 Remedial Action Assessment Well Network

3.1 Multiple-Regression Analysis for Monitor Wells 299-W15-1, -7, and -11 ....................... 3.6

3.2 Multiple-Regression Analysis for Monitor Well 299-W15-31A......................................

3.3 Summary of Regression Analysis Results for Wells 299-W14-9, 299-W15-1, -7, -11 , and $-31 \mathrm{~A}$.

3.4 Vadose Zone Model Analysis Results for Wells 299-W15-1, -7, -11, and -31A .................. 3.12

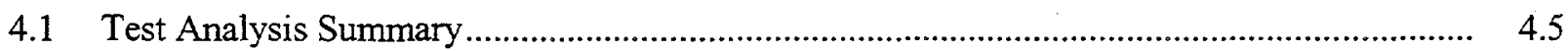




\subsection{Introduction}

Pacific Northwest National Laboratory's ${ }^{(a)}$ Hanford Groundwater Monitoring Project assesses the potential for on- and offsite migration of contamination within the shallow unconfined aquifer system and the underlying upper basalt-confined aquifer system at the Hanford Site. As part of this activity, waterlevel measurements (i.e., water-level elevations) are routinely monitored within selected wells completed in these aquifer systems to determine groundwater-flow directions and gradients. Analysis of hydraulic head conditions provides areal and temporal information that can be used in the development of a watertable, or potentiometric, map for inferring lateral groundwater-flow patterns and for assessing the flow dynamics of the monitored aquifer system. In addition, analysis of hydraulic head responses obtained in wells during hydrologic tests (e.g., pumping tests) provides estimates of hydraulic properties, which are important for evaluating groundwater-flow velocity and transport travel time within the aquifer system.

A program has been implemented on the Hanford Site that uses the pumping and treatment of contaminated groundwater as part of their remediation strategy (e.g., DOE/RL 2000). Often, the treated water is reinjected into the aquifer at injection well sites. The implementation of remedial pump-and-treat systems, however, results in hydraulic pressure responses both areally and vertically (i.e., with depth) within the pumped aquifer. The area within the aquifer affected by the pump-and-treat system (i.e., radius of influence) is commonly estimated based on detecting associated water-level responses within surrounding monitor wells. Discernible hydrologic responses can also be analyzed, under favorable conditions, to provide estimates of aquifer hydraulic properties. The hydraulic response caused by a pump-and-treat system provides the opportunity to produce a large-scale aquifer test over a longer duration than is practical for standard hydrologic tests. The analysis of large-scale, hydrologic test responses can result in improved estimates of hydraulic properties and better estimates of remediation times for the aquifer system.

An inherent assumption in hydraulic test analysis is that the well water-level responses analyzed are caused solely by the imposed hydrologic stress. Natural external stresses such as barometric pressure fluctuations, however, can have a discernible impact on well water-level measurements. These temporal barometric effects may significantly mask water-level responses within more distant wells that are only slightly affected $(\leq 0.10 \mathrm{~m})$ by the test system. External stress effects, therefore, can greatly diminish the ability to analyze the associated well responses for hydraulic property characterization. External stresses can also lead to erroneous indications of the radius of influence of the imposed pump-and-treat system remediation activities. When these extraneous influences are significant, adjustments or removal of the barometric effects from the test-response record may be required for quantitative hydraulic property determination and area-of-influence assessment.

This report examines the possible hydrologic effects of pump-and-treat remediation actions within unconfined aquifers and provides a detailed analysis of water-level measurements for selected 200-ZP-1 pump-and-treat system monitor wells during the recent $\mathrm{Y} 2 \mathrm{~K}$ shutdown and restart activity (December

(a) Pacific Northwest National Laboratory is operated for the U.S. Department of Energy by Battelle. 
1999/January 2000). Section 2.0 describes aspects of the 200-ZP-1 pump-and-treat system and the remediation of the existing carbon tetrachloride groundwater contamination. The effects of barometric pressure fluctuations and their removal from monitor well water levels are discussed in Section 3.0. Results of the hydrologic test analyses are given in Section 4.0. Section 5.0 describes the influences that aquifer and well characteristics have on the hydrologic responses produced by pump-and-treat systems. Conclusions are given in Section 6.0, followed by the references cited in the text in Section 7.0. An appendix of additional information is provided. Also, a list of the scientific nomenclature used throughout this report is provided on page xi. 


\subsection{0-ZP-1 Pump-and-Treat System}

The 200-ZP-1 pump-and-treat system was put into operation in August 1994 as part of a designed interim remediation activity to treat carbon tetrachloride $\left(\mathrm{CCl}_{4}\right)$ contamination within the 200 -West Area, north of the Plutonium Finishing Plant. The interim remediation activity was implemented in three phases: Phase I (completed over August 1994 to July 1996) consisted of a pilot-scale treatability field test, Phase II (completed between August 1996 to August 1997) consisted of a small-scale field test program, and Phase III (initiated in August 1997 and currently ongoing) represents an expansion of pumpand-treat system activities initiated under Phases I and II. Pertinent information pertaining to the design, history, and analysis of the operation of the 200-ZP-1 pump-and-treat system can be found in annual U.S. Department of Energy (DOE).reports (e.g., DOE/RL 1998, 1999, 2000). Locations of various extraction, injection, and monitor wells used in the 200-ZP-1 pump-and-treat system are shown in Figure 2.1.

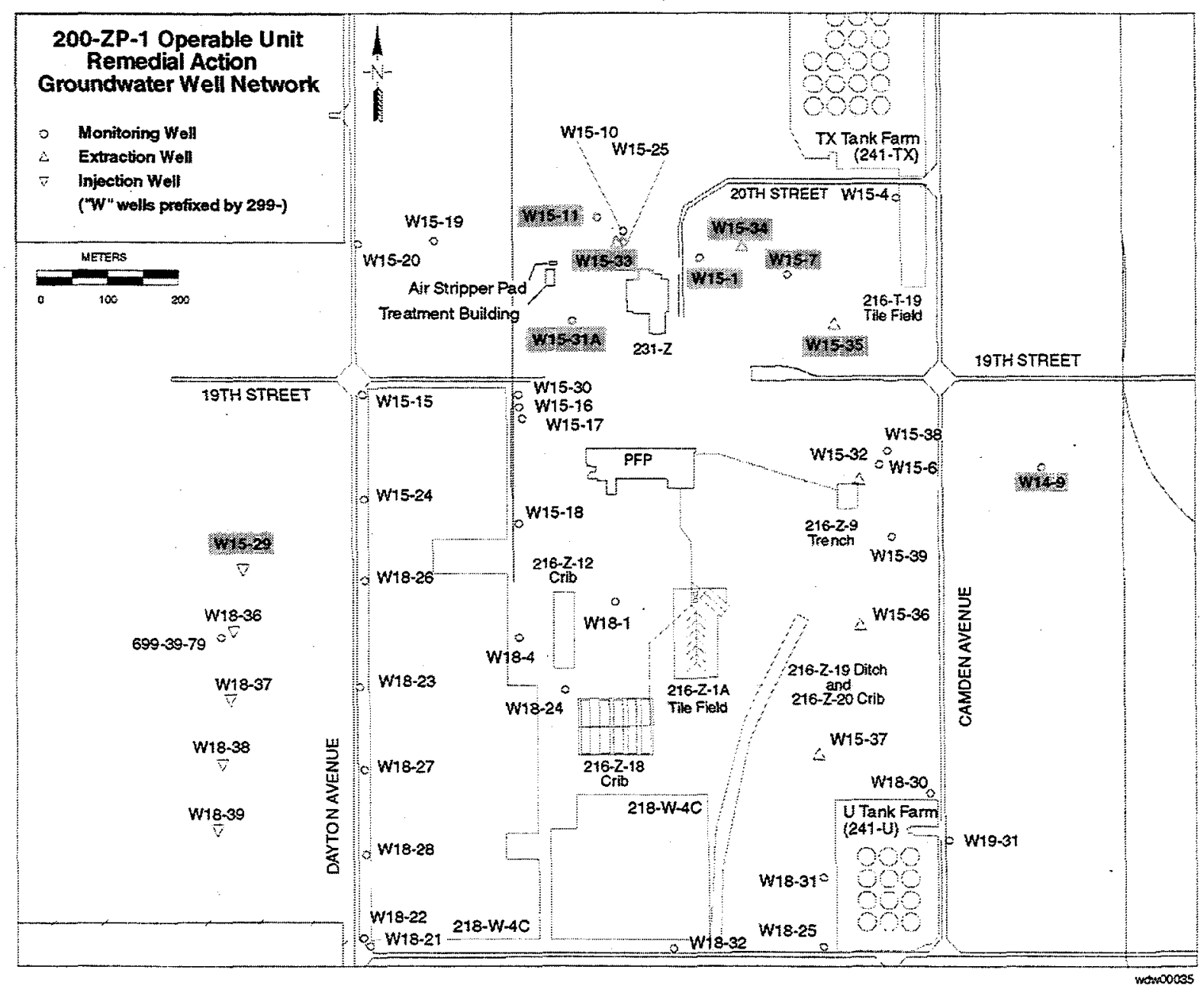

Note: Shaded wells designate 200-ZP-1 wells discussed in this report.

Figure 2.1. Location Map of Wells Within the 200-ZP-1 Operable Unit (adapted from Hartman 1999) 
As noted in Hartman et al. (2000), interim action items specified in ROD (1995) for the remediation activity included

- preventing further movement of $\mathrm{CCl}_{4}$ contamination from the highest concentration area of the plume (i.e., $\mathrm{CCl}_{4}$ area $>2,000 \mu \mathrm{g} / \mathrm{L}$ )

- reducing contamination in the area of highest $\mathrm{CCl}_{4}$ concentrations

- providing information that will lead to development of a final remedy that will be protective of human health and the environment.

Figure 2.2 shows a generalized geologic cross section of sediments in the vicinity of the $200-\mathrm{ZP}-1$ pump-and-treat system, which is installed within the uppermost aquifer in the central 200-West Area. The aquifer is unconfined and lies within Ringold Unit E, which is reported by Lindsey (1995) to be composed of gravel, with a fine-sand matrix and contains local sand and silt beds. These sediments are partially to well-indurated and have variable amounts of secondary mineralization. The uppermost aquifer is underlain by a lacustrine mud unit called the Ringold Lower Mud. This mud unit separates the uppermost aquifer from a locally confined aquifer within the underlying Ringold Unit A gravel (basal Ringold), which lies above the basalt bedrock. Other confined aquifers are present within the deeper basalt formations. The mud unit that separates the uppermost unconfined aquifer from the underlying Ringold Unit A gravel is continuous over most of the Hanford Site, but is missing just north of the 200-West Area, 2,000 $\mathrm{m}$ from the 200-ZP-1 pump-and-treat system.

To evaluate the aquifer hydraulic response to the $\mathrm{Y} 2 \mathrm{~K}$ shutdown (December 14, 1999) and restart (January 3, 2000), four monitor wells within the 200-ZP-1 network (299-W15-1, -7, -11, and -31A) were selected for detailed water-level analysis. To facilitate the analysis of stresses imposed by the pump-andtreat system for hydraulic characterization purposes, a variety of monitor-well to extraction-well distance relationships were examined. Two wells were selected that were likely to be primarily affected by only one of the extraction wells. For this test analysis case, the two selected monitor wells were located at different radial distances from extraction well 299-W15-33. For the remaining analysis case, two monitor wells were selected that were located between and affected primarily by two different pairs of extraction wells. For this case, monitor well 299-W15-1 is located between extraction wells 299-W15-33 and -34, while monitor well 299-W15-7 is situated between extraction wells $299-W 15-34$ and -35 . The distance relationships between the monitor and extraction wells are shown in Figure 2.1 and listed in Table 2.1, respectively. Pertinent well-completion information is also provided in Table 2.2 .

Figure 2.3 shows the observed well water-level responses for the four selected 200-ZP-1 monitor wells over the period October 14, 1999 to February 14, 2000 (1999 calendar days 290 to 410), which shows well responses prior to, during, and following the $\mathrm{Y} 2 \mathrm{~K}$ shutdown/restart period. Also shown for visual comparison is the atmospheric pressure response during this period, as recorded at the nearby Hanford Meteorology Station. Notable times during the baseline monitoring period when the pump-andtreat system was inactive (i.e., shutdown) include November 15 - December 1, 1999 (1999 calendar days 


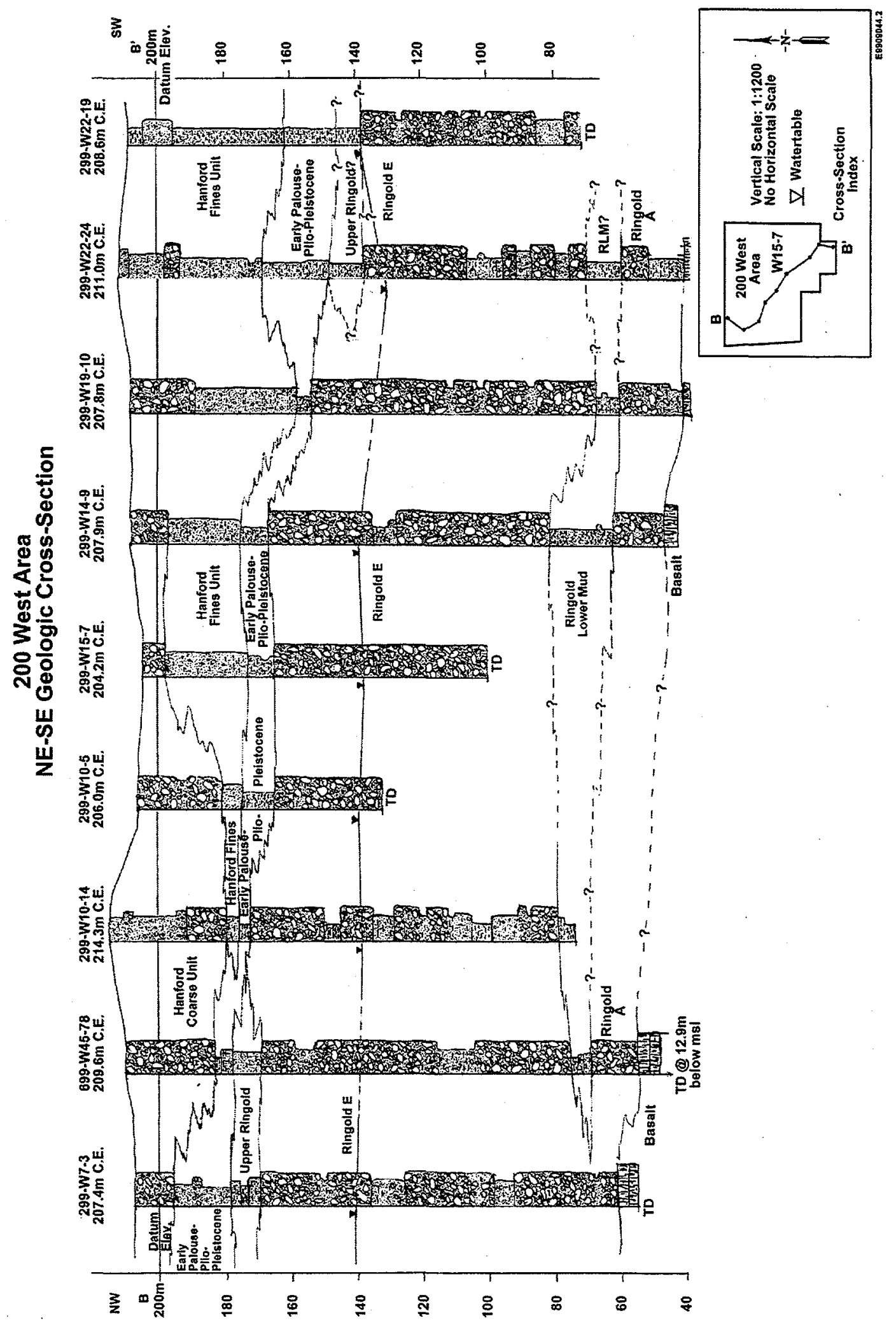

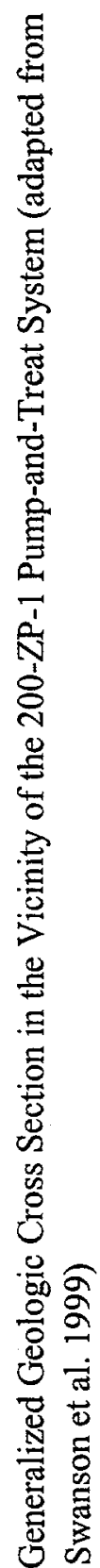

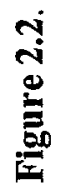


Table 2.1. Distance Relationships Between Selected Wells Within the 200-ZP-1 Remedial Action Assessment Well Network

\begin{tabular}{|c|c|c|c|c|}
\hline \multirow[b]{2}{*}{ Well } & \multicolumn{4}{|c|}{ Well-Distance Relationships, $\mathrm{m}$} \\
\hline & $\begin{array}{c}\text { From Well } \\
299-W 15-33\end{array}$ & $\begin{array}{c}\text { From Well } \\
299-W 15-34\end{array}$ & $\begin{array}{c}\text { From Well } \\
299-W 15-35\end{array}$ & $\begin{array}{c}\text { From Well } \\
299-W 15-29\end{array}$ \\
\hline 299-W15-1 & 123.32 & 61.64 & 205.63 & 769.27 \\
\hline 299-W15-7 & 247.00 & 74.31 & 92.33 & 860.90 \\
\hline 299-W15-11 & 39.97 & 205.11 & 358.76 & 697.10 \\
\hline 299-W15-29 & 688.85 & 828.08 & 888.67 & 0.00 \\
\hline 299-W15-31A & 124.06 & 258.31 & 362.17 & 574.84 \\
\hline 299-W15-33 & 0.00 & 180.22 & 326.39 & 688.85 \\
\hline 299-W15-34 & 180.22 & 0.00 & 165.43 & 828.08 \\
\hline $299-W 15-35$ & 326.39 & 165.43 & 0.00 & 888.67 \\
\hline \multicolumn{5}{|c|}{$\begin{array}{l}\text { Monitor Wells: } 299-W 15-1,-7,-11,-31 \text { A. } \\
\text { Extraction Wells: } 299-W 15-33,-34,-35 \text {. } \\
\text { Injection Well: } 299-W 15-29 .\end{array}$} \\
\hline
\end{tabular}

Table 2.2. As-Built Relationships for Selected Wells Within the 200-ZP-1 Remedial Action Assessment Well Network

\begin{tabular}{|c|c|c|c|}
\hline \multirow[b]{2}{*}{ Well } & \multicolumn{3}{|c|}{ As-Built Relationships, $\mathrm{m}$} \\
\hline & $\begin{array}{c}\text { Ground-Surface/Brass- } \\
\text { Cap Elevation, m, MSL } \\
\text { (NAVD88) }\end{array}$ & $\begin{array}{l}\text { Depth Below Ground } \\
\text { Surface/Brass Cap, m }\end{array}$ & $\begin{array}{c}\text { Saturated Well-Screen Section, } \\
\text { m, MSL (NAVD88) }\end{array}$ \\
\hline 299-W15-1 & 206.11 & $57.91-82.30$ & $\begin{array}{c}138.5-123.81 \\
(14.69)^{(a)}\end{array}$ \\
\hline 299-W15-7 & 203.33 & $55.47-106.68$ & $\begin{array}{c}138.5-96.65 \\
(41.85) \\
\end{array}$ \\
\hline 299-W15-11 & 207.35 & $55.78-90.53$ & $\begin{array}{c}138.5-116.82 \\
(21.68)\end{array}$ \\
\hline 299-W15-29 & 212.15 & $64.04-88.43$ & $\begin{array}{c}138.5-123.73 \\
(14.77)\end{array}$ \\
\hline $299-W 15-31 \mathrm{~A}$ & 207.66 & $64.76-76.93$ & $\begin{array}{c}138.5-130.73 \\
(7.77)\end{array}$ \\
\hline 299-W15-33 & 206.83 & $64.54-80.47$ & $\begin{array}{c}138.5-126.37 \\
(12.13) \\
\end{array}$ \\
\hline 299-W15-34 & 204.91 & $64.16-79.43$ & $\begin{array}{c}138.5-125.48 \\
(13.02)\end{array}$ \\
\hline 299-W15-35 & 202.88 & $62.83-78.09$ & $\begin{array}{c}138.5-124.79 \\
(13.71) \\
\end{array}$ \\
\hline \multicolumn{4}{|c|}{$\begin{array}{l}\text { (a) Number in parentheses is saturated thickness. } \\
\text { Monitor Wells: } 299-\text { W15-1, }-7,-11,-31 \text { A. } \\
\text { Extraction Wells: } 299-\text { W } 15-33,-34,-35 \text {. } \\
\text { Injection Well: } 299-\text { W } 15-29 . \\
\text { MSL: mean sea level. NAVD 88: North American Vertical Datum of } 1988 .\end{array}$} \\
\hline
\end{tabular}




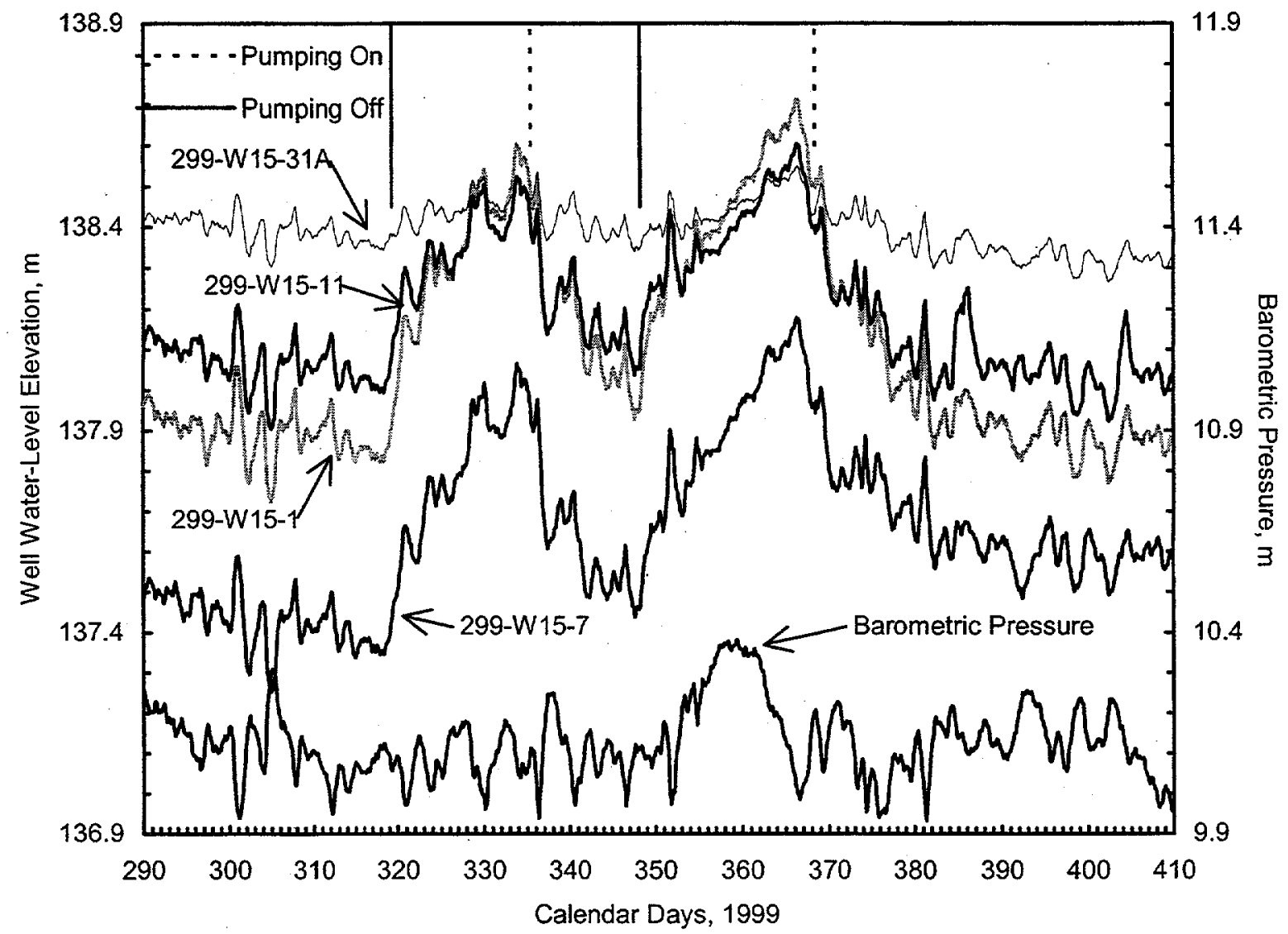

Figure 2.3. Baseline Water-Level Elevation and Atmospheric Pressure Measurements for Monitor Wells 299-W15-1, -7, -11, and -31A (October 14, 1999 to February 14, 2000)

319 to 335), December 14, 1999 - January 3, 2000 (1999 calendar days 348 to 368), and February 13, 2000 (1999 calendar day 410). The pump-and-treat system was active during all other times during the baseline time period.

As indicated in Figure 2.3, water-level responses for wells 299-W15-1, -7, and -11 exhibit similar baseline patterns during the time period, which reflect $200-\mathrm{ZP}-1$ pump-and-treat system activities. The effects of temporal barometric pressure fluctuations also exhibit an easily discernible inverse relationship (i.e., increasing barometric pressure causes a decreasing well water-level elevation), which is superimposed on the pump-and-treat induced response at the monitor wells. In contrast to these well-response patterns, well 299-W15-31 A exhibits a less obvious response to pump-and-treat activities, and temporal barometric pressure fluctuations significantly mask any observable pump-and-treat response. The smaller water-level response at well 299-W15-31A associated with pump-and-treat activities may be attributable, in part, to the overall greater distance to the extraction well centers.

Pumping at the various extraction wells was not uniform during the periods when the 200-ZP-1 pump and treat system was active. Figure 2.4 shows the daily discharge variability at the three closest extraction wells and the associated well water-level responses at monitor well 299-W15-11 for the baseline 


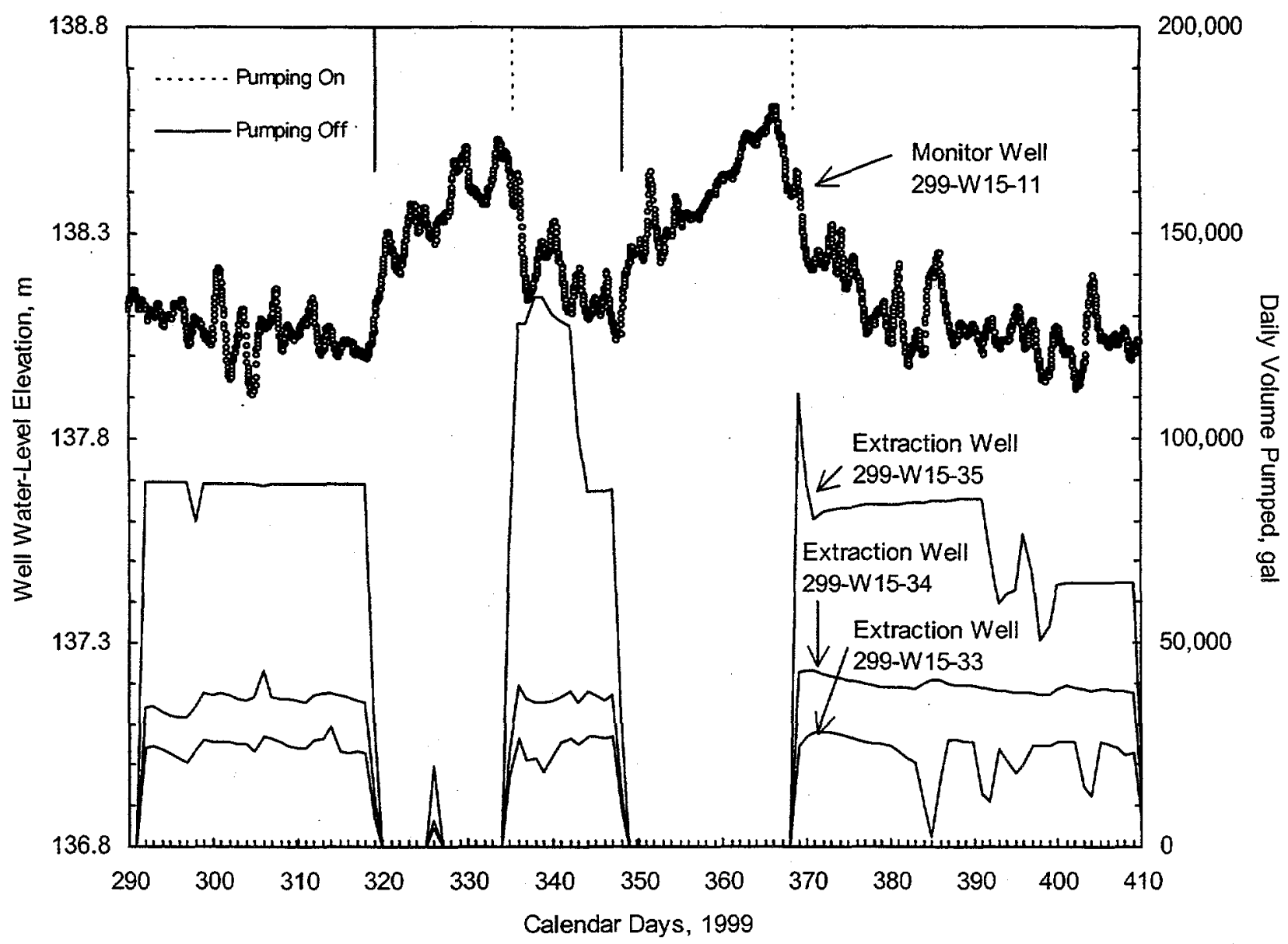

Figure 2.4. Daily Pumping History for Extraction Wells 299-W15-33, -34, and -35 and Associated Water-Level Responses for Monitor Well 299-W15-11

monitoring period. As shown, more daily pumping variability was exhibited for extraction wells 299W15-33 and -35 during the test system restart on January 3, 2000 (1999 calendar day 368). Because of its proximity $(\sim 40 \mathrm{~m})$ to extraction well $299-\mathrm{W} 15-33$, daily pumping variability had a slight but noticeable effect on the well water-level response. Because of the great distance $(575$ to $860 \mathrm{~m})$ to the closest injection well (i.e., well 299-W15-29), no significant effect was anticipated on the four monitor well water-level responses examined in this report. For this reason, no injection rate history is shown in Figure 2.4; however, for completeness, injection occurring at well 299-W15-29 was included in the subsequent test analysis section. 


\subsection{Barometric Effects}

The following discussion of barometric effects on well water-level measurements is taken primarily from Spane (1999). Briefly stated, however, well water-level elevations and hydraulic head conditions within aquifers commonly respond to variations in atmospheric pressure. Barometric fluctuations represent an areal, blanket stress applied directly at land surface and to the open well water-level surface. The manner in which a well/aquifer system responds to changes in atmospheric pressure, however, is variable and directly related to the degree of aquifer confinement and hydraulic/storage characteristics of the well/aquifer system. Rasmussen and Crawford (1997) identified three conceptual models that describe well water-level measurement response associated with barometric pressure change. These include an instantaneous well response within confined aquifers, a delayed well response within unconfined aquifers (because of the delayed transmission of barometric pressure through the vadose zone), and a delayed well response associated with well characteristics (i.e., wellbore-storage and wellskin effects).

Rasmussen and Crawford (1997) provided a method for distinguishing the operative response model affecting well water-level measurements associated with barometric pressure change. Diagnostic plots for the three well-response models are shown in Figure 3.1. The plots show the time-lag dependence of each barometric response model associated with a unit step change in atmospheric pressure. As shown in Figure 3.1, each barometric response model has a distinguishing shape pattern that can be used diagnostically to identify the response model. As might be expected, composite responses can occur between the wellbore-storage model and either aquifer model.

It should be noted that the barometric model patterns indicated in Figure 3.1 are specifically for well water-level response. Different barometric response relationships would occur for total head conditions within the aquifer (i.e., non-well-response models). Aquifer total head barometric response models within confined and unconfined aquifer systems would be the inverse of those exhibited for the well water-level response. Knowing the effect of barometric pressure on the aquifer total head is important when well measurements are used spatially for determining areal groundwater-flow characteristics (i.e., flow direction, velocity). For well test analysis applications, however, conversion to aquifer head conditions is not necessary, and removing barometric fluctuation effects directly from well water-level measurements (i.e., water-level elevations) using one of the methods discussed in Spane (1999) may be more convenient for field test comparisons. For this reason, the remainder of the discussion will deal primarily with well water-level elevations and not aquifer total head conditions.

As noted above, composite wellbore-storage/skin models with either confined or unconfined aquifer models can occur. Spane (1999) presented diagnostic plots that show composite model patterns for a variety of wellbore-storage/skin conditions for both aquifer models. Figure 3.2 shows an example of composite model behavior for an unconfined aquifer with wellbore storage (skin $=0$ ) for the given test conditions. 


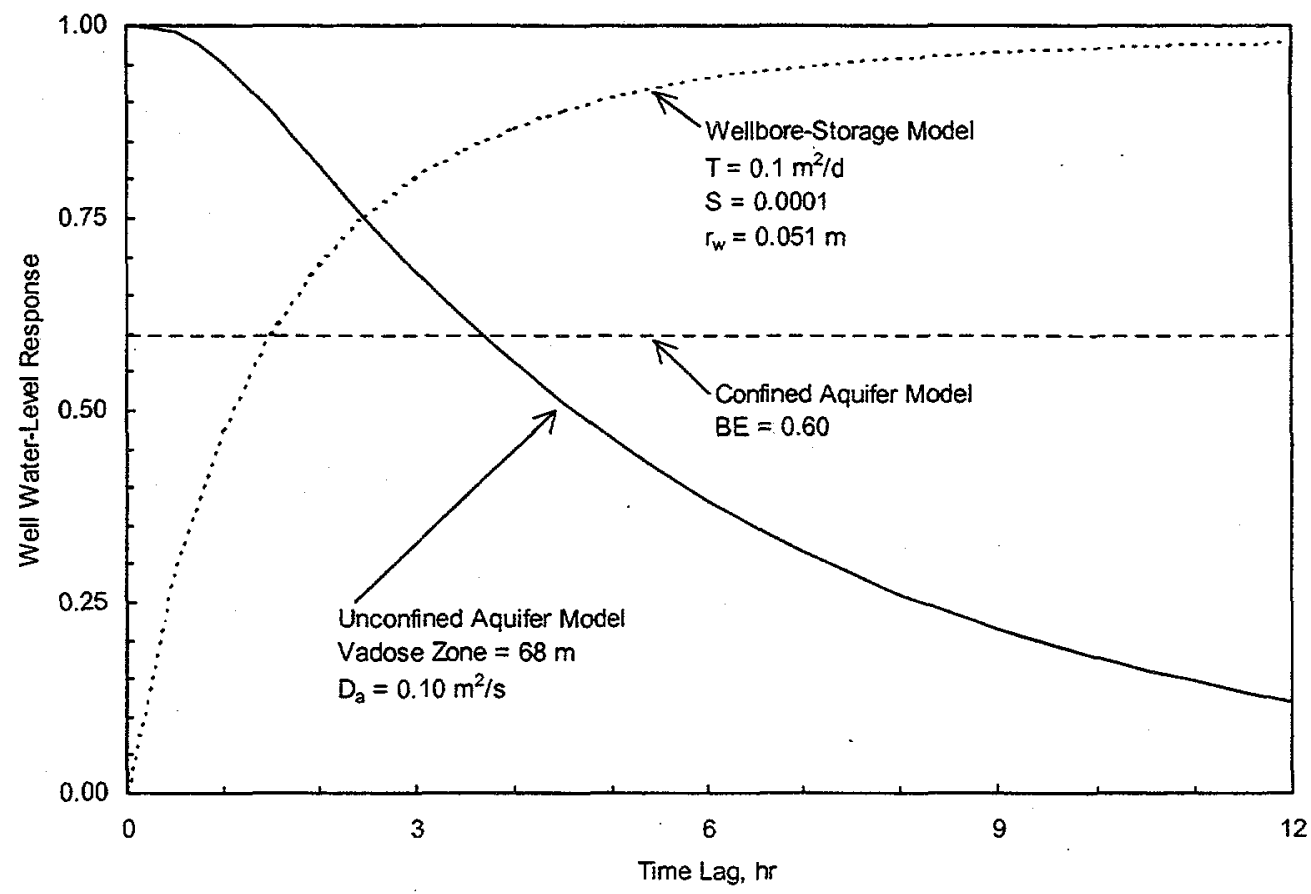

Figure 3.1. Well Barometric Pressure-Response Models. (adapted from Spane 1999)

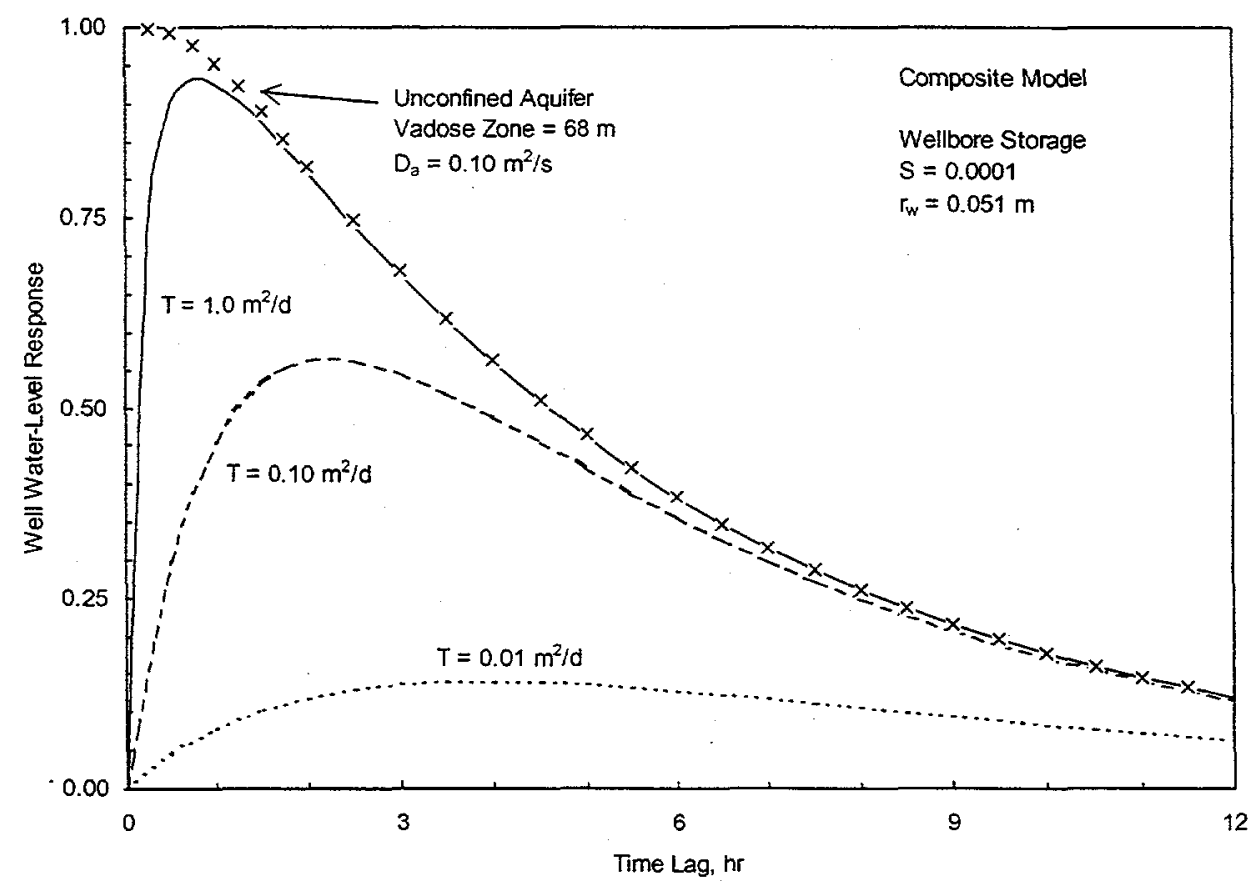

Figure 3.2. Composite Diagnostic Response Function for Wellbore-Storage/Unconfined Aquifer Model (adapted from Spane 1999) 


\subsection{Removal Methods}

Generally, stresses imposed by hydrologic tests exceed those imposed by atmospheric pressure fluctuations on the aquifer. The removal of barometric effects, however, is more important for hydrologic tests of long duration because of the low-magnitude changes in hydraulic head at late times when radial flow conditions are likely to be established. Removal of barometric effects is also critical for tests with lowmagnitude hydraulic responses such as slug interference tests or for monitor wells at large radial distances. For analysis of the 200-ZP-1 Operable Unit pump-and-treat response, removal of barometric effects was important for the late-time data.

Removal of barometric effects depends on the diagnostic response model exhibited by the well/ aquifer system with different removal methods recommended for confined and unconfined aquifers, as well as for those exhibiting composite model-response behavior. As noted in Spane (1999), the removal of barometric fluctuations from hydrologic test data requires the following steps:

1. collect test site atmospheric pressure values and associated aquifer formation pressure values for a pre- or post-test baseline period, during which no other extraneous stresses are imposed on the well/aquifer system

2. determine the long- and short-term barometric efficiencies (BE) for the baseline well data record, using the linear-regression algorithms outlined in Rasmussen and Crawford (1997) for distinguishing between confined and unconfined aquifer behavior

3. perform diagnostic barometric response analysis of the baseline well data record using the multipleregression convolution method described by Rasmussen and Crawford (1997) to distinguish between aquifer or composite well-/aquifer-model behavior

4. depending on the operative well/aquifer-response model, remove barometric induced changes from the test data record using either multiple-regression deconvolution or the Clark (1967) method.

For confined aquifer test applications, it is recommended that a minimum of 5 to 7 days of pre- and/or post-test baseline data be collected for calculating $B E$, while for unconfined aquifer locations exhibiting significant time-lag characteristics (i.e., large vadose zone thickness and/or low pneumatic diffusivity), longer baseline periods may be required for calculating the long- and short-term barometric efficiency $\left(\mathrm{BE}_{\text {long }}\right.$ and $\mathrm{BE}_{\text {short }}$ ) relationships. Spane (1999) notes that test data recording frequencies between 10 to 60 min during baseline collection periods produce consistent $\mathrm{BE}$ calculations for Hanford Site conditions (i.e., vadose zone thickness $=25$ to $75 \mathrm{~m}$, pneumatic diffusivities $\left[D_{\mathrm{a}}\right]=0.01$ to $0.1 \mathrm{~m}^{2} / \mathrm{s}$ ); however, for shallow water-table locations, higher baseline recording frequencies might be required.

As discussed in Rasmussen and Crawford (1997), long-term regression is determined by direct linear regression of the observed barometric and well water-level data, while short-term regression can be determined by linear-regression analysis of the observed changes in barometric and well water-level data using the Clark (1967) method. (Note: A discussion of BE calculation using the Clark 1967 method is presented in Spane 1999). A comparison of the linear-regression slopes (i.e., BE values) for the two 
methods is suggestive of either confined or unconfined aquifer behavior. As indicated by Rasmussen and Crawford (1997) for confined aquifer situations, wherein wellbore storage and well skin are not significant, no difference in the calculated $B E_{\text {long }}$ and $B E_{\text {short }}$ linear-regression relationships is expected, while for unconfined aquifers, $B E_{\text {short }}>\mathrm{BE}_{\text {long. }}$. For cases where wellbore storage/well skin are evident, a $B E_{\text {long }}$ $>\mathrm{BE}_{\text {short }}$ relationship for composite well/confined aquifer systems is exhibited.

To evaluate more fully the operative barometric response model (i.e., between aquifer or composite well/aquifer behavior), analysis of the baseline well data record using the multiple-regression method described by Rasmussen and Crawford (1997) is recommended. Once the operative well/aquiferresponse model has been identified, barometric induced changes within the hydrologic test data can be removed using either multiple-regression deconvolution (for delayed, unconfined aquifer-response systems) or the Clark (1967) method (for simple, confined aquifer models). Removal of barometric effects during testing requires that a reference atmospheric pressure be used to correct the aquifer test data record. For most hydrologic test applications, the observed atmospheric pressure immediately prior to test initiation is used as the reference atmospheric pressure. Examples and discussions of removing barometric pressure effects from hydrologic test data for confined aquifers on the Hanford Site using the Clark (1967) method are provided in Spane $(1992,1993)$. An example of the corrective procedure for test data that exhibit delayed well-response characteristics (i.e., for unconfined aquifer or composite well/aquifer models) is provided below.

Because water-level measurements from unconfined aquifer wells exhibit variable time-lagged responses to barometric fluctuations (i.e., the well water-level response is dependent on the duration/ magnitude of the barometric pressure change and vadose zone characteristics), the removal procedure is not as simple or straightforward as for wells monitoring confined aquifers. The initial steps for removing barometric effects from either confined or unconfined aquifer hydrologic test data are the same for steps 1,2, and 3 listed above. Linear-regression and multiple-regression diagnostic methods are used to verify the operative barometric response model. Then, assuming that a delayed, unconfined aquifer response is indicated, one of the methods discussed below can be used to remove barometric effects from head measurements collected during hydrologic tests. The removal method selected is dependent on the type of response model exhibited (e.g., unconfined aquifer or composite wellbore storage/unconfined aquifer) and characteristics of the monitoring system employed. Multiple regression can be used for either response model. However, the vadose zone model can only be used to predict aquifer-model response and does not account for composite wellbore-storage/skin-model conditions. Because the 200-ZP-1 monitor wells are open-well completions, the closed-system method discussed in Spane (1999) does not apply. The two applicable removal methods discussed include the multiple-regression technique and the analytically based vadose zone model. A brief description and discussion of each method are provided below.

\subsubsection{Multiple-Regression Techniques}

Multiple-regression deconvolution techniques have been shown by Rasmussen and Crawford (1997) and Spane (1999) to be effective in removing barometric effects from hydrologic test data that exhibit either aquifer or composite wellbore-storage/aquifer-response characteristics. To demonstrate the removal procedure, baseline water-level data for the four 200-ZP-1 monitor wells (299-W15-1, -7, -11 , 
and -31A) shown in Figure 2.1 were analyzed for barometric response characterization. Normally, baseline data analysis should be performed during non-test/stress periods. However, because the pumpand-treat system is an operating facility, a baseline period completely reflective of non-test/stress conditions is not available. For the barometric response analysis, periods during the pump-and-treat operation were examined between October 14, 1999 to February 14, 2000 for possible baseline analysis use, where well response would likely be more affected by barometric fluctuations and less on actual facility operation. Because the test system pumping periods were of longer duration than recovery periods, well water-level response during the latter part of the extended pumping cycles were examined for possible baseline analysis. Based on this examination, the 19-day time period between October 27 to November 15, 1999 (1999 calendar days 300 to 319) was identified as being suitable for barometric response characterization.

The 19-day baseline water-level response records for monitor wells 299-W15-1, -7, -11, and -31A were analyzed using the multiple-regression convolution technique described in Rasmussen and Crawford (1997) and Spane (1999). Results from the multiple-regression analysis for the individual wells are listed in Tables 3.1, 3.2, and 3.3. Figure 3.3 shows the barometric response patterns (i.e., regression sum columns from Tables 3.1 and 3.2) obtained from the multiple-regression analysis for each well. All four monitor wells exhibit a similar diagnostic response pattern that is consistent with a composite model, consisting of an unconfined aquifer system with wellbore-storage/skin effects evident during the early time-lag periods (see Figure 3.2 for composite model comparison). As shown, monitor wells 299-W15-1, -7, and -11 exhibit nearly identical barometric response patterns, which indicates very similar vadose zone pressure transmission characteristics (i.e., $D_{2}$ ) for the areas surrounding the wells. The fourth well site (299-W15-31A) exhibits vadose zone transmission characteristics that are nearly twice as high as the other well sites.

To quantify the spatial variation in vadose zone characteristics at the selected monitor well locations, barometric response characteristics were examined using the Weeks (1979) analytical method and a vadose zone thickness of $70 \mathrm{~m}$. As shown in Figure 3.3, the $D_{a}$ values of 0.025 and $0.04 \mathrm{~m}^{2} / \mathrm{s}$ appear to bound the intermediate to late-time water-level barometric response characteristics of the four monitor well sites. (Note: The vadose zone model can only be used to predict aquifer-model response and does not account for composite wellbore-storage/skin-model conditions, which are evident during early time-lag periods). The bounding $\mathrm{D}_{\mathrm{a}}$ values for the four selected monitor wells are within the range $\left(0.01\right.$ to $\left.0.04 \mathrm{~m}^{2} / \mathrm{s}\right)$ that has been commonly observed at other 200 -West Area locations.

Because it is less definitive in distinguishing between operative barometric models (i.e., only between aquifer models), linear-regression analysis was performed on the same 19-day baseline as a corroborative check on the multiple-regression analysis results. As shown in Table 3.3, the calculated $\mathrm{BE}_{\text {short }}$ values were greater than the calculated $\mathrm{BE}_{\text {long }}$ for each of the selected monitor wells analyzed, which, as noted previously, indicates unconfined aquifer-model behavior. This is consistent with the aquifer model identified through multiple-regression analysis also in Table 3.3. 
Table 3.1. Multiple-Regression Analysis for Monitor Wells 299-W15-1, - 7, and - 11

\begin{tabular}{|c|c|c|c|c|c|c|}
\hline \multirow[b]{3}{*}{ Time Lag, hr } & \multicolumn{6}{|c|}{ Well Water-Level/Barometric Regression Analysis } \\
\hline & \multicolumn{2}{|c|}{$299-W 15-1$} & \multicolumn{2}{|c|}{$299-W 15-7$} & \multicolumn{2}{|c|}{$299-W 15-11$} \\
\hline & $\begin{array}{l}\text { Regression } \\
\text { Coefficient }\end{array}$ & $\begin{array}{c}\text { Regression } \\
\text { Coefficient } \\
\text { Sum }^{\mathrm{a}}\end{array}$ & $\begin{array}{l}\text { Regression } \\
\text { Coefficient }\end{array}$ & $\begin{array}{c}\text { Regression } \\
\text { Coefficient } \\
\text { Sum }^{2}\end{array}$ & $\begin{array}{l}\text { Regression } \\
\text { Coefficient }\end{array}$ & $\begin{array}{c}\text { Regression } \\
\text { Coefficient } \\
\text { Sum }^{\text {a }}\end{array}$ \\
\hline 0 & -0.78402 & 0.7840 & -0.75542 & 0.7554 & -0.62375 & 0.6238 \\
\hline 1 & -0.08371 & 0.8677 & -0.10722 & 0.8626 & -0.14378 & 0.7675 \\
\hline 2 & -0.09811 & 0.9658 & -0.14379 & 1.0064 & -0.12919 & 0.8967 \\
\hline 3 & 0.05538 & 0.9105 & 0.07971 & 0.9267 & 0.06974 & 0.8270 \\
\hline 4 & 0.05522 & 0.8552 & 0.07727 & 0.8495 & 0.00839 & 0.8186 \\
\hline 5 & -0.02549 & 0.8807 & -0.03473 & 0.8842 & -0.04229 & 0.8609 \\
\hline 6 & 0.03448 & 0.8463 & 0.07090 & 0.8133 & 0.02584 & 0.8350 \\
\hline 7 & -0.02128 & 0.8675 & -0.08397 & 0.8973 & -0.04612 & 0.8812 \\
\hline 8 & 0.07165 & 0.7959 & 0.08704 & 0.8102 & 0.17140 & 0.7098 \\
\hline 9 & 0.05210 & 0.7438 & 0.06674 & 0.7435 & 0.04319 & 0.6666 \\
\hline 10 & 0.01725 & 0.7265 & 0.05591 & 0.6876 & 0.03221 & 0.6344 \\
\hline 11 & 0.02710 & 0.6994 & -0.06187 & 0.7494 & -0.08915 & 0.7235 \\
\hline 12 & 0.02451 & 0.6749 & 0.07869 & 0.6707 & 0.08184 & 0.6417 \\
\hline 13 & 0.03046 & 0.6445 & 0.04353 & 0.6272 & 0.07574 & 0.5659 \\
\hline 14 & 0.04255 & 0.6019 & 0.01564 & 0.6116 & 0.00711 & 0.5588 \\
\hline 15 & 0.02059 & 0.5813 & -0.03040 & 0.6420 & -0.03538 & 0.5942 \\
\hline 16 & 0.03456 & 0.5468 & 0.09824 & 0.5437 & 0.02695 & 0.5673 \\
\hline 17 & -0.01729 & 0.5641 & -0.02228 & 0.5660 & 0.01384 & 0.5534 \\
\hline 18 & 0.05907 & 0.5050 & 0.05949 & 0.5065 & 0.05026 & 0.5032 \\
\hline 19 & 0.00520 & 0.4998 & 0.02036 & 0.4862 & -0.01646 & 0.5196 \\
\hline 20 & 0.01804 & 0.4817 & -0.04293 & 0.5291 & 0.01149 & 0.5081 \\
\hline 21 & 0.01602 & 0.4657 & 0.06255 & 0.4665 & 0.03385 & 0.4743 \\
\hline 22 & -0.04201 & 0.5077 & -0.03960 & 0.5061 & -0.01807 & 0.4923 \\
\hline 23 & 0.11030 & 0.3974 & 0.07827 & 0.4279 & 0.01973 & 0.4726 \\
\hline 24 & -0.08067 & 0.4781 & -0.01588 & 0.4438 & -0.08174 & 0.5544 \\
\hline 25 & -0.00946 & 0.4876 & -0.01067 & 0.4544 & 0.04827 & 0.5061 \\
\hline 26 & 0.08597 & 0.4016 & 0.09383 & 0.3606 & 0.11797 & 0.3881 \\
\hline 27 & 0.05039 & 0.3512 & 0.00019 & 0.3604 & 0.10042 & 0.2877 \\
\hline 28 & 0.02676 & 0.3244 & 0.04775 & 0.3127 & 0.06977 & 0.2179 \\
\hline 29 & 0.06915 & 0.2553 & 0.03488 & 0.2778 & 0.02112 & 0.1968 \\
\hline 30 & -0.04593 & 0.3012 & 0.00009 & 0.2777 & -0.00002 & 0.1968 \\
\hline 31 & -0.03558 & 0.3368 & -0.00828 & 0.2860 & -0.04838 & 0.2452 \\
\hline 32 & 0.04239 & 0.2944 & -0.02520 & 0.3112 & -0.07081 & 0.3160 \\
\hline 33 & 0.00574 & 0.2887 & 0.01348 & 0.2977 & -0.02629 & 0.3423 \\
\hline 34 & 0.03295 & 0.2557 & 0.01577 & 0.2819 & -0.02262 & 0.3649 \\
\hline 35 & -0.03016 & 0.2859 & 0.02029 & 0.2616 & 0.05480 & 0.3101 \\
\hline 36 & -0.04207 & 0.3280 & -0.04233 & 0.3040 & -0.00519 & 0.3153 \\
\hline 37 & 0.00681 & 0.3211 & -0.03340 & 0.3374 & -0.03743 & 0.3527 \\
\hline 38 & 0.03495 & 0.2862 & 0.04824 & 0.2891 & 0.01555 & 0.3372 \\
\hline 39 & -0.01410 & 0.3003 & 0.00917 & 0.2799 & 0.02011 & 0.3171 \\
\hline 40 & 0.03840 & 0.2619 & 0.00595 & 0.2740 & 0.03276 & 0.2843 \\
\hline 41 & 0.05022 & 0.2117 & 0.05355 & 0.2204 & 0.05265 & 0.2317 \\
\hline
\end{tabular}


Table 3.2. Multiple-Regression Analysis for Monitor Well 299-W15-31A

\begin{tabular}{|c|c|c|c|c|c|}
\hline \multicolumn{6}{|c|}{ Well 299-W15-31A Water-Level/Barometric Regression Analysis } \\
\hline $\begin{array}{l}\text { Time Lag, } \\
\mathrm{hr}\end{array}$ & $\begin{array}{l}\text { Regression } \\
\text { Coefficient }\end{array}$ & $\begin{array}{c}\text { Regression } \\
\text { Coefficient } \\
\text { Sum }^{(a)}\end{array}$ & $\begin{array}{c}\text { Time Lag, } \\
\mathbf{h r}\end{array}$ & $\begin{array}{l}\text { Regression } \\
\text { Coefficient }\end{array}$ & $\begin{array}{c}\text { Regression } \\
\text { Coefficient } \\
\text { Sum }^{\text {(a) }}\end{array}$ \\
\hline 0 & -0.34015 & 0.3402 & 28 & 0.02325 & 0.1591 \\
\hline 1 & -0.11598 & 0.4561 & 29 & 0.01949 & 0.1396 \\
\hline 2 & -0.03967 & 0.4958 & 30 & -0.00659 & 0.1462 \\
\hline 3 & 0.05164 & 0.4442 & 31 & 0.02188 & 0.1243 \\
\hline 4 & 0.01051 & 0.4337 & 32 & -0.02210 & 0.1464 \\
\hline 5 & 0.00527 & 0.4284 & 33 & 0.02844 & 0.1179 \\
\hline 6 & 0.00774 & 0.4206 & 34 & -0.01006 & 0.1280 \\
\hline 7 & -0.01306 & 0.4337 & 35 & 0.03385 & 0.0941 \\
\hline 8 & 0.03414 & 0.3996 & 36 & -0.01188 & 0.1060 \\
\hline 9 & 0.00500 & 0.3946 & 37 & -0.03998 & 0.1460 \\
\hline 10 & 0.02074 & 0.3738 & 38 & 0.01979 & 0.1262 \\
\hline 11 & -0.02209 & 0.3959 & 39 & -0.00786 & 0.1341 \\
\hline 12 & 0.03693 & 0.3590 & 40 & 0.01345 & 0.1206 \\
\hline 13 & 0.03759 & 0.3214 & 41 & 0.03280 & 0.0878 \\
\hline 14 & 0.00895 & 0.3124 & 42 & 0.00905 & 0.0788 \\
\hline 15 & -0.00655 & 0.3190 & 43 & -0.03011 & 0.1089 \\
\hline 16 & 0.04921 & 0.2698 & 44 & 0.03366 & 0.0752 \\
\hline 17 & 0.00380 & 0.2660 & 45 & -0.01119 & 0.0864 \\
\hline 18 & -0.00173 & 0.2677 & 46 & 0.00364 & 0.0828 \\
\hline 19 & 0.02709 & 0.2406 & 47 & -0.04474 & 0.1275 \\
\hline 20 & 0.01646 & 0.2242 & 48 & 0.03941 & 0.0881 \\
\hline 21 & -0.00223 & 0.2264 & 49 & 0.00739 & 0.0807 \\
\hline 22 & -0.01087 & 0.2373 & 50 & 0.03884 & 0.0419 \\
\hline 23 & 0.00337 & 0.2339 & 51 & -0.04348 & 0.0854 \\
\hline 24 & -0.01236 & 0.2463 & 52 & -0.00330 & 0.0887 \\
\hline 25 & 0.02667 & 0.2196 & 53 & 0.04676 & 0.0419 \\
\hline 26 & 0.02839 & 0.1912 & 54 & -0.03680 & 0.0787 \\
\hline 27 & 0.00888 & 0.1823 & 55 & 0.01952 & 0.0592 \\
\hline
\end{tabular}


Table 3.3. Summary of Regression Analysis Results for Wells 299-W14-9, 299-W15-1, -7, -11, and 31A

\begin{tabular}{|c|c|c|c|c|}
\hline \multirow[b]{2}{*}{ Well } & \multicolumn{3}{|c|}{ Linear Regression Analysis } & \multirow{2}{*}{$\begin{array}{l}\text { Multiple-Regression Analysis } \\
\text { Conceptual Model }\end{array}$} \\
\hline & $\mathrm{BE}_{\text {long }}$ & $\mathrm{BE}_{\text {short }}$ & Aquifer Model & \\
\hline $299-W 14-9^{(a)}$ & 0.65 & 0.66 & Confined & $\begin{array}{l}\text { Composite: Confined aquifer with minor } \\
\text { wellbore storage/skin }\end{array}$ \\
\hline 299-W15-1 & 0.59 & 0.90 & Unconfined & $\begin{array}{l}\text { Composite: Unconfined aquifer with } \\
\text { wellbore storage/skin }\end{array}$ \\
\hline $299-W 15-7$ & 0.54 & 0.90 & Unconfined & $\begin{array}{l}\text { Composite: Unconfined aquifer with } \\
\text { wellbore storage/skin }\end{array}$ \\
\hline 299-W15-11 & 0.39 & 0.82 & Unconfined & $\begin{array}{l}\text { Composite: Unconfined aquifer with } \\
\text { wellbore storage/skin }\end{array}$ \\
\hline $299-W 15-31 A$ & 0.34 & 0.45 & Unconfined & $\begin{array}{l}\text { Composite: Unconfined aquifer with } \\
\text { wellbore storage/skin }\end{array}$ \\
\hline
\end{tabular}

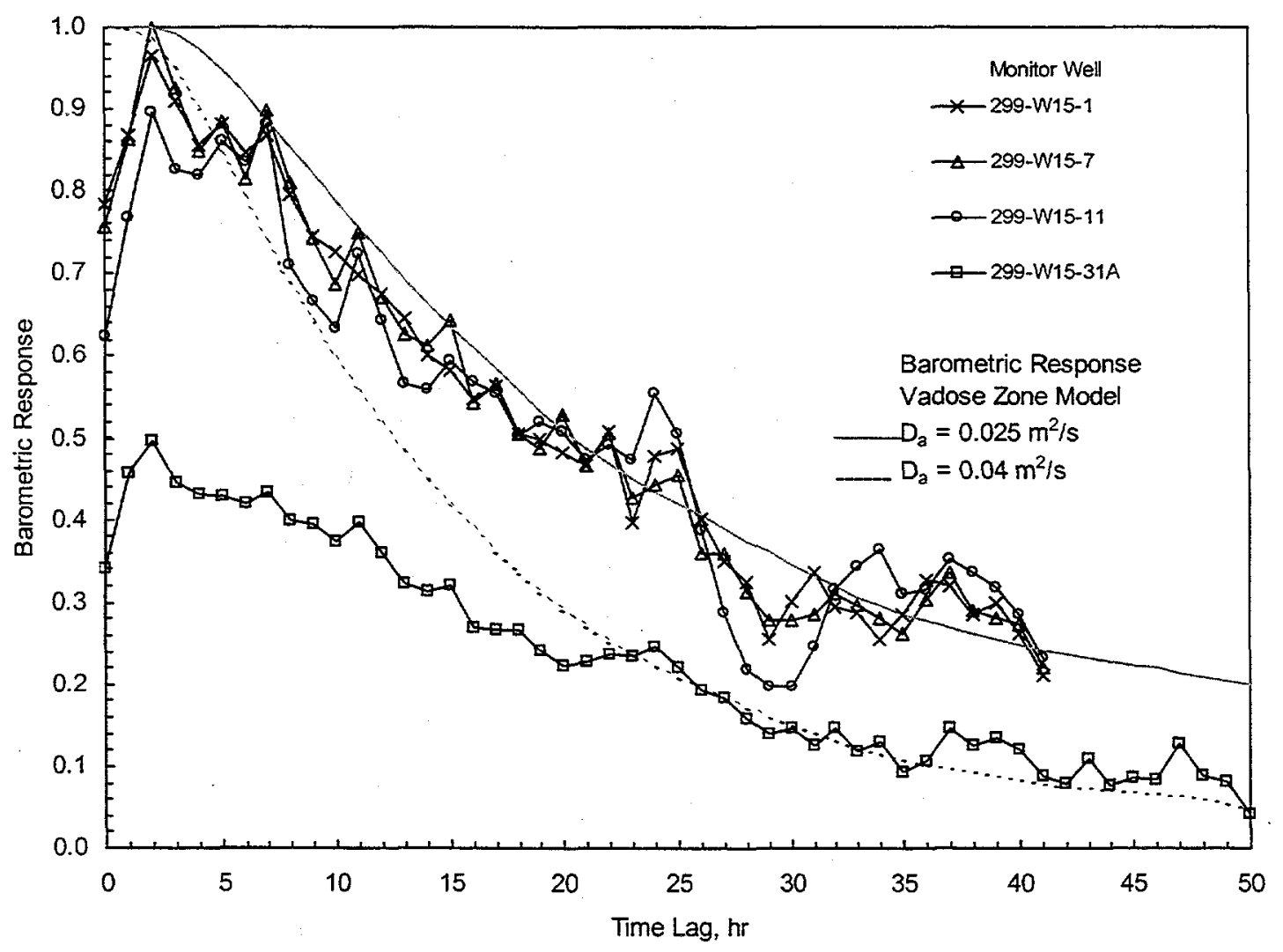

Figure 3.3. Water-Level Barometric Response Patterns for Monitor Wells 299-W15-1, - 7, -11, and -31A 
To demonstrate the multiple-regression deconvolution method, the observed, predicted, and corrected well water-level responses for well 299-W15-1 during the baseline period are shown in Figure 3.4. The regression coefficients listed in Table 3.1 for well 299-W15-1 were used with the regression deconvolution technique described in Rasmussen and Crawford (1997) and Spane (1999) to predict and correct the water-level response observed at the well site. As shown in the figure, a close match between observed and predicted response is evident using the multiple-regression technique $\left(r^{2}=0.99\right)$. The overall "smoothness" and lack of significant variability in the corrected response (i.e., in comparison to the observed response) indicates the effectiveness of the regression method for removing barometric stress effects from the well water-level response record. Similar barometric removal results were obtained using the regression method for the other monitor well sites. Comparison plots of the observed, predicted, and corrected well water-level responses for the other monitor wells using the multipleregression technique are in the Appendix.

Figure 3.5 shows the observed, predicted, and corrected water-level elevation responses for well 299-W15-1 and the observed barometric pressure pattern over the period of interest (1999 calendar days

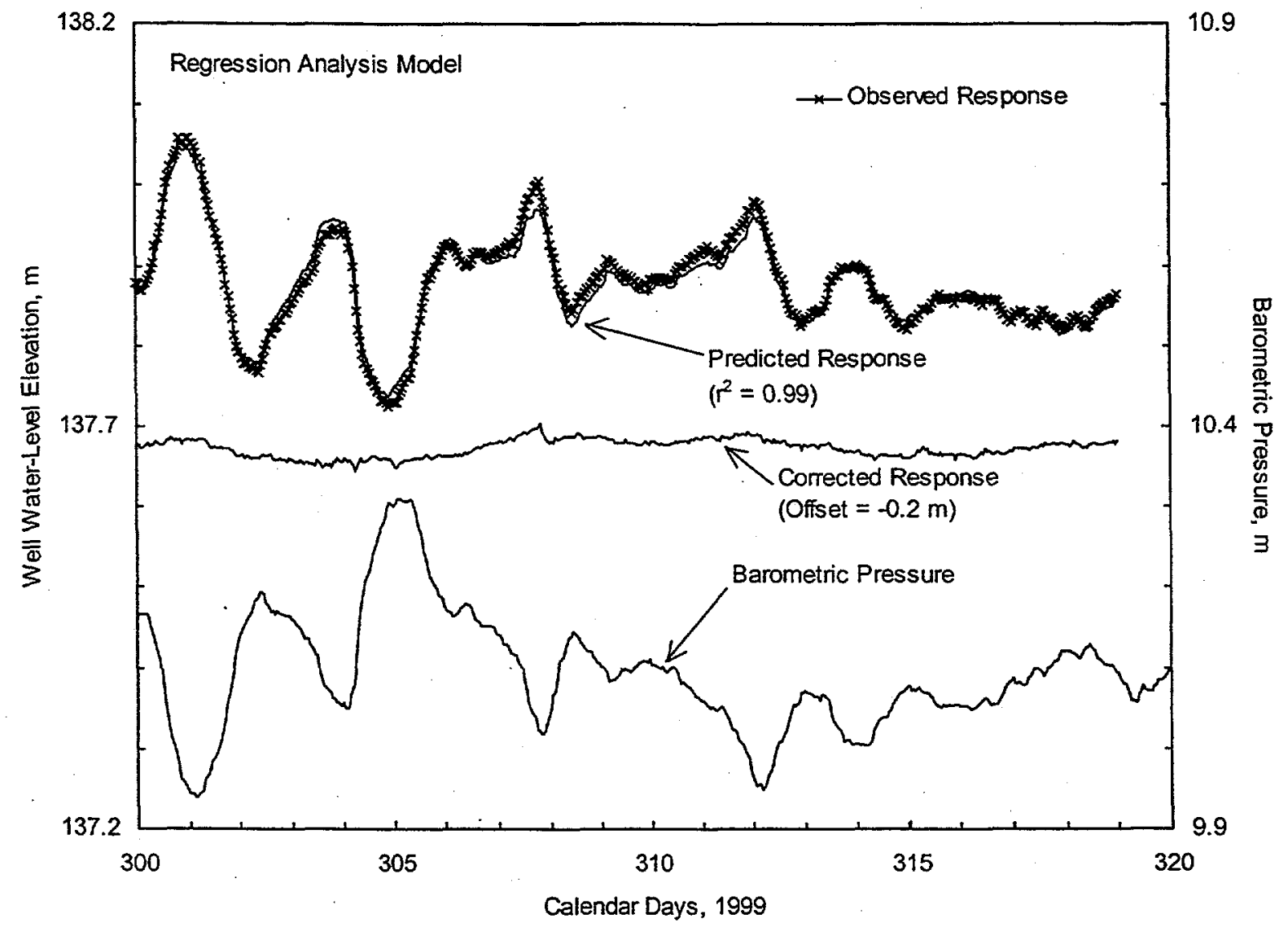

Figure 3.4. Multiple-Regression, Model-Predicted, and Barometric Corrected Water-Level Elevation Responses for Monitor Well 299-W15-1, October 27 to November 15, 1999 (1999 Calendar Days 300 to 319 ) 


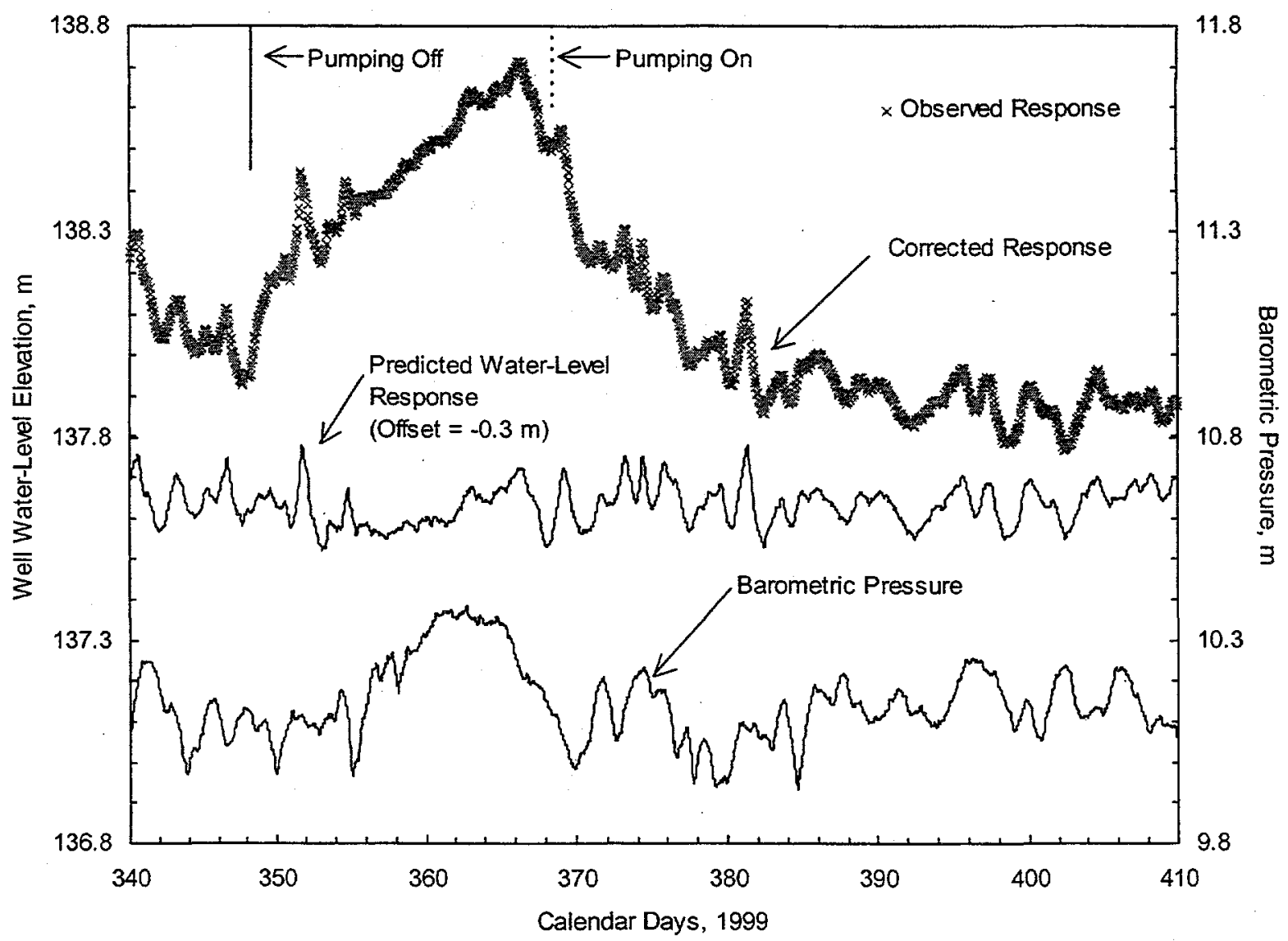

Figure 3.5. Multiple-Regression, Model-Predicted, and Barometric Corrected Water-Level Elevation Responses for Monitor Well 299-W15-1, December 6, 1999 to February 14, 2000 (1999 Calendar Days 340 to 410 )

340 to 410 ) encompassing the $\mathrm{Y} 2 \mathrm{~K}$ shutdown (December 14, 1999) and restart (January 3, 2000). As shown, the barometric pressure fluctuated by $0.45 \mathrm{~m}$ over this period. Based on the multiple-regression analysis results, the associated well water-level elevation (predicted response in Figure 3.5 ) would be expected to vary by $0.26 \mathrm{~m}$, solely the result of barometric pressure variation. This imposed barometric pressure effect is $\sim 1 / 3$ of the total well water-level variation observed during this period. The corrected water-level response is relatively smooth after barometric stress removal, which provides a more definitive analysis of the impact of pump-and-treat activities (i.e., for area of influence and hydraulic property characterization). Examples of analyzing the corrected well responses for hydraulic property determination are provided in Section 4.0.

\subsubsection{Vadose Zone Model}

The vadose zone model (Weeks 1979) was also used to analyze the observed well responses to evaluate its utility for removing barometric effects from the monitor well water-level data. A detailed description of the analytical basis of the vadose zone model (Weeks method) is provided in Weeks (1979), Rasmussen and Crawford (1997), and Spane (1999). 
Figure 3.6 shows the results of matching the observed water-level elevation at well 299-W15-1 with the response predicted using the vadose zone model over the same 19-day baseline period (1999 calendar days 300 to 319 ). As shown, a very close match (correlation coefficient, $r^{2}=0.99$ ) between the observed and predicted response was obtained using $D_{a}$ equal to $0.02 \mathrm{~m}^{2} / \mathrm{s}$ and background water-level trend of $-0.00188 \mathrm{~m} / \mathrm{d}$. The negative water-level elevation trend is consistent with the anticipated effects of groundwater pumping occurring at nearby extraction wells during the 19-day baseline period. The barometric corrected response exhibits a similarly smooth, but slightly more variable, pattern compared to the response corrected using multiple regression and shown in Figure 3.4. Similar analysis results (not shown) were obtained with the vadose zone model technique for the other three monitor wells. Table 3.4 summarizes the results of the vadose zone model analysis for each monitor well location.

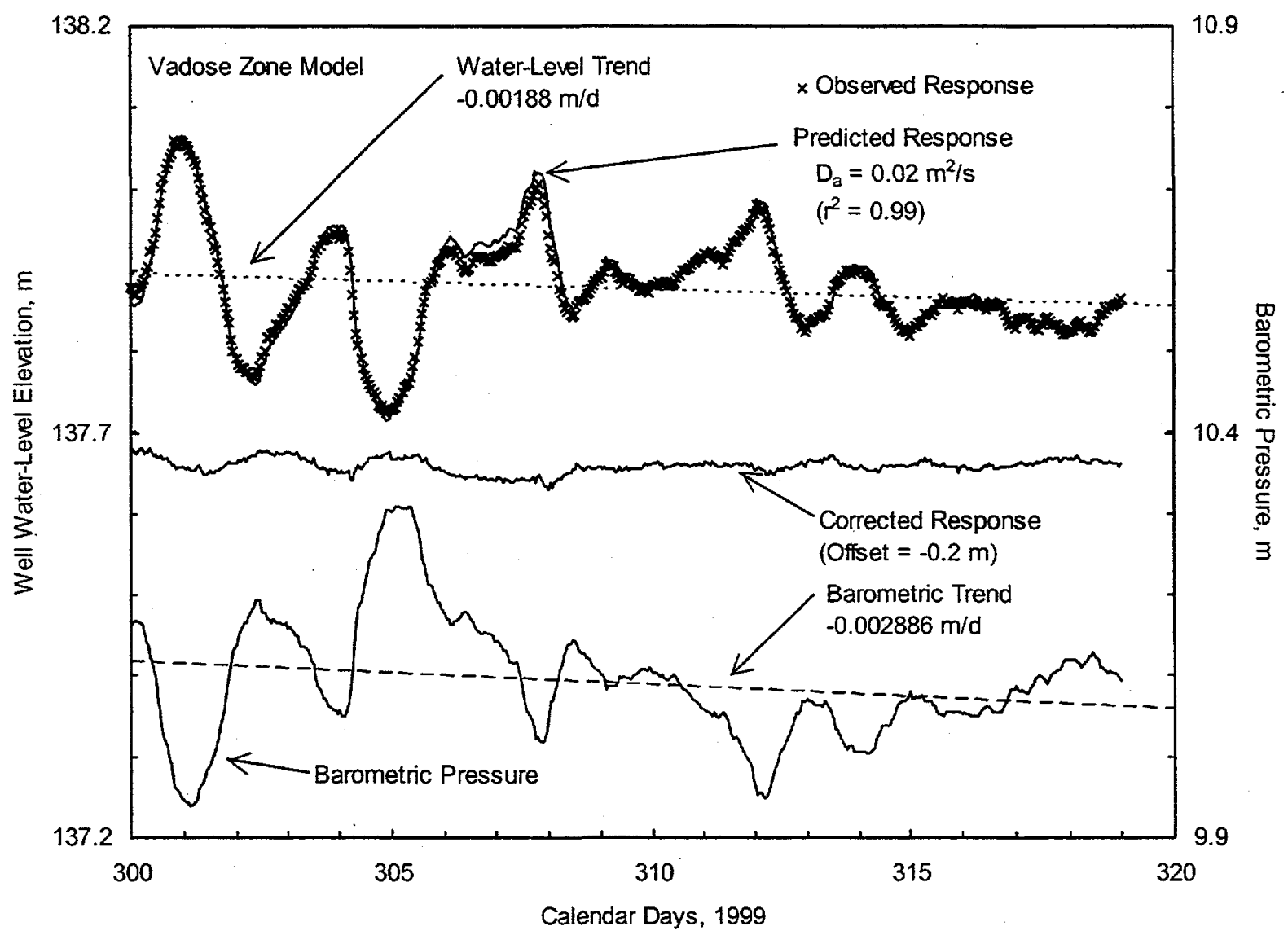

Figure 3.6 Vadose Zone, Model-Predicted, and Barometric Corrected Water-Level Elevation Responses for Monitor Well 299-W15-1, October 27 to November 15, 1999 (1999 Calendar Days 300 to 319) 
Table 3.4. Vadose Zone Model Analysis Results for Wells 299-W15-1, -7, -11, and -31A

\begin{tabular}{|c|c|c|c|c|c|}
\hline \multirow[b]{2}{*}{ Well } & \multirow[b]{2}{*}{$\begin{array}{c}\text { Vadose Zone } \\
\text { Thickness, } \\
\text { m }\end{array}$} & \multicolumn{3}{|c|}{ Vadose Zone Model Analysis Parameters } & \multirow{2}{*}{$\begin{array}{c}\text { Multiple Regression } \\
\text { Model Analysis } \\
\text { Correlation } \\
\text { Coefficient, } \\
\mathrm{r}^{2} \\
\end{array}$} \\
\hline & & $\begin{array}{c}\text { Pneumatic } \\
\text { Diffusivity, } \mathrm{D}_{\mathrm{a}} \text {, } \\
\mathrm{m}^{2} / \mathrm{s}\end{array}$ & $\begin{array}{l}\text { Water-Level } \\
\text { Trend, } \\
\text { m/d }\end{array}$ & $\begin{array}{c}\text { Correlation } \\
\text { Coefficient, } \\
\mathrm{r}^{2}\end{array}$ & \\
\hline 299-W15-1 & 68.2 & 0.020 & -0.00188 & 0.994 & 0.987 \\
\hline 299-W15-7 & 65.9 & 0.019 & -0.00188 & 0.993 & 0.983 \\
\hline 299-W15-11 & 69.3 & 0.020 & -0.00188 & 0.994 & 0.988 \\
\hline $299-W 15-31 \mathrm{~A}$ & 69.3 & 0.020 & -0.00188 & 0.987 & 0.978 \\
\hline
\end{tabular}

\subsubsection{Removal Method Comparison}

Spane (1999) previously compared barometric removal characteristics from well water-level measurements using multiple-regression and vadose zone model techniques for Hanford Site conditions. Although the comparison of barometric removal methods was not fully comprehensive, a number of observations were presented about their characteristics and application. Multiple-regression deconvolution techniques appear to have a wider application in removing barometric effects from various aquifer and composite well-/aquifer-response systems. Because of this wider adaptability, higher quality correction results are likely. Multiple-regression methods, however, require longer baseline data periods to be effective, and quantitative characterization of the physical system properties controlling the barometric response cannot be directly determined by the matching analysis results.

In comparison, Spane (1999) found that the vadose zone model can be applied with minimal baseline data and physical system properties (e.g., $D_{\mathrm{a}}$, vadose zone thickness, background water-table trend) can be determined directly from the analysis. A weakness of the vadose zone model is its inability to account for wellbore-storage, well-skin, and specific boundary situations where the water table occurs within the well-screen section, allowing direct transmission of the atmospheric pressure signal to the water table through the well. Depending on the imposed severity of these local well and boundary conditions, removal of barometric effects from aquifer test data may be more limited using the vadose zone model.

Based on information provided in Spane (1999) and initial baseline analysis results, the decision was made to use the multiple-regression deconvolution method for removing barometric effects from well water-level measurements used in the 200-ZP-1 analysis. 


\subsection{Hydrologic Test Analysis}

As noted in Section 2.0, because of the short duration of the recovery period (i.e., 20 days, December 14, 1999 to January 3, 2000) associated with the Y2K shutdown of the 200-ZP-1 pump-andtreat system, hydrologic test analysis efforts were concentrated primarily on the more lengthy restart period, which represents 43 days between January 3 and February 14, 2000. This longer duration pumping/ drawdown water-level data set was selected initially as the best opportunity for analyzing monitor well response under radial flow conditions. The establishment of radial flow conditions during testing minimizes the adverse influence of some complexities that can affect early to intermediate test time response (e.g., wellbore-storage, skin, partial penetration, and delayed-yield effects) and provides better analytical opportunities for determining hydraulic properties (e.g., hydraulic conductivity $\left[\mathrm{K}_{\mathrm{r}}\right.$ and $\left.\mathrm{K}_{\mathrm{v}}\right]$ and specific yield $\left[\mathrm{S}_{\mathrm{y}}\right]$ ).

All analyzed water-level data from the monitor wells were corrected for barometric pressure fluctuations using the multiple-regression deconvolution technique described in Section 3.0. Diagnostic analysis of the barometric corrected drawdown test response was first conducted to determine test system characteristics and to identify test data that display infinite-acting, radial flow behavior. Quantitative analysis of the monitor well $\mathrm{Y} 2 \mathrm{~K}$ restart drawdown was then performed by type-curve fitting of $\log$-log plots. Straight-line analysis of semi-logarithmic data plots of water-level change versus time were not appropriate because infinite-acting, radial flow conditions were not established at any of the monitor wells. Diagnostic analysis of the $\mathrm{Y} 2 \mathrm{~K}$ recovery test data was also performed for qualitative comparison with the more extensive drawdown data response. The analytical methods used are described in this section, followed by analysis results for each of the selected monitor wells.

\subsection{Diagnostic Analysis and Derivative Plots}

Log-log plots of water level versus time have traditionally been used for diagnostic purposes and, more recently, the derivative of the water level or pressure has also been used (Bourdet et al. 1989; Spane 1993) as a diagnostic tool. The derivative of the water level with respect to the natural logarithm of time (i.e., essentially the slope of the semi-log plot) was calculated and plotted on the log-log plots of drawdown versus time. Use of derivatives has been shown to improve significantly the diagnostic and quantitative analysis of various hydrologic test methods (Bourdet et al. 1989; Spane 1993). The improvement in test analysis is attributed to the sensitivity of pressure derivatives to various test/ formation conditions. Specific applications for which derivatives are particularly useful include the following:

- determining formation-response characteristics (confined or unconfined aquifer) and boundary conditions (impermeable or constant head) that are evident within the test data

- assisting in the selection of the appropriate type-curve solution through combined typecurve/derivative plot matching 
- determining when infinite-acting, radial flow conditions are established and, therefore, when straightline analysis methods are applicable.

Figure 4.1 shows log-log drawdown and derivative responses that are characteristic of some commonly encountered formation conditions. The early data, occurring before the straight-line approximation is valid or where wellbore storage is dominant, produce a steep, upward-trending derivative. The derivative normally decreases during transition from wellbore storage to radial flow and stabilizes at a constant value when infinite-acting, radial flow conditions are established. The stable derivative reflects the straight line on the semi-log plot for infinite-acting radial flow. Unconfined and double-porosity aquifers may show two stable derivative sections at the same vertical position, separated by a "valley" representing the transition from one storage value to the other. Diagnostic derivative plots are also useful in

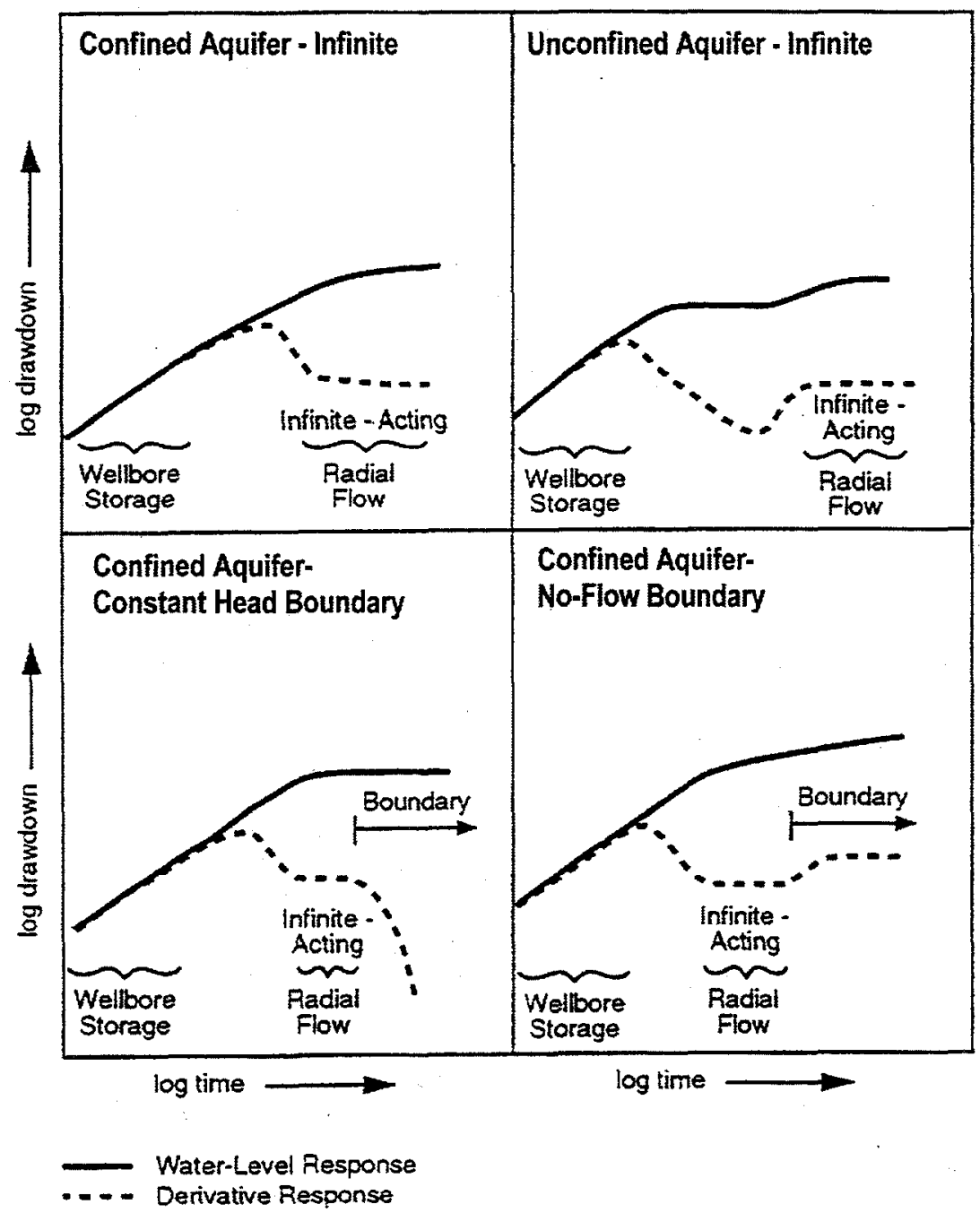

Figure 4.1. Characteristic Log-Log Drawdown and Drawdown Derivative Plots for Various Hydrogeologic Formation and Boundary Conditions 
identifying boundary effects. A linear, no-flow boundary will result in a doubling of the magnitude of the derivative. If radial flow is established before the influence of the boundary is seen, a stable derivative will occur for a time followed by an upward shift to twice the original value. Constant-head boundaries display a downward trend in the derivative, which may be preceded by a stable derivative if radial flow conditions occur before the boundary effect becomes dominant. For the diagnostic and test analysis aspects of this report, derivative responses were calculated using the DERIV program, which is described in Spane and Wurstner (1993).

\subsection{Type-Curve Method}

Type-curve matching methods (Theis 1935; Hantush 1964; Neuman 1972, 1974, 1975) are commonly used in the analysis of pumping test responses. To support this analysis aspect, type curves were generated using the WTAQ3 computer program described by Moench (1997.). WTAQ3 can be used to generate type curves that represent a wide range of test and aquifer conditions, including partially penetrating wells, confined or unconfined aquifer models, and wellbore storage at both the stress (pump) and observation (monitor) well locations. The type-curve generation program also allows for noninstantaneous release (drainage-delay factor) of water from the unsaturated zone. However, this was found to not be a significant factor in the analysis of the selected 200-ZP-1 monitor well response; therefore, the type curves used in the analyses for this report all reflect an instantaneous release of water, which is the approach used by Neuman $(1972,1974,1975)$.

To generate composite response-type curves, which represent the combined effect of all pumping and injection wells, the dimensionless response for each individual pumping and injection well included in the analysis was first generated for each selected monitor well site. These dimensionless responses depend on the assumed values of sigma, $\sigma=\mathrm{S} / \mathrm{S}_{\mathrm{y}}$, and vertical anisotropy, $\mathrm{K}_{\mathrm{D}}=\mathrm{K}_{\mathrm{v}} / \mathrm{K}_{\mathrm{h}}$. They are also influenced by the assumed storativity, $\mathrm{S}$, value because of its effect on wellbore storage. Dimensional curves were then generated for each stress well by inputting the appropriate radial distances and flow rates for each pumping and injection well. The combined predicted response was then developed by using superposition to produce a composite drawdown curve response at each selected monitor well location. The composite curves could then be shifted by adjusting the values of transmissivity, $T$, and $S_{y}$ until the best match with the observed data was obtained. (Note that adjusting $\mathrm{S}_{\mathrm{y}}$ also changes the value of $\mathrm{S}$ because $\sigma$ was held constant.)

\subsection{Straight-Line Method}

For straight-line analysis methods, the rate of change of water levels within the well during drawdown and/or recovery is analyzed to estimate hydraulic properties. Because well effects are constant with time during constant-rate tests, straight-line methods can be used to analyze quantitatively the water-level response at both pumping and observation wells. The semi-log, straight-line analysis techniques commonly used are based on either the Cooper and Jacob (1946) method (for drawdown analysis) or the Theis (1935) recovery method (for recovery analysis). These methods are theoretically restricted to the analysis of test responses from wells that fully penetrate non-leaky, homogeneous, isotropic, confined aquifers. 
Straight-line methods, however, may be applied under non-ideal well and aquifer conditions if infiniteacting, radial flow conditions exist. Infinite-acting, radial flow conditions are indicated during testing when the change in pressure, at the point of observation, increases in proportion to the logarithm of time. As discussed above, the use of diagnostic derivative methods (Bourdet et al. 1989) makes it easier to identify the portions within the test data where straight-line analysis is appropriate. As will be discussed, derivative analysis of the observed test responses indicated that radial flow conditions were not established at any of the selected monitor well locations. Use of straight-line analysis methods, therefore, were not appropriate. The use of straight-line analysis methods are mentioned in this report, however, because of their common use to analyze pumping test results.

\subsection{Analysis Results}

Analysis details and results for each of the four selected monitor wells are provided in the following section. As noted previously, test data associated with the 200-ZP-1 test system restart on January 3 , 2000 , following the planned test system Y2K shutdown on December 14,1999, was the focus of the detailed test analysis. The test data analyzed ranged between January 3 to February 14, 2000, which provided a 43-day record. On February 14, 2000, the test system was temporarily shut down once again for general maintenance. Pertinent information pertaining to well construction and distance to extraction/ injection wells is provided in Tables 2.1 and 2.2.

Flow rates for each of the pumping and injection wells over the 43-day drawdown period are shown in Figure 2.4. The flow rate at extraction well 299 -W15-35 dropped by $\sim 25 \%$ at $\sim 35,000$ min after the start of the drawdown period. This variation is apparent in the plotted data for some of the monitor wells. Other flow-rate changes also occurred but were shorter in duration. Average flow rate for the entire drawdown period, however, was used in generating type responses for each of the pumping and injection wells.

The type-curve analysis approach described above requires some initial estimates of $K_{D}, S$, and $S_{y}$. As a general analysis approach, initial estimate values for these parameters for type-curve generation were assigned as $0.1,0.0001$, and 0.1 , respectively. The values were adjusted (except for $\mathrm{K}_{\mathrm{D}}$ ) on a trialand-error basis until a visually acceptable match with the observed combined drawdown and drawdown derivative plot was attained. To lessen the complexity of the type-curve matching procedure and to provide a uniform basis of comparing analytical results for the various selected monitor well locations, $\mathrm{K}_{\mathrm{D}}$ was held constant at a value of 0.1 . Changes in $\mathrm{K}_{\mathrm{D}}$ between 0.02 and 0.5 , however, were not found to improve significantly the type-curve match results.

Because of fluctuations that occurred in daily discharge rates at individual pumping wells during the $\mathrm{Y} 2 \mathrm{~K}$ restart period, more emphasis was placed on matching the late-time drawdown data with the composite type curves. The matching of late-time drawdown data reduced the impact of discharge variation that was evident particularly during the early stages of the restart period. As will be seen because of the discharge-rate variability, the composite type-curve matches did not closely match early test time behavior; consequently, analysis results for $\mathrm{S}$ are considered to be only qualitative estimates. A summary of the final test analysis parameters and results is provided in Table 4.1. 
Table 4.1. Test Analysis Summary

\begin{tabular}{|l|c|c|c|c|c||}
\hline \multirow{2}{*}{ Monitor Well } & \multicolumn{5}{|c|}{ Hydrologic Property Estimates } \\
\cline { 2 - 6 } & $\begin{array}{c}\mathrm{T}, \\
\mathrm{m}^{2} / \mathrm{d}\end{array}$ & $\begin{array}{c}\mathrm{K}_{\mathrm{h}}, \\
\mathrm{m} / \mathrm{d}\end{array}$ & $\mathrm{K}_{\mathrm{D}}{ }^{(\mathrm{a})}$ & $\mathrm{S}^{(\mathrm{b})}$ & $\mathrm{S}_{\mathrm{y}}$ \\
\hline \hline $299-\mathrm{W} 15-1$ & 230 & 3.5 & 0.1 & $2.7 \mathrm{E}-05$ & 0.027 \\
\hline $299-\mathrm{W} 15-7$ & 390 & 6.0 & 0.1 & $3.0 \mathrm{E}-05$ & 0.030 \\
\hline $299-\mathrm{W} 15-11$ & 240 & 3.7 & 0.1 & $2.3 \mathrm{E}-05$ & 0.023 \\
\hline 299-W15-31A & 430 & 6.6 & 0.1 & $3.5 \mathrm{E}-05$ & 0.035 \\
\hline Average & 325 & 5.0 & 0.1 & $2.9 \mathrm{E}-05$ & 0.029 \\
\hline $\begin{array}{l}\text { (a) Assumed estimate value. } \\
\text { (b) S estimate based on assumed } \sigma=0.001 \text { and calculated } \mathrm{S}_{\mathrm{y}} \text { value. }\end{array}$ \\
\hline
\end{tabular}

\subsection{Test Analysis Summary}

\subsubsection{Well 299-W15-1}

The water-level response at monitor well $299-\mathrm{W} 15-1$ is a composite of the responses from pumping and injection wells operating during the $\mathrm{Y} 2 \mathrm{~K}$ restart pumping period that began on January 3, 2000 . Monitor well 299-W15-1 is influenced primarily by wells $299-$ W15-33, -34 , and -35 and is located within $\sim 200 \mathrm{~m}$ of these wells (see Figure 2.1 and Table 2.1). This well is also influenced to a lesser extent by injection well 299-W15-29, which is located $769 \mathrm{~m}$ away, but has a higher injection rate than the pumping wells. Other pumping and injection wells were determined to have a negligible effect on the response at 299-W15-1. As discussed in Section 5.0, the radius of influence of the various pump-andtreat wells is controlled by a number of aquifer property and operational factors.

Figure 4.2 shows a log-log plot of the drawdown data and derivative of the drawdown observed at well 299-W15-1. The derivative plot does not become horizontal during the test, which indicates that infinite-acting, radial flow conditions are not established during the drawdown period. Therefore, semi$\log$, straight-line analysis techniques are not appropriate for analyzing these data. Also shown in Figure 4.2 is the composite type curve and derivative plots that provided the best fit to the test data. The type curve was generated using WTAQ3 assuming $\mathrm{K}_{\mathrm{D}}=0.1$ and $\sigma=0.001$. The type curve accounts for delayed yield caused by the unconfined aquifer, wellbore storage, and partial penetration at the stress and monitor well locations. Well 299-W15-1 was screened across the water table and penetrated the upper $14.7 \mathrm{~m}$ of the $\sim 65-\mathrm{m}$-thick aquifer. Additional well-completion information is listed in Table 2.2 .

The best-fit, type-curve match shown in Figure 4.2 was obtained using the following hydrologic properties: $T=230 \mathrm{~m}^{2} / \mathrm{d}, \mathrm{S}_{\mathrm{y}}=0.027$, and $\mathrm{S}=2.7 \mathrm{E}-05$. Initial type curves were generated, assuming $S_{y}=0.1$ and $S=1 E-04$. However, it was found that lower values of $S_{y}$ provided a better type-curve fit of 


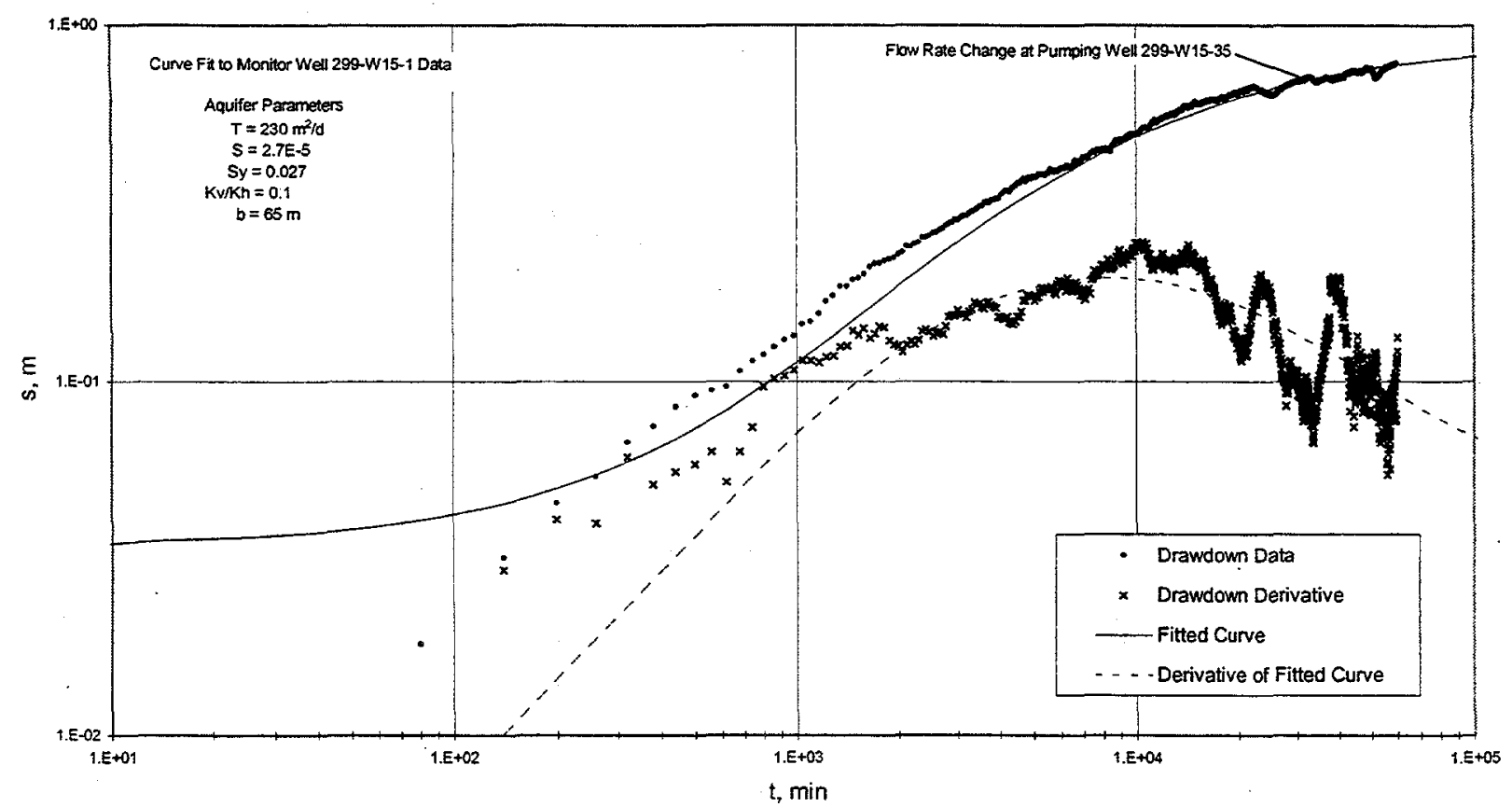

Figure 4.2. Composite Type-Curve and Derivative Plot Analysis of Drawdown Test Data for Monitor Well 299-W15-1

the data. The drawdown data reflect mainly the later-time, delayed-yield response of the unconfined aquifer, which is more affected by $S_{y}$. The early-time response is not clearly exhibited in the observed data, which indicates a large uncertainty in the calculated values of $\sigma$ and $S$.

Various values of $\mathrm{K}_{\mathrm{D}}$ and $\sigma$ were tried in an attempt to improve the type-curve match using a higher value of $S_{y}$. These attempts were not successful and caused significant departures in matching the early part of the curve. Figure 4.3 shows calculated drawdown curves, assuming three different values of $\mathrm{K}_{\mathrm{D}}$ and an assumed $S_{y}$ value of 0.1 . However, it was still necessary to use relatively low values of $S_{y}$ to match the late-time drawdown data. The best match to the shape of the curve was obtained using $\mathrm{K}_{\mathrm{D}}=0.1$. Changing the value of $\sigma$ had little effect on the curve match because of the lack of earlytime drawdown data.

Initial analyses considered only the impacts from the three nearest pumping wells (299-W15-33, -34 , and -35). The relatively low values of $S_{y}$ calculated from the type-curve analyses, however, would indicate some hydrologic impact from more distant wells after relatively long pumping time. Because of these findings, the effect of injection well 299-W15-29 was also included in the monitor well analysis. As discussed above, dimensional type curves were calculated for each of the stress wells and combined using superposition to obtain a composite drawdown curve for the monitor well location. Figure 4.4 shows the responses at 299-W15-1 from each of the four stress wells and the composite drawdown, which was calculated by combining the drawdown for all wells. The impact of the injection well is apparent only at relatively late time. Other distant injection and pumping wells were not included in the analysis because they have little impact $(<0.1 \mathrm{~m})$ and would tend to offset one another. 


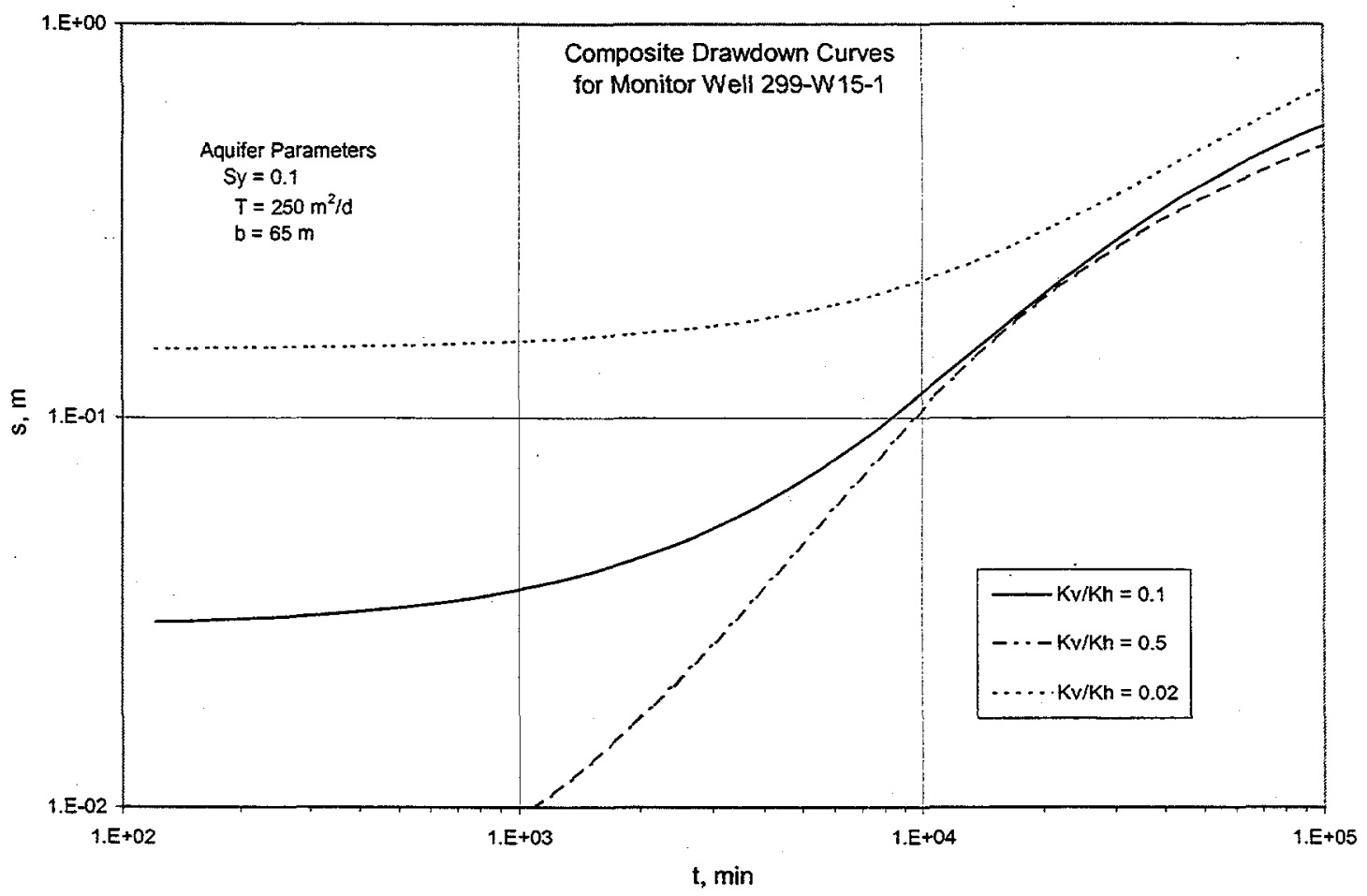

Figure 4.3. Calculated Drawdown Curves for Selected $\mathrm{K}_{\mathrm{D}}$ Values

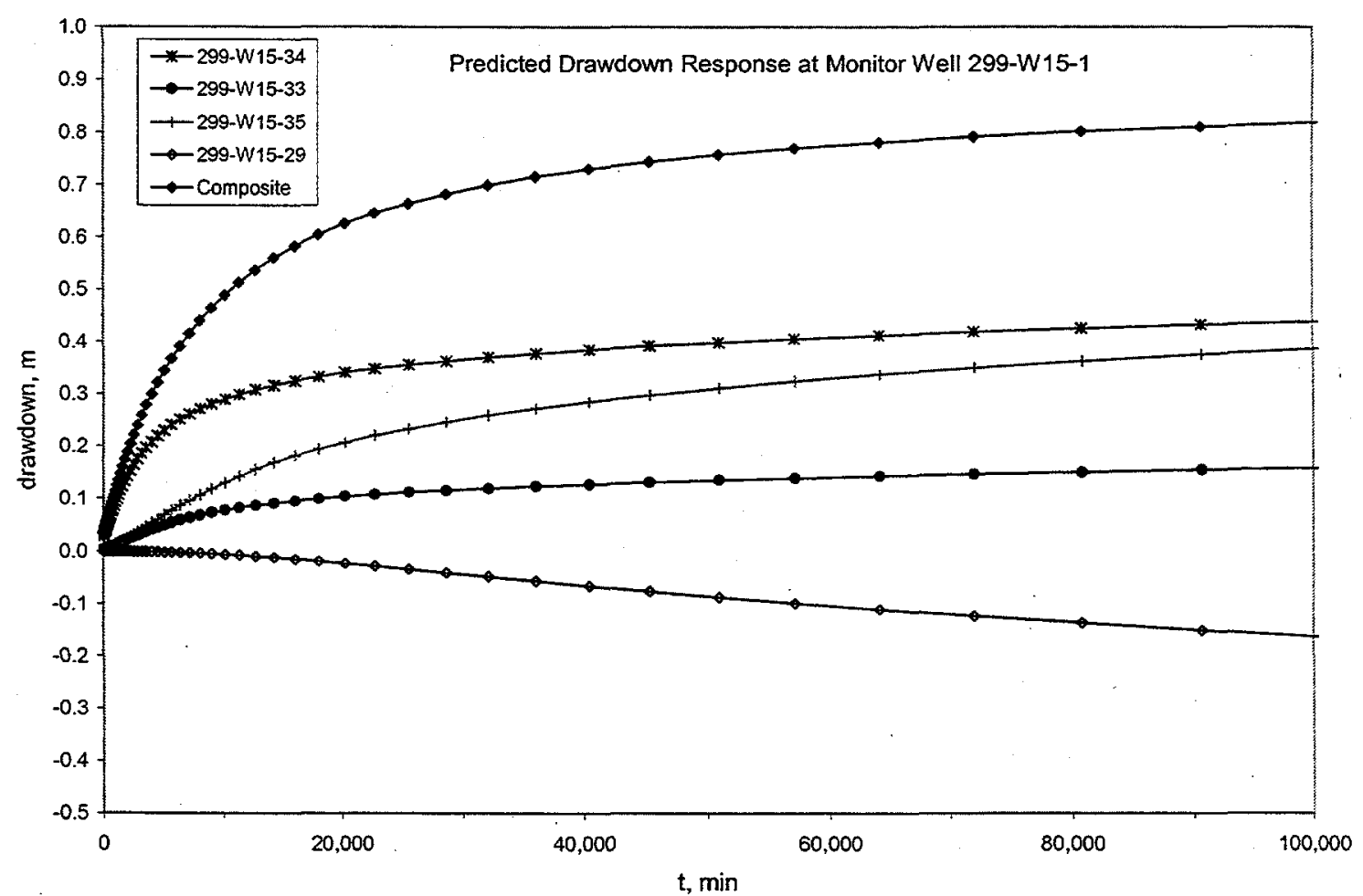

Figure 4.4. Predicted Responses at Monitor Well 299-W15-1 for the Four 200-ZP-1 Stress Wells 


\subsubsection{Well 299-W15-7}

Monitor well $299-$ W15-7 is also influenced primarily by pumping wells $299-$ W15-33, -34 , and -35 and is located within $100 \mathrm{~m}$ of wells $299-\mathrm{W} 15-34$ and -35 (see Figure 2.1 and Table 2.1). This well is also influenced to a lesser extent by injection well 299-W15-29, which is located $861 \mathrm{~m}$ away, but has a higher injection rate than the pumping wells. Other pumping and injection wells were determined to have a negligible effect on the response at 299-W15-7.

Figure 4.5 shows a log-log plot of the drawdown data and derivative of the drawdown observed at well 299-W15-7. The derivative plot does not become horizontal during the test, which indicates that infinite-acting, radial flow conditions were not established during the drawdown period. Therefore, semi$\log$, straight-line analysis techniques are not appropriate for analyzing these data. Daily variations in pumping rate at well 299-W15-35 are more apparent in the water-level response at this well because of its smaller radial distance.

Figure 4.5 also shows the composite type curve and derivative plot that provided the best fit to the test data. As for well 299-W15-1, the type curve was generated using WTAQ3, assuming a $K_{D}$ of 0.1 and a $\sigma$ value of 0.001 . The type curve accounts for delayed-yield, wellbore-storage, and partial penetration conditions at the stress and monitor well locations. Monitor well 299-W15-7 is screened across the

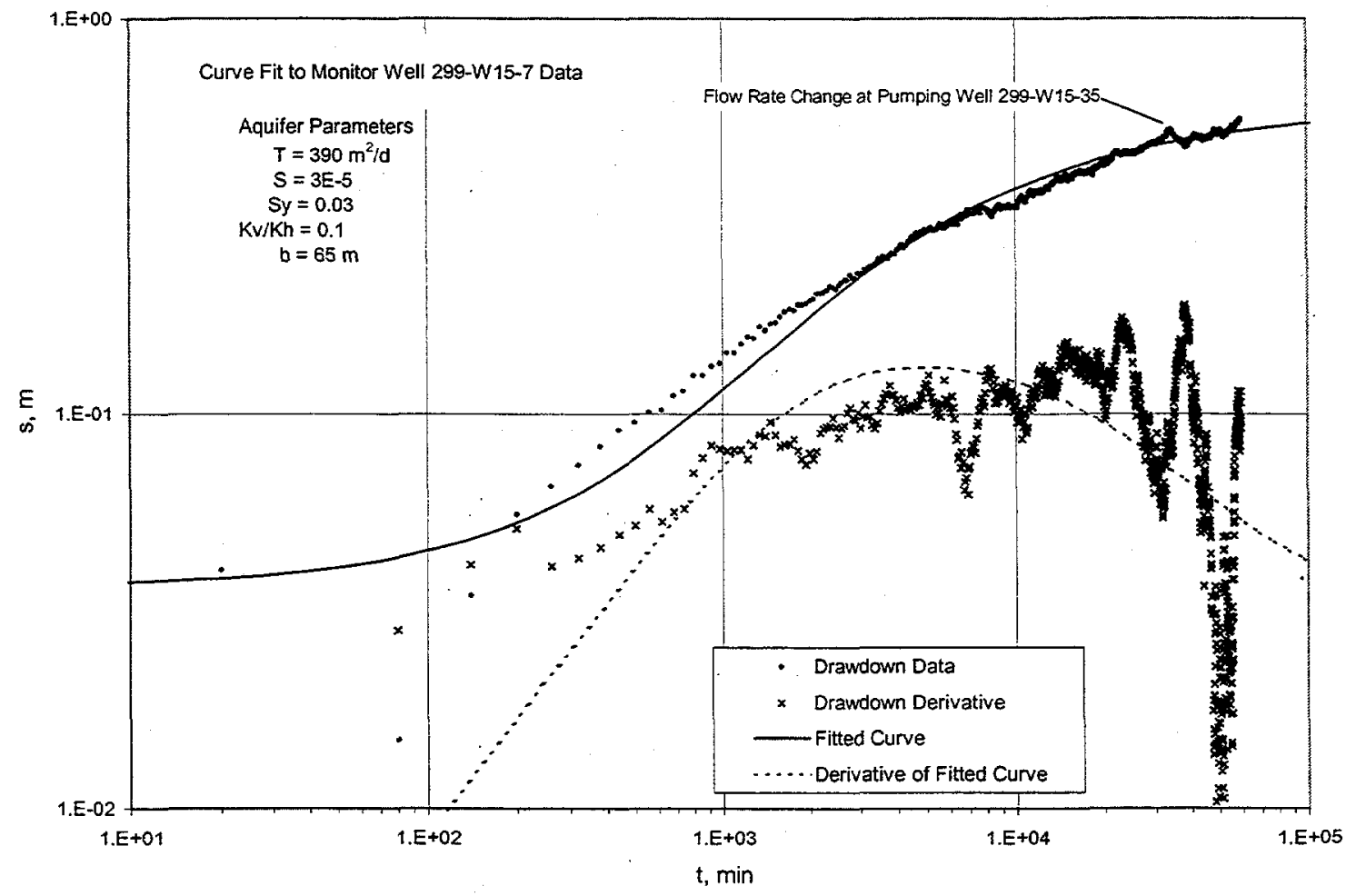

Figure 4.5. Composite Type-Curve and Derivative Plot Analysis of Drawdown Test Data for Monitor Well 299-W15-7 
water table and penetrates the upper $41.6 \mathrm{~m}$ of the $\sim 65$-m-thick aquifer. Additional well-completion information is shown in Table 2.2. The best-fit, type-curve match was obtained using the following hydrologic properties: $\mathrm{T}=390 \mathrm{~m}^{2} / \mathrm{d}, \mathrm{S}_{\mathrm{y}}=0.03$, and $\mathrm{S}=3.0 \mathrm{E}-05$. Again, relatively low values of $\mathrm{S}_{\mathrm{y}}$ were required to obtain a reasonable fit of the data regardless of assumed values of $K_{D}$ and $\sigma$. The drawdown data reflect mainly the later-time, delayed-yield response of the unconfined aquifer, which is dominated by $S_{y}$. The early-time response is not clearly exhibited in the observed data, which indicates a large uncertainty in the calculated values of $\sigma$ and $S$ for this well site.

\subsubsection{Well 299-W15-11}

The water-level response at well $299-\mathrm{W} 15-11$ is also influenced primarily by pumping wells 299-W15-33; -34, and -35 and is located within $40 \mathrm{~m}$ of well 299-W15-33 and within $400 \mathrm{~m}$ of the other two pumping wells (see Figure 2.1 and Table 2.1). The hydrologic response at well 299-W15-11 is also influenced to a lesser extent by injection well 299-W15-29, which is located $697 \mathrm{~m}$ away, but has a higher injection rate than the pumping wells. Other pumping and injection wells were determined to have a negligible effect on the response at well 299-W15-11.

Figure 4.6 shows the log-log plot of the drawdown data and derivative of the drawdown observed at well 299-W15-11. Several flow-rate variations that occurred at pumping well 299-W15-33 (after

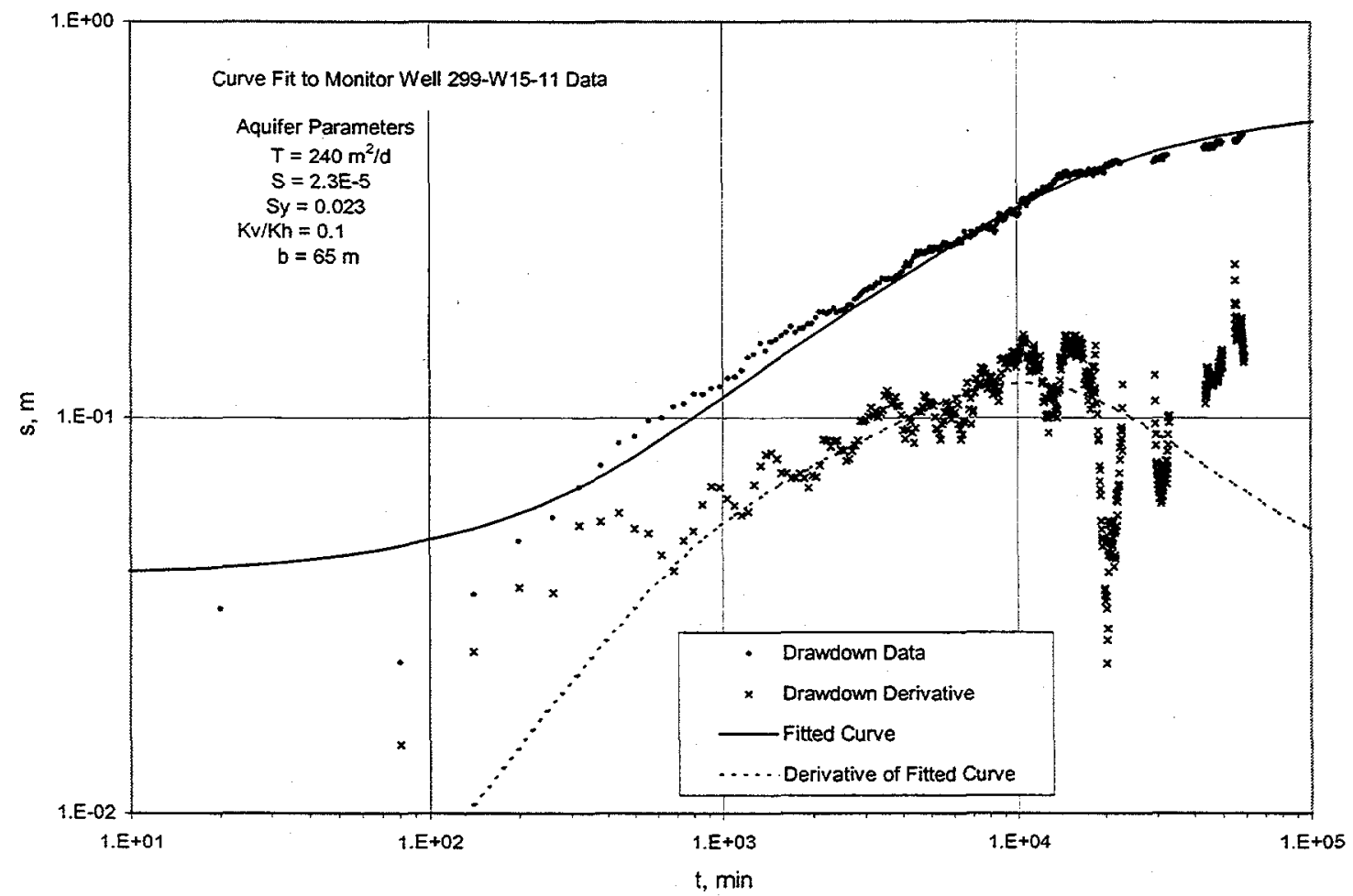

Figure 4.6. Composite Type-Curve and Derivative Plot Analysis of Drawdown Test Data for Monitor Well 299-W15-11 
$22,000 \mathrm{~min}$ ) are also evident in the drawdown plot. As shown in the figure, the derivative plot does not become horizontal during the test, which indicates that infinite-acting, radial flow conditions were not established during the drawdown period. Therefore, semi-log, straight-line analysis techniques are not appropriate for analyzing these data. Several flow-rate variations that occurred at pumping well 299-W15-33 (after 22,000 $\mathrm{min}$ ) are also evident in the drawdown plot.

Figure 4.6 also shows the composite type curve and derivative plot that provided the best fit to the test data. The type curve was generated using WTAQ3, assuming a $K_{D}$ of 0.1 and a $\sigma$ value of 0.001 . The type curve accounts for delayed-yield, wellbore-storage, and partial penetration conditions at the stress and monitor well locations. Monitor well 299-W15-11 is screened across the water table and penetrates the upper $21.7 \mathrm{~m}$ of the $\sim 65-\mathrm{m}$-thick aquifer. Additional well-completion information is shown in Table 2.2. The best-fit, type-curve match was obtained using the following hydrologic properties: $\mathrm{T}=240 \mathrm{~m}^{2} / \mathrm{d}, \mathrm{S}_{\mathrm{y}}=0.023$, and $\mathrm{S}=2.3 \mathrm{E}-05$. Again, as for the other monitor well sites, relatively low values of $S_{y}$ were required to obtain a reasonable fit of the data regardless of assumed values of $K_{D}$ and $\sigma$. The drawdown data are more reflective of late-time, delayed-yield response of the unconfined aquifer, which is more strongly influenced by $\mathrm{S}_{\mathrm{y}}$. The early-time response is not clearly exhibited in the measured data, which indicates a large uncertainty in the calculated values of $\sigma$ and $S$.

\subsubsection{Well 299-W15-31A}

Monitor well 299-W15-31A is located within $124 \mathrm{~m}$ of well 299-W15-33 and within $400 \mathrm{~m}$ of 299-W15-34 and -35 (see Figure 2.1 and Table 2.1). The hydrologic response exhibited at 299-W15-31A is also influenced by injection well 299-W15-29, which is located $574 \mathrm{~m}$ away, but has a higher injection rate than the pumping wells. Other pumping and injection wells were determined to have a negligible effect on the response at 299-W15-31A.

Figure 4.7 shows a log-log plot of the drawdown data and derivative of the drawdown observed at well 299-W15-31A. Several flow-rate variations that occurred at pumping well 299-W15-33 (after $22,000 \mathrm{~min}$ ) are also apparent in the drawdown data. As shown in the figure, the derivative plot does not become horizontal during the test, which indicates that infinite-acting, radial flow conditions were not established during the drawdown period. Semi-log, straight-line analysis techniques, therefore, are not appropriate for analyzing these data.

Figure 4.7 also shows the composite type curve and derivative plot that provided the best fit to the test data. The type curve was generated using WTAQ3, assuming $a K_{D}$ of 0.1 and a $\sigma$ value of 0.001 . The type curve accounts for delayed-yield, wellbore-storage, and partial penetration conditions at the stress and monitor well locations. Monitor well 299-W15-31A is screened across the water table and penetrated the upper $7.7 \mathrm{~m}$ of the $\sim 65-\mathrm{m}$-thick aquifer. Additional well-completion information is shown in Table 2.2. The best-fit, type-curve match was obtained using the following hydrologic properties: $\mathrm{T}=430 \mathrm{~m}^{2} / \mathrm{d}, \mathrm{S}_{\mathrm{y}}=0.035$, and $\mathrm{S}=3.5 \mathrm{E}-05$. Again, as for the other monitor well sites, relatively low values of $S_{y}$ were required to obtain a reasonable fit of the data regardless of assumed values of $K_{D}$ and $\sigma$. The drawdown data are more reflective of late-time, delayed-yield response of the unconfined aquifer, which is more strongly influenced by $S_{y}$. The early-time response is not clearly exhibited in the measured data, which indicates a large uncertainty in the calculated values of $\sigma$ and $S$. 


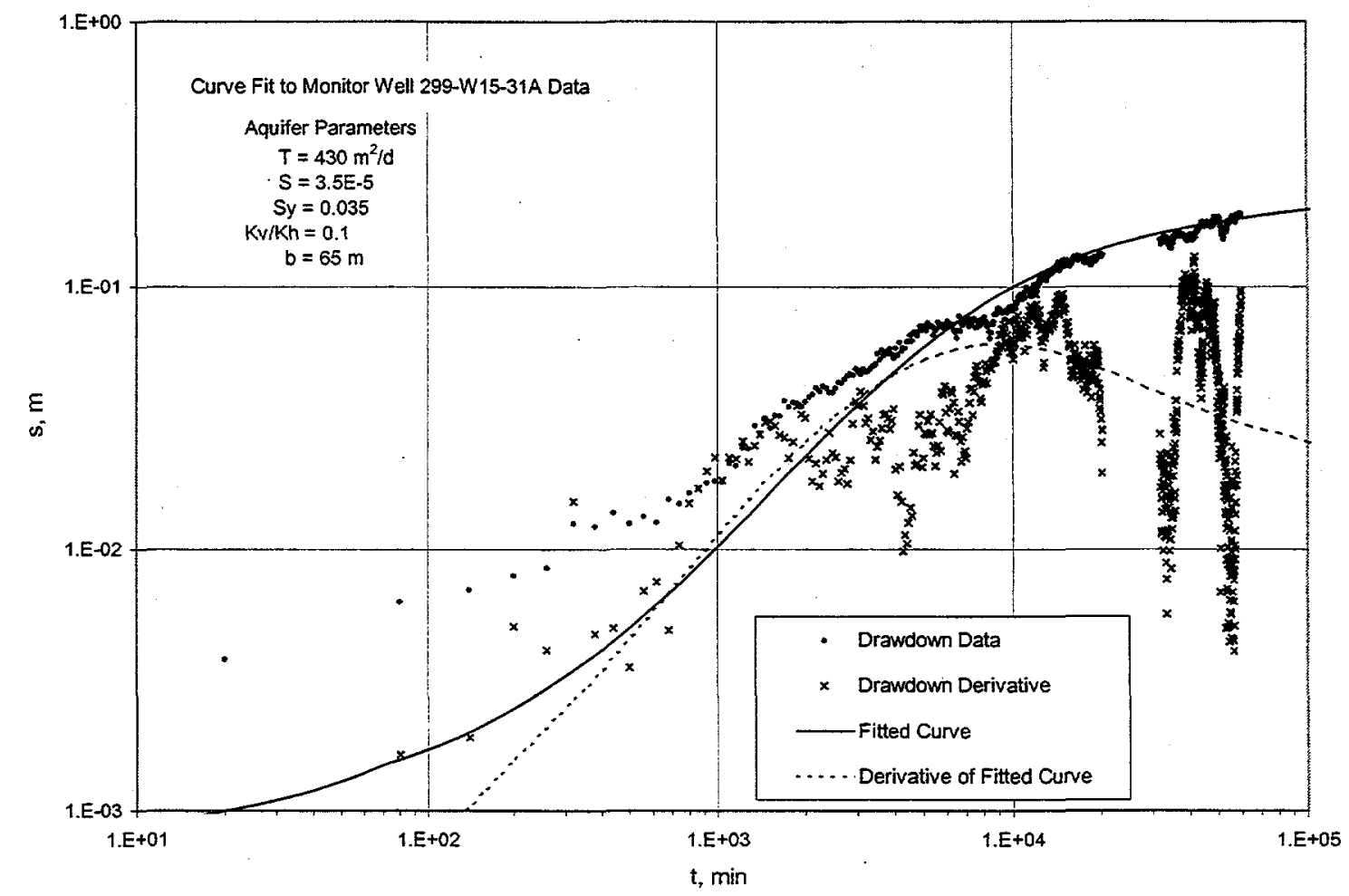

Figure 4.7. Composite Type-Curve and Derivative Plot Analysis of Drawdown Test Data for Monitor Well 299-W15-31A

\subsection{Result Comparison}

Table 4.1 lists the hydrologic property values calculated from the composite analysis of the observed drawdown at selected 200-ZP-1 monitor wells during the 43-day period following the $\mathrm{Y} 2 \mathrm{~K}$ restart (i.e., January 3 to February 14, 2000). A comparison of the results listed in Table 4.1 indicates a fairly close correspondence for $T$, ranging between 230 and $430 \mathrm{~m}^{2} / \mathrm{d}$. The average result of $325 \mathrm{~m}^{2} / \mathrm{d}$ is nearly identical to the large-scale analysis value of $327 \mathrm{~m}^{2} \mathrm{~d}$ reported in Wurstner et al. (1995) and close to the $300-\mathrm{m}^{2} / \mathrm{d}$ value reported in Newcomb and Strand (1953) for the 200 -West Area. The large-scale analysis values reported in Newcomb and Strand (1953) and Wurstner et al. (1995) are based on analyzing the growth and decline of the groundwater mound beneath the 200-West Area, respectively, that were associated with water disposal practices in the area.

Given the uniform value for aquifer thickness of $65 \mathrm{~m}$ used in the test analysis, the calculated $\mathrm{K}_{\mathrm{h}}$ also indicated a close correspondence, ranging between 3.5 and $6.6 \mathrm{~m} / \mathrm{d}$. The calculated range and average value $(5.0 \mathrm{~m} / \mathrm{d})$ obtained from the composite analysis compares very closely to the baseline value of $5.2 \mathrm{~m} / \mathrm{d}$ used for this area in previous numerical simulations of sitewide groundwater flow (e.g., Law et al. 1996) and 200-ZP-1 pump-and-treat activities (Freeman-Pollard et al. 1996). It should be noted that a wide range in $\mathrm{K}_{\mathrm{h}}$ values is listed for the 200-West Area in several earlier reports (e.g., DOE/RL 1993; 
$\mathrm{K}_{\mathrm{h}}=0.02$ to $61 \mathrm{~m} / \mathrm{d}$ ). These results, however, are generally based on single-well slug tests or shortduration (e.g., <8-hr) pumping tests, which have a much smaller radius of investigation (e.g., 1 to $10 \mathrm{~m}$ ) in comparison to the large-scale investigated by the 200 -ZP-1 test facility (e.g., 100 to $1,000 \mathrm{~m}$ ).

Comparison of the results listed in Table 4.1 also indicates a fairly close correspondence for $\mathrm{S}_{\mathrm{y}}$, ranging between 0.023 and 0.035 . The estimates obtained for $S_{y}$, however, $(\approx 0.03)$ appear to be lower than what would be expected (i.e., between 0.05 to 0.25 ) for this hydrogeologic unit. The large-scale mound analysis results reported in Newcomb and Strand (1953) and Wurstner et al. (1995) of 0.11 and 0.17 , respectively, appear to be more reasonable. The reason for this apparently low estimate for $\mathrm{S}_{\mathrm{y}}$ from the composite analysis is not currently understood. This lower-than-expected value for $S_{y}$, however, is consistent with findings from other unconfined aquifer location investigations where typecurve analysis methods were used (Moench 1994). For example, Mock and Merz (1993) report $S_{y}$ values based on type-curve analysis results that range between 0.02 and 0.07 (average value $=0.04$ ) for a multi-well unconfined aquifer pumping test that employed six monitor wells. A more controlled hydrologic test in the future (including tracer testing) at the 200-ZP-1 pump-and-treat facility may provide more definitive information pertaining to this important hydrologic parameter. 


\subsection{Hydrologic Influence}

The hydrologic impact of the 200-ZP-1 pump-and-treat system within the unconfined aquifer system in the 200-West Area can be predicted using the existing analytical models presented in Neuman (1972, 1974, 1975). Major factors affecting the areal influence and vertical response within the unconfined aquifer include vertical anisotropy $\left(\mathrm{K}_{\mathrm{D}}\right)$ of aquifer hydraulic conductivity $\left(\mathrm{K}_{\mathrm{h}}, \mathrm{K}_{\mathrm{v}}\right)$, penetration aspect of the pumping and injection wells, aquifer thickness (b), and magnitude and duration of pump-and-treat cycles. Of particular importance are the unconfined aquifer conditions that cause the formation to respond in a manner that deviates from that predicted using a Theisian analytical model (Theis 1935), which is strictly valid for only confined aquifer systems.

\subsection{Unconfined Aquifer Conditions}

As background, the following discussion (taken primarily from Spane 1993 and Spane and Wurstner 1993) provides a brief summary of how unconfined aquifers respond during pumping tests. The manner in which unconfined aquifers respond during pumping is attributed primarily to the way groundwater is released from storage. For confined aquifers, groundwater is released from elastic storage, resulting from compression of water and compression of the aquifer matrix. For unconfined aquifers, groundwater is produced both from elastic storage and by gravity drainage from the lowering water-table surface. As pumping time increases, the elastic storage, represented by the storativity (S) becomes less important and gravity drainage represented by the aquifer specific yield $\left(\mathrm{S}_{\mathrm{y}}\right)$ becomes dominant in controlling drawdown within unconfined aquifers (Neuman 1972, 1974, 1975, 1979).

The fact that unconfined aquifers produce groundwater from two sources of storage and that the water table is not fixed during testing causes unconfined aquifer pumping tests to depart from the response predicted by the Theis (1935) equation for confined aquifer systems. Walton (1960) states that unconfined aquifer, constant-rate, pumping tests conducted within fully penetrating wells are characterized by the presence of three distinct segments on a time-drawdown curve. In the first segment, the aquifer reacts as a confined aquifer, with groundwater being produced through the expansion of water and compaction of the aquifer matrix. Drawdowns during this segment follow the pattern predicted using the Theis equation, with aquifer storage equal to only S. In the second segment of the drawdown curve, the rate of drawdown decreases as gravity drainage (i.e., vertical groundwater-flow component) becomes important within the aquifer. Gravity drainage (also referred to as delayed yield) within the unconfined aquifer causes the time-drawdown curve to deviate significantly from that predicted by the Theis equation because of the presence of recharge in the form of interstitial storage in the vicinity of the pumped well. In the third segment, vertical groundwater-flow effects become insignificant and radial flow conditions are once again predominant within the aquifer. Drawdowns during this segment follow the response predicted using the Theis equation, with aquifer storage equal to its combined $S$ and $S_{y}$.

The influence and duration of the first two segments of the time-drawdown curve are reported by Neuman (1972) to be largely controlled by the parameter $\sigma=\mathrm{S} / \mathrm{S}_{\mathrm{y}}$. The smaller the value of $\sigma$, the more pronounced the effects of vertical flow become. In summarizing the significance of vertical flow within 
unconfined aquifers, Neuman (1979) states that “...the effect of vertical drainage on the average drawdown is felt almost simultaneously everywhere in a large segment of the aquifer: there is no indication that the relative intensity of this effect varies significantly with radial distance from the pumping well."

In addition to the effect that $\sigma$ has on the pumping test response pattern, Neuman (1972) also described unconfined test behavior with respect to a dimensionless $\beta$ parameter, which is defined as:

$$
\beta=K_{D} r^{2} / b^{2}
$$

where $\mathrm{K}_{\mathrm{D}}=$ vertical anisotropy; ratio of vertical to horizontal hydraulic conductivity, $\mathrm{K}_{\mathrm{v}} / \mathrm{K}_{\mathrm{h}}$; dimensionless

$\mathrm{r}=$ radial distance from pumped well to observation well location; $\mathrm{L}$

$\mathrm{b}=$ aquifer thickness; $\mathrm{L}$.

Figure 5.1 shows a comparison of the dimensionless drawdown $\left(\mathrm{s}_{D}\right)$ versus dimensionless time $\left(\mathrm{t}_{\mathrm{s}}\right)$ plot for confined aquifers as predicted using the Theis (1935) equation and unconfined aquifer behavior

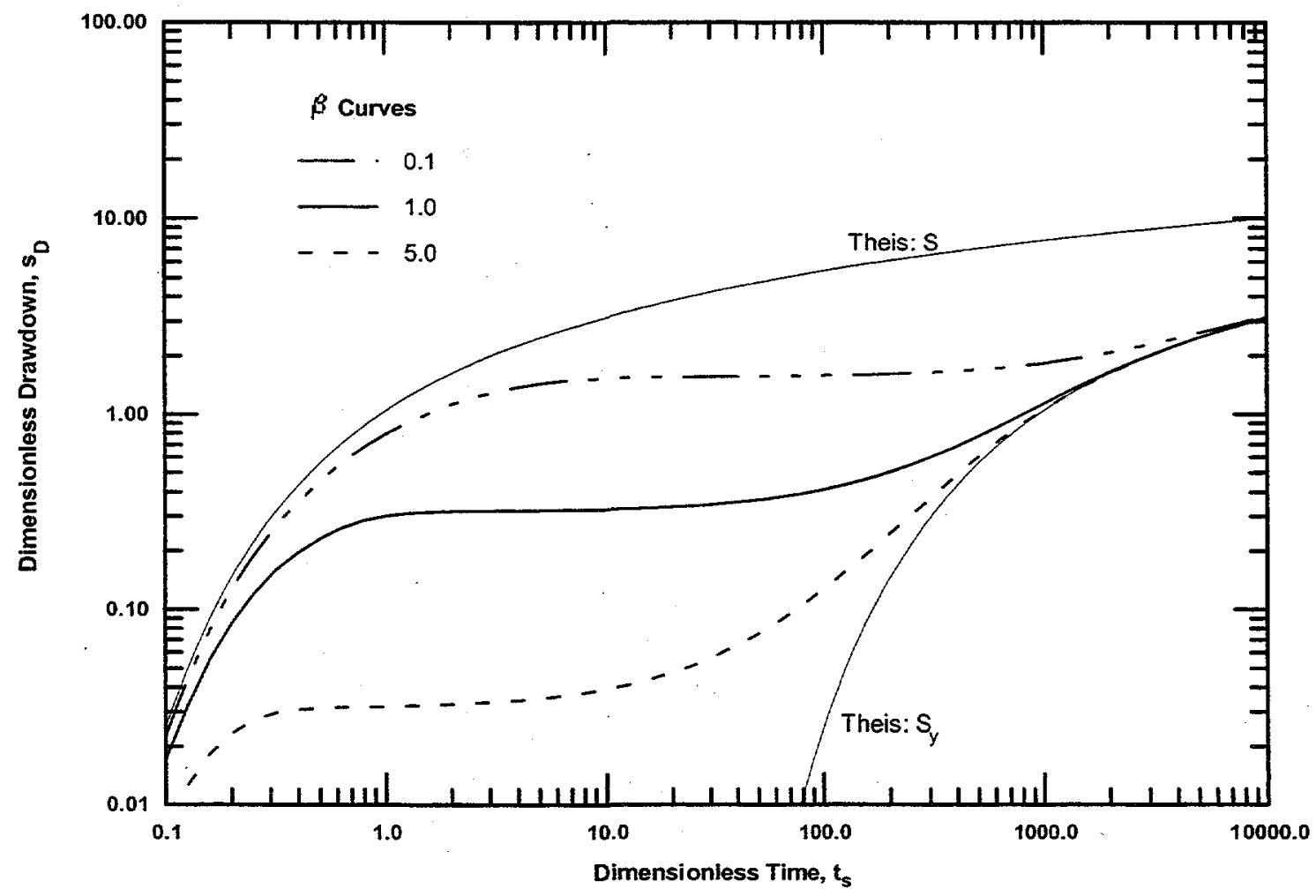

Figure 5.1. Dimensionless Type-Curve Responses for Fully Penetrating Wells Within Unconfined Aquifers 
for $\sigma=0.001$ and selected $\beta$ values using the analytical solution described in Neuman (1972). The responses shown in the figure were generated using the DELAY2 program reported in Neuman (1975) for the selected $\beta$ values indicated. Similar dimensionless response plots are presented in Neuman (1975, Figure 1).

Dimensionless drawdown $\left(\mathrm{s}_{\mathrm{D}}\right)$, and dimensionless time $\left(\mathrm{t}_{\mathrm{s}}\right)$, are defined as:

$$
\mathrm{S}_{\mathrm{D}}=4 \pi \mathrm{T} \mathrm{s} / \mathrm{Q}
$$

and

$$
t_{s}=T t /\left(r^{2} S\right)
$$

where $\begin{aligned} \mathrm{T} & =\text { transmissivity } \mathrm{L}^{2} / \mathrm{T} \\ \mathrm{S} & =\text { storativity } ; \text { dimensionless } \\ \mathrm{S} & =\text { drawdown } \mathrm{L} \\ \mathrm{t} & =\text { time } \mathrm{T} \\ \mathrm{Q} & =\text { pumping rate } ; \mathrm{L}^{3} / \mathrm{T}\end{aligned}$

As indicated in Figure 5.1, unconfined aquifer response deviates more quickly from the early elastic confined aquifer behavior (i.e., Theis: $S$ ) with increasingly higher $\beta$ value. In addition, less predicted drawdown is evident within unconfined aquifers that exhibit higher $\beta$ value conditions. Possible factors contributing to higher $\beta$ value conditions (as shown in Equation 5.1) include higher values of $\mathrm{K}_{\mathrm{D}}\left(\mathrm{K}_{\mathrm{v}} / \mathrm{K}_{\mathrm{h}}\right)$, greater radial distance, and/or smaller aquifer thickness. Eventually, unconfined aquifer response for fully penetrating wells converges with that predicted for confined aquifer conditions using the Theis (1935) equation with respect to $S_{y}$, as indicated in the figure. As discussed earlier, at the point of convergence, vertical flow within the unconfined aquifer at this location is insignificant and radial flow conditions are predominant. The time $(t)$ required for convergence (and establishment of radial flow conditions at this location) can be estimated using a modified form of Equation 5.3.

$$
t=\left(\operatorname{ty~} r^{2} S_{y}\right) / T
$$

where $\quad t_{y}=$ dimensionless time with respect to the specific yield $=t s \sigma$

$\mathrm{S}_{\mathrm{y}}=$ specific yield, dimensionless.

For example, the estimated time required for radial flow conditions to become dominant in an unconfined aquifer exhibiting a $\beta$.value of 1 (e.g., $K_{D}=1, r / b=1$ ), for a $t_{s}$ value of 2,500 (convergence value from Figure 5.1), $\sigma=0.001, \mathrm{r}=100 \mathrm{~m}, \mathrm{~S}_{\mathrm{y}}=0.2, \mathrm{~T}=250 \mathrm{~m}^{2} / \mathrm{d}$ would be $\sim 20$ days.

\subsubsection{Aquifer Depth}

It should be noted that the previous discussion and Figure 5.1 is for the average drawdown that would be observed for a fully penetrating observation well. Unlike confined aquifer systems, wells completed at 
different depths within unconfined aquifers can exhibit significantly different drawdown patterns for a given location within the aquifer. This is attributed, again, to vertical flow effects, which occur during pumping tests within unconfined aquifers. To illustrate the differences in aquifer drawdown for different depth relationships, Figure 5.2 shows the predicted drawdown for an observation well completed in the upper and lower $5 \%$ of the aquifer. The conditions are identical to those shown in Figure 5.1 for an unconfined aquifer with a $\beta$ value of 1 . For comparison purposes, the average dimensionless drawdown predicted for the aquifer (as shown in Figure 5.1 for $\beta=1$ ) is also presented. As indicated, more drawdown would be exhibited for the lower $5 \%$ of the aquifer and considerably less drawdown for the upper $5 \%$ of the aquifer, which is near the water table. The implication is that a significant downward flow of groundwater would be imposed through the aquifer at this location for a substantial part of the pumping drawdown phase. In addition, a considerably longer time for convergence to radial flow conditions (i.e., decrease in vertical flow gradient) is indicated for the two depth intervals examined in Figure 5.2, particularly for the top 5\% of the aquifer. The drawdown relationships shown in Figure 5.2 are similar to findings presented in Neuman (1972, Figure 4).

\subsubsection{Vertical Anisotropy}

As noted earlier, $K_{D}$ has a significant impact on unconfined aquifer drawdown. For average drawdown relationships, a decrease in $K_{D}$ (lower $K_{v}$ compared to $K_{h}$ ) is associated with a lower

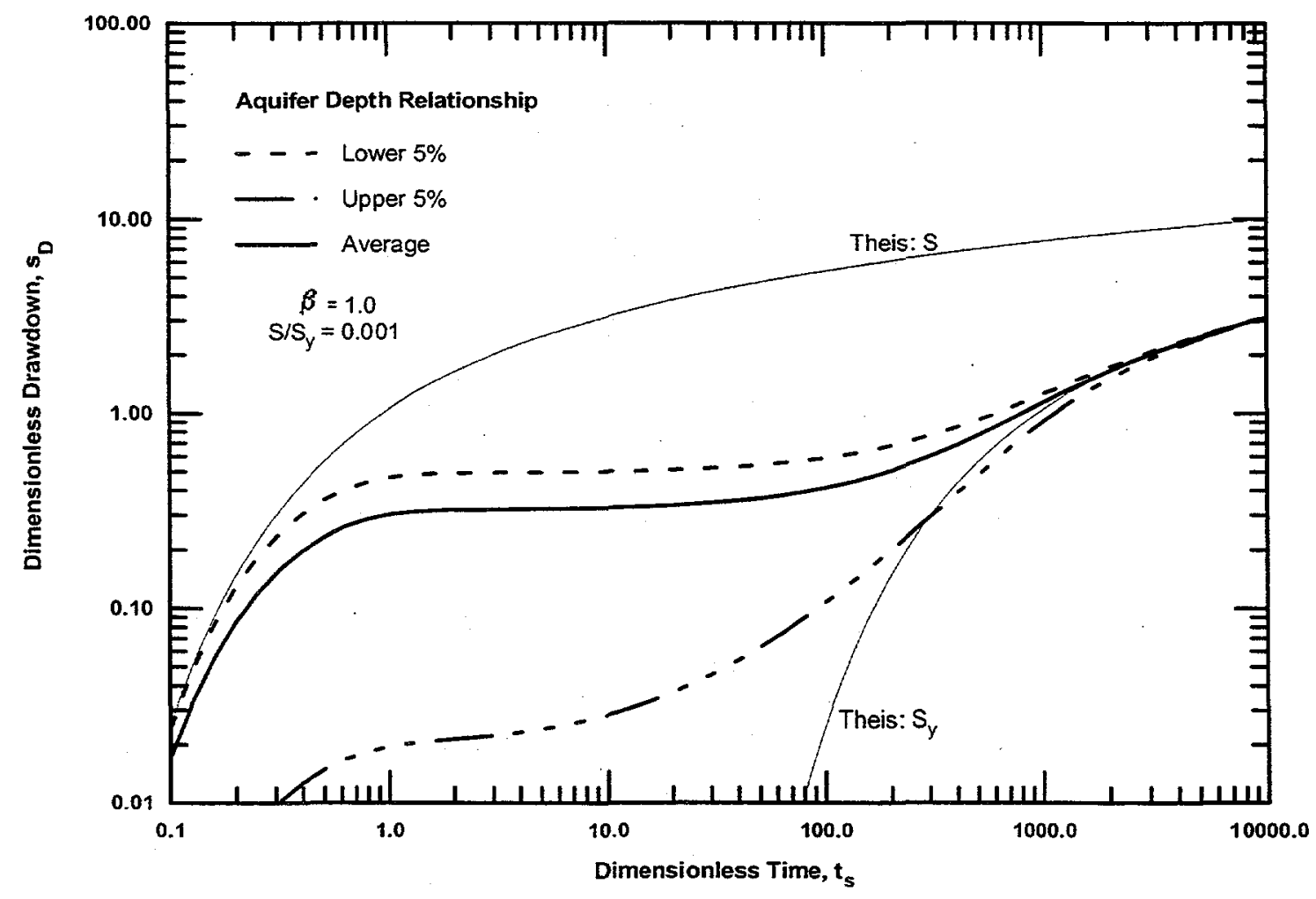

Figure 5.2. Dimensionless Type-Curve Responses as a Function of Aquifer Depth (upper and lower $5 \%$ of the aquifer) 
$\beta$ curve value (Equation 5.1), which was shown in Figure 5.1 to cause more average drawdown within the aquifer, and extends the time of significant vertical flow within the aquifer. To illustrate the impact of vertical anisotropy between the top and bottom of the aquifer, the same depth conditions used in Figure 5.2 (i.e., the upper and lower $5 \%$ ) were examined for $\mathrm{K}_{\mathrm{D}}$ values 1.0 and $0.1(\beta=1.0$ and 0.1$)$. As shown in Figure 5.3, a pattern of increased drawdown (i.e., during early and intermediate test times) and an extended period of vertical flow within the aquifer are indicated between the top and bottom of the aquifer.

\subsubsection{Well Partial Penetration}

For situations where the pumping wells do not fully penetrate the aquifer, additional distortion to predicted drawdown will occur. The effects of partial penetration are difficult to quantify universally because different drawdown patterns will be produced for given aquifer-depth location and for different $\mathrm{K}_{\mathrm{D}}, \mathrm{r}$, and $\mathrm{b}$ relationships. This complexity is shown in Figure 5.4 (taken from Neuman 1975), which shows the dimensionless flow pattern as a function of aquifer depth and radial distance from a pumping

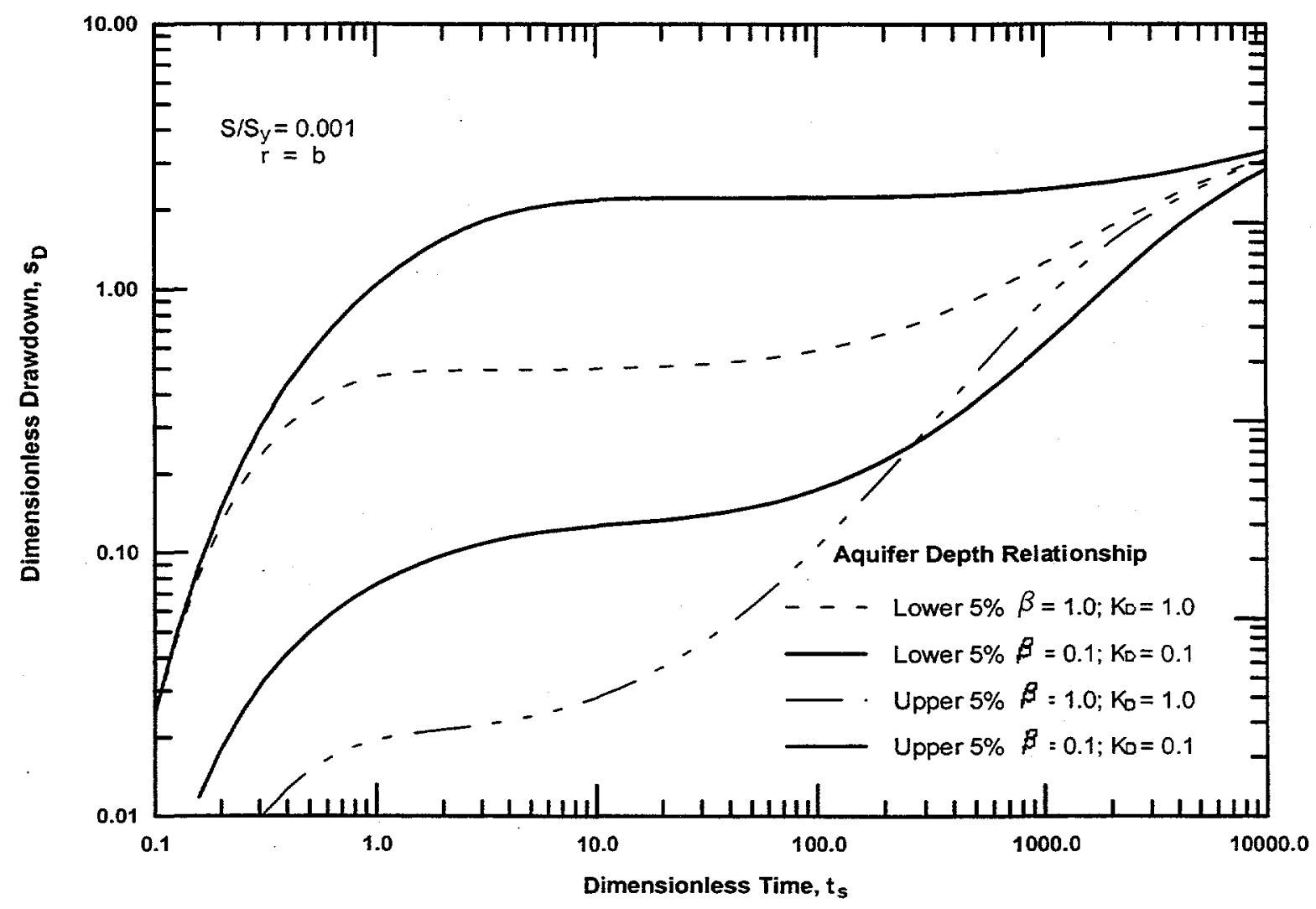

Figure 5.3. Dimensionless Type-Curve Responses as a Function of Aquifer Depth and Vertical Anisotropy $\left(\mathrm{K}_{\mathrm{D}}=0.1\right.$ and 1.0) 


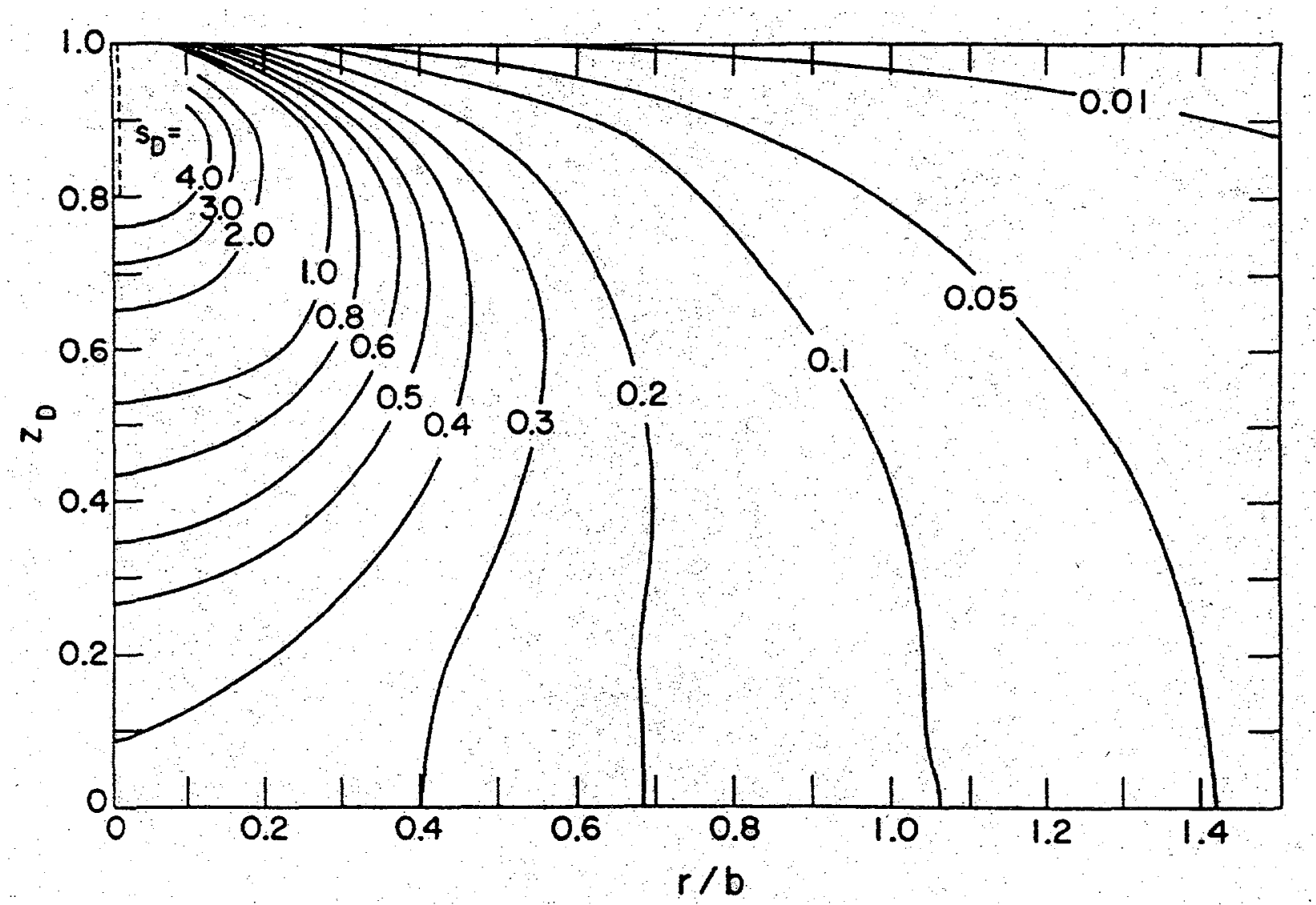

Figure 5.4. Dimensionless Flow Pattern Around Pumping Well that Penetrates the Upper $20 \%$ of an Isotropic Unconfined Aquifer $\left(\sigma=10^{-2}\right.$ and $\left.t_{s} \beta=1.0\right)$ (from Neuman 1974)

well completed in the upper $20 \%$ of an isotropic (i.e., $\mathrm{K}_{\mathrm{D}}=1.0$ ) unconfined aquifer for a dimensionless time $\left(t_{s}=1 / \beta\right)$. As indicated in the figure, for $r / b$ values $<0.6$, greater drawdown is indicated within the middle part of the aquifer in comparison to the upper and lower $20 \%$ of the aquifer. For the lower part of the aquifer, essentially lateral flow conditions exist for $r / b \geq 0.5$ and upward flow toward the pumping well for $\mathrm{r} / \mathrm{b}$ values $<0.5$. Of particular note is that a downward flow condition is indicated for the upper part of the aquifer for all $\mathrm{r} / \mathrm{b}$ values, which becomes more vertical and affects more of the aquifer depth with increasing distance from the pumping well.

The above discussion pertains to drawdown patterns within an isotropic unconfined aquifer. The $\mathrm{K}_{\mathrm{D}}$ effects tend to distort the drawdown pattern presented for different pumping well-penetration depths and aquifer-depth relationships. Generally speaking, however, for decreasing $\mathrm{K}_{\mathrm{D}}$ values, increased drawdown would be indicated within the upper parts of the aquifer (i.e., the zone the pumping well penetrates) and less for the middle and lower parts of the aquifer. Neuman (1975) states that the effect of partial penetration on drawdown diminish with distance and for radial distances $(r)$ greater than $b /\left(\mathrm{K}_{\mathrm{D}}\right)^{1 / 2}$ disappear completely when time (t) exceeds: 


$$
t=10 S_{y} r^{2} / T
$$

For illustration purposes, if the same input values for the example considered earlier for calculating the time required to establish radial flow conditions for a fully penetrating pumping well (i.e., $\beta=1$, $\mathrm{K}_{\mathrm{D}}=1, \mathrm{r} / \mathrm{b}=1, \mathrm{r}=100 \mathrm{~m}, \mathrm{~S}_{\mathrm{y}}=0.2, \mathrm{~T}=250 \mathrm{~m}^{2} / \mathrm{d}$ ) are used, the calculated time for disappearance of partial penetration well effects would be $\sim 80$ days. The calculation indicates that the partial penetration effects cause a delay factor of four ( 80 versus 20 days) for establishment of radial flow conditions during pumping for the example considered.

\subsection{Radius of Influence}

The radius of influence is commonly defined as the distance from a pumping or injection well for which an imposed pressure perturbation may be detected. The radius of influence imposed by the 200-ZP-1 pump-and-treat system has been previously reported based on observed monitor well responses associated with termination or initiation of pump-and-treat activities. For example, DOE/RL (1998) reports that the radius of influence from the extraction wells is measurable to a distance of $252.5 \mathrm{~m}$, while $\mathrm{DOE} / \mathrm{RL}$ (2000) reports that the upgradient "...radius of influence near the northern extraction wells was calculated to extend beyond monitor well 299-W15-31A (located 124.1 m from well 299-W15-33, with $0.11 \mathrm{~m}$ of measured drawdown)....The overall impact to the aquifer downgradient of the extraction wells, particularly around the TX and U tank farms is unclear and requires additional monitoring to determine."

Clearly, the pressure perturbation effects of the 200-ZP-1 pump-and-treat system extend beyond 125 and $250 \mathrm{~m}$ acknowledged in these reports, particularly if a detectable pressure perturbation is defined as being $0.01 \mathrm{~m}$ or lower. (Note: Spane et al. 1996 recommend use of test equipment with pressure resolution capabilities of $0.001 \mathrm{~m}$ for certain hydrologic tests.) The ability to detect such small, imposed, hydrologic responses is greatly increased by using external stress-removal techniques (e.g., multipleregression deconvolution method) as demonstrated in Section 3.0.

Because average drawdown within isotropic unconfined aquifers eventually becomes coincident with that predicted for confined aquifer systems for fully penetrating wells, the Theis (1935) solution (with respect to $S+S_{y}$ ) has been used for predicting the radius of influence of pump-and-treat systems. To examine the validity of this application, distance drawdowns were developed based on the Theis confined aquifer solution and compared with those developed for unconfined aquifer test response using the analytical code WTAQ3, described in Moench (1997). Figure 5.5 shows the predicted distance-drawdownresponse comparisons from a fully penetrating pumping well after 1 week, 1 month and 1 year for the following input parameters: $T=250 \mathrm{~m}^{2} / \mathrm{d}, \mathrm{K}_{\mathrm{D}}=1.0, \mathrm{~S}_{\mathrm{y}}=0.10, \sigma=0.001, \mathrm{~b}=65 \mathrm{~m}, \mathrm{r}_{\mathrm{w}}=0.102 \mathrm{~m}$, and $\mathrm{Q}=379 \mathrm{~L} / \mathrm{min}$. As shown, the Theis confined aquifer solution gives coincident results with those predicted by the unconfined aquifer solution for test times of 1 month and 1 year and, therefore, can be used reliably to predict average drawdown within the aquifer. If the radius of influence is defined as the lateral distance to where a measurable hydrologic response of $0.01 \mathrm{~m}$ is produced, then a radial distance of $>500 \mathrm{~m}$ is indicated for pumping times of 1 month or more. 


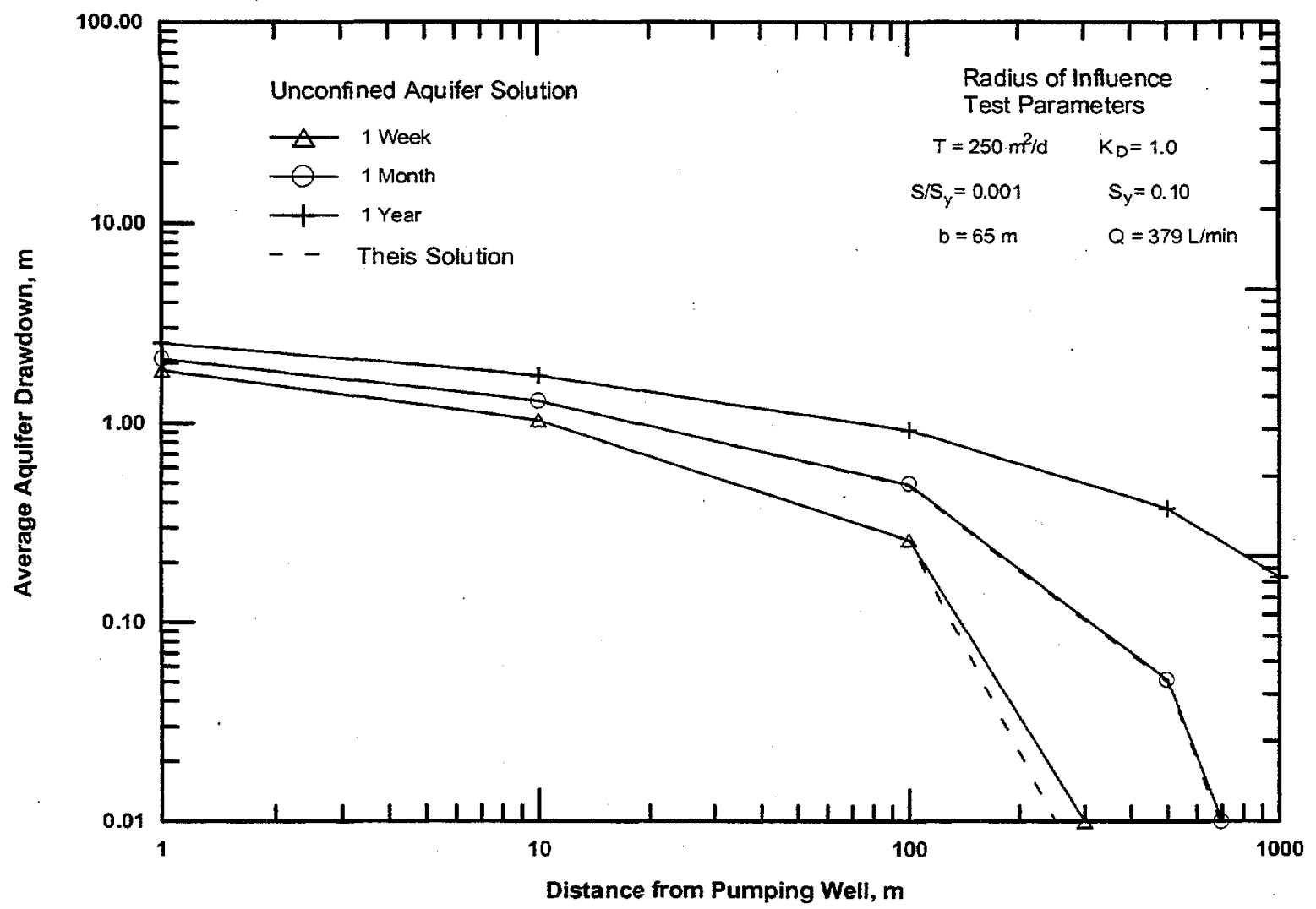

Figure 5.5. Predicted Average Aquifer Drawdown Versus Distance After 1 Week, 1 Month, and 1 Year

It should be noted that the previous discussion pertains to the vertical average drawdown within an isotropic unconfined aquifer. As discussed earlier, because of inherent unconfined aquifer-response characteristics, which result in vertical flow conditions, differences in drawdown with aquifer depth would be expected for a given radial distance. To illustrate the actual vertical drawdown difference and vertical flow potential, the predicted distance drawdown for the upper and lower $5 \%$ of an anisotropic unconfined aquifer $\left(\mathrm{K}_{\mathrm{D}}=0.1\right)$ is displayed in Figure 5.6. Except for $\mathrm{K}_{\mathrm{D}}$, the same aquifer conditions specified in Figure 5.5 were used for generating the distance-drawdown relationships after 1 week of pumping. As shown, less drawdown occurs for the top of the unconfined aquifer, indicating a downward vertical flow component over the entire radial distance examined. This distance-drawdown relationship pattern (between the aquifer top and bottom), with diminished drawdown differences $(\leq 0.06 \mathrm{~m})$, was evident after 1 month of pumping (not shown). Eventually, with extended pumping times, drawdown differences between the top and bottom of the unconfined aquifer decrease and become essentially equivalent, indicating the end of vertical flow conditions. Small drawdown differences (e.g., $\leq 0.004 \mathrm{~m}$ ), however, were still evident after 1 year of pumping (not shown) for radial distances $>100 \mathrm{~m}$ from the pumping well. 


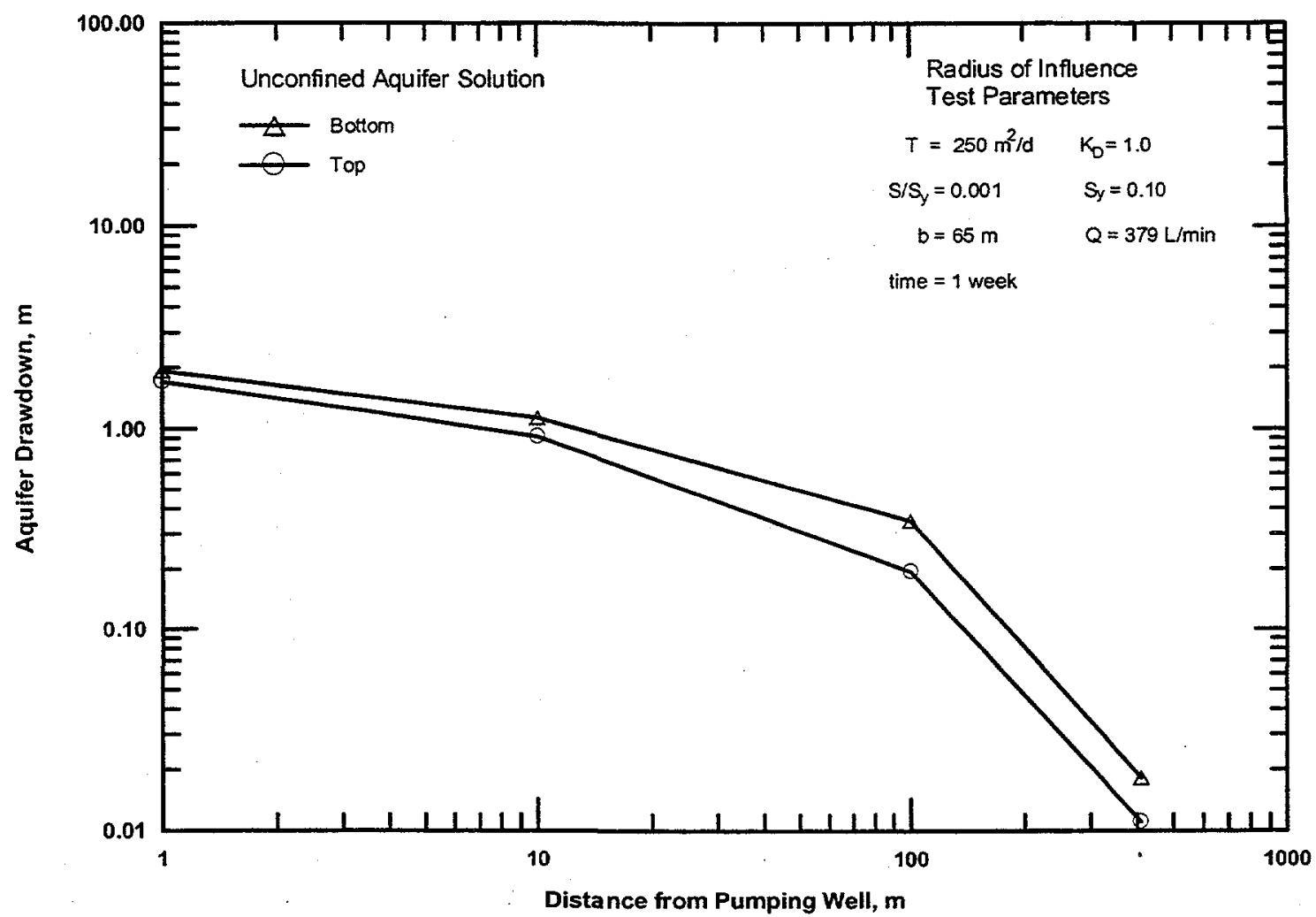

Figure 5.6. Predicted Aquifer Drawdown After 1 Week as a Function of Aquifer Depth (upper and lower $5 \%$ of the aquifer)

\subsection{Effect on Confined Aquifer}

A locally confined sedimentary aquifer (the basal Ringold) underlies the unconfined aquifer in the vicinity of the 200-ZP-1 pump-and-treat system. These aquifers are separated by the Ringold Lower Mud Unit. Because the pumping and injection wells are completed within the upper part of the unconfined aquifer and are relatively distant vertically (i.e., $>50 \mathrm{~m}$ ) from the underlying locally confined aquifer, no associated hydrologic response within this hydrogeologic unit was anticipated. To assess the potential hydrologic impact on the underlying confined aquifer, the water-level response at monitor well 299-W14-9 was examined. As noted in DOE/RL (2000), well 299-W14-9 is completed below the Ringold Lower Mud Unit and is relatively distant from the northern pumping wells, as shown in Figure 2.1. Because of its completion in the underlying confined aquifer system, well 299-W14-9 is not monitored routinely as part of the 200-ZP-1 monitor well network. An automated water-level monitoring. system, however, was installed in this well beginning on December 16, 1999 ( 2 days after the Y2K shutdown/ recovery period) and continuing through February 14,2000. Figure 5.7 shows the observed baseline water-level response and barometric pressure record for this time period. As indicated in the figure, no obvious response to 200-ZP-1 pump-and-treat activities is evident in the uncorrected record. 


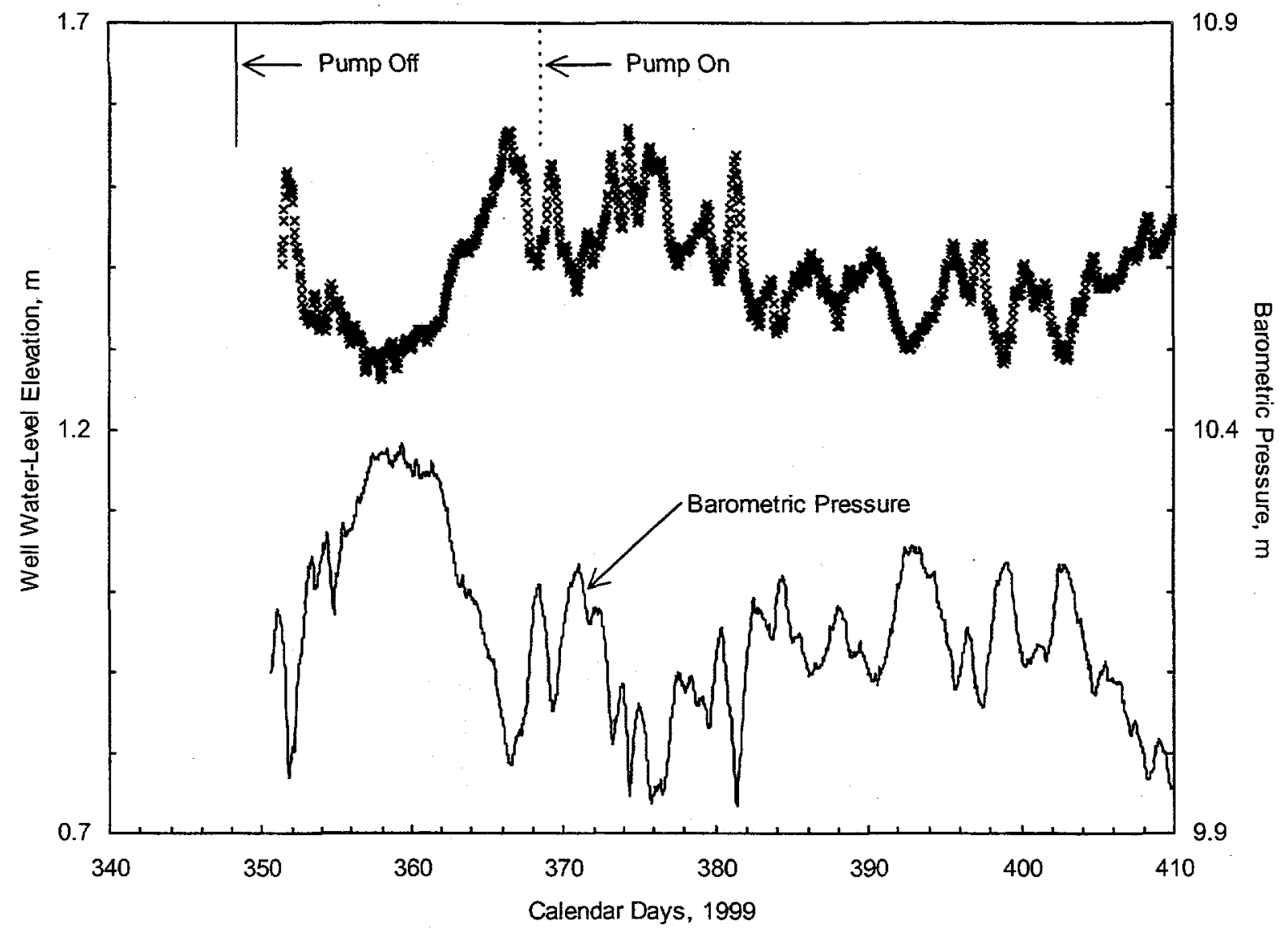

Figure 5.7. Baseline Water-Level Elevation and Barometric Pressure Measurements for Monitor Well 299-W14-9, December 16, 1999 to February 14, 2000

Because any associated responses to 200-ZP-1 pump-and-treat activities would likely be small within the underlying confined aquifer, efforts were made to remove the barometric fluctuations evident from the well 299-W14-9 water-level response. The multiple-regression deconvolution techniques described in Section 3.0 were used to analyze and remove barometric effects evident within the well record. Because water-level data were not available for the well site prior to the $\mathrm{Y} 2 \mathrm{~K}$ shutdown, the same 19-day baseline period (October 27 to November 15, 1999) used for selected 200-ZP-1 unconfined aquifer monitor wells could not be used. To complete the analysis, a 19-day period between January 25 and February 13, 2000 was examined for well/barometric response characteristics. The time period selected for analysis occurs $\sim 3$ to 6 weeks after the Y2K restart and is representative of fairly stable areal drawdown conditions within the overlying unconfined aquifer system. Figure 5.8 shows the barometric response pattern obtained from the observed water-level elevation multiple-regression analysis for this well. As indicated in the figure, a distinctly different pattern is exhibited for this well in comparison to the other 200-ZP-1 unconfined aquifer monitor wells shown in Figure 3.3. The response pattern is consistent with a confined aquifer system model (i.e., no dependence with time lag) with minor wellborestorage/skin effects evident during the early time-lag periods. Linear regression analysis was also 


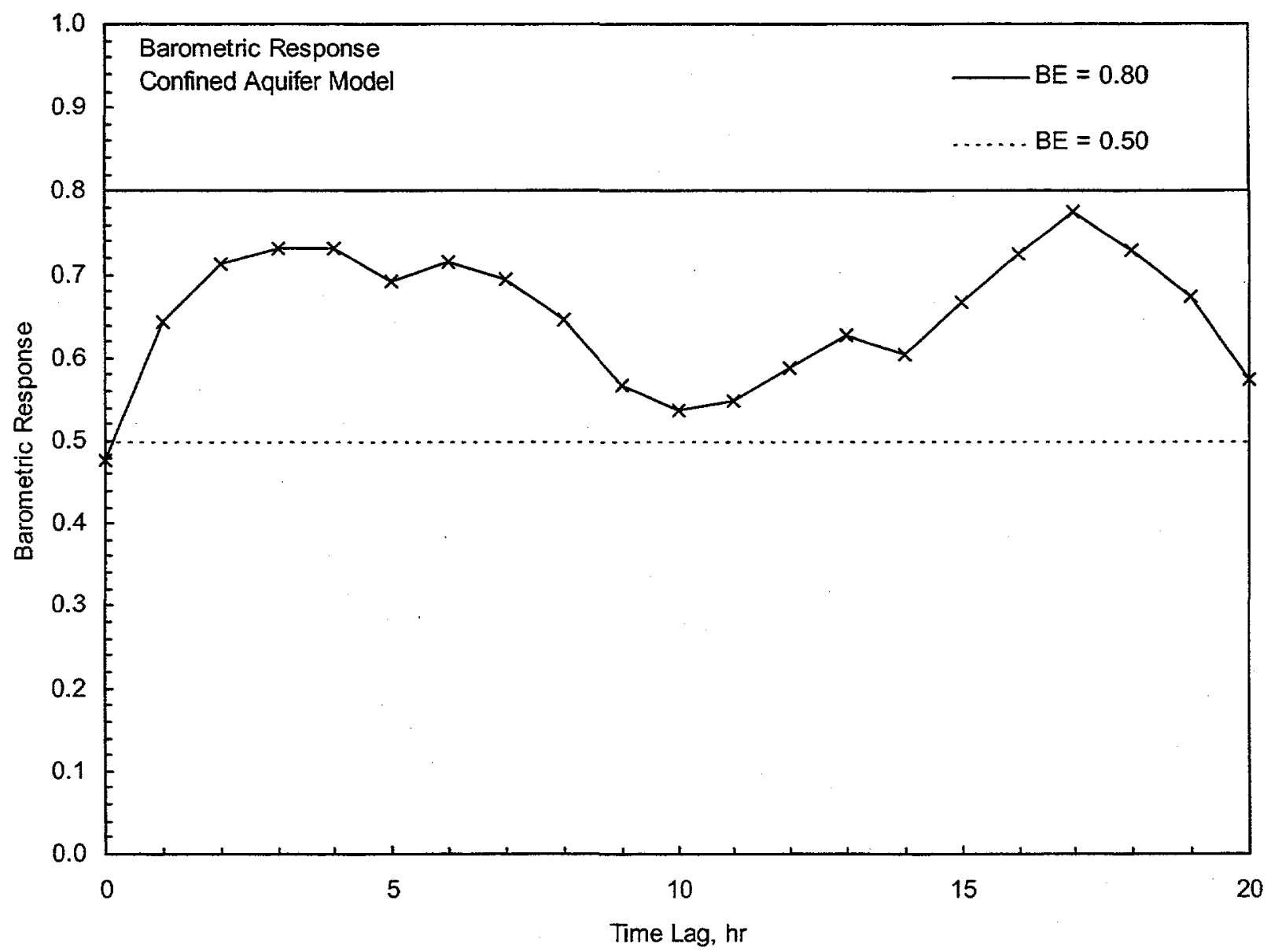

Figure 5.8. Water-Level Barometric Response Pattern for Monitor Well 299-W14-9

performed on the same baseline as a corroborative check on the multiple-regression analysis results. As shown in Table 3.3, the calculated $\mathrm{BE}_{\text {short }}$ and $\mathrm{BE}_{\text {long }}$ values are nearly identical (i.e., $\mathrm{BE} \approx 0.66$ ), which as noted previously, indicates confined aquifer model behavior.

Based on the barometric regression characteristics, barometric stress effects were removed by using the multiple-regression deconvolution method described in Section 3.0. Figure 5.9 shows the observed, predicted, and corrected well water-level responses for well 299-W14-9 over the 19-day analysis period. As shown in the figure, a reasonably close match between observed and predicted responses was obtained using the multiple-regression technique $\left(\mathrm{r}^{2}=0.96\right)$. The pattern of the residual corrected response shown in Figure 5.9 suggests the presence of additional external stress factors (i.e., earthtides). (Note: For a discussion on well water-level responses associated with earthtides, see Hsieh et al. 1988.) Because the effects of earthtides are usually quite small in sedimentary aquifers, the period during the $\mathrm{Y} 2 \mathrm{~K}$ shutdown period was examined to improve identification of any association within the corrected response to earthtide effects. Figure 5.10 shows the barometric corrected response compared to the theoretical earthtide potential, which was derived using the ETIDE computer program described in Hydrotechnique Associates (1984). As shown, an obviously associated, though small ( $\leq 0.04 \mathrm{~m})$, earthtide response is 


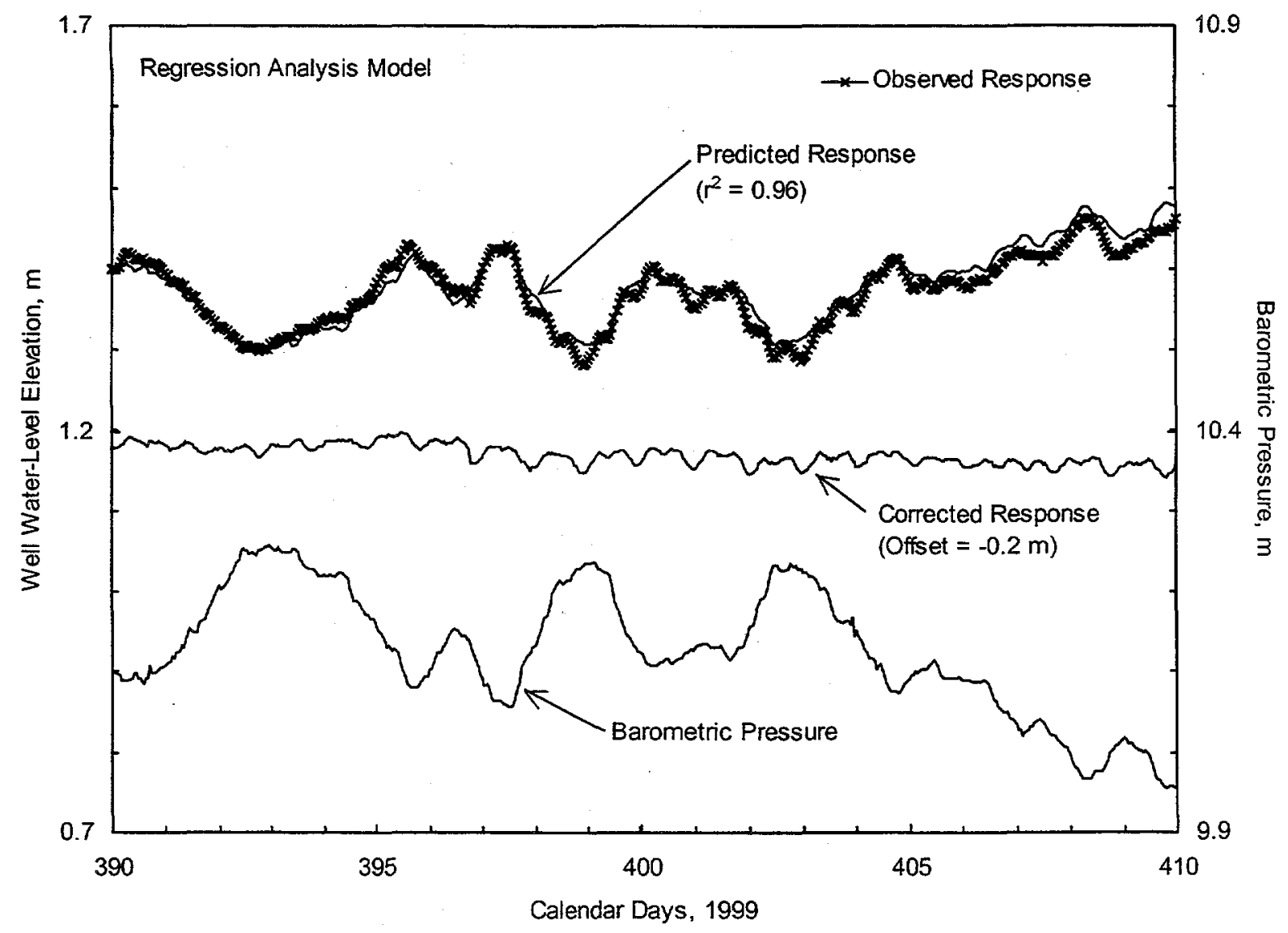

Figure 5.9. Multiple-Regression, Model-Predicted, and Barometric Corrected Water-Level Elevation Responses for Monitor Well 299-W14-9, January 25 to February 13, 2000 (1999 Calendar Days 390 to 409 )

evident in the barometric corrected data. The resolution of such small-magnitude earthtide effects further confirms the use of multiple-regression deconvolution techniques for effective barometric stress removal and, additionally, for identifying small, induced, pump-and-treat hydrologic response effects in monitor well records.

The same multiple-regression techniques can also be used to remove additional earthtide effects from the well water-level record. Figure 5.10 shows the water-level response for well 299-W14-9 during the Y2K shutdown period corrected for both earthtide and barometric effects. As indicated, the final corrected response has most of its diurnal variability removed. Figure 5.11 shows the observed and final corrected response over the total time period of record. As indicated, a definite linear increase in water level $(+0.07 \mathrm{~m})$ is exhibited during the Y2K shutdown period and a closely matched drawdown pattern $(-0.10 \mathrm{~m})$ is also evident during the restart of pump-and-treat activities. The consistent hydrologic response patterns within the corrected water-level response at well 299-W14-9 suggests that 200-ZP-1 activities may be imposing a hydrologic effect on the underlying confined aquifer system beneath the Ringold Lower Mud Unit. 


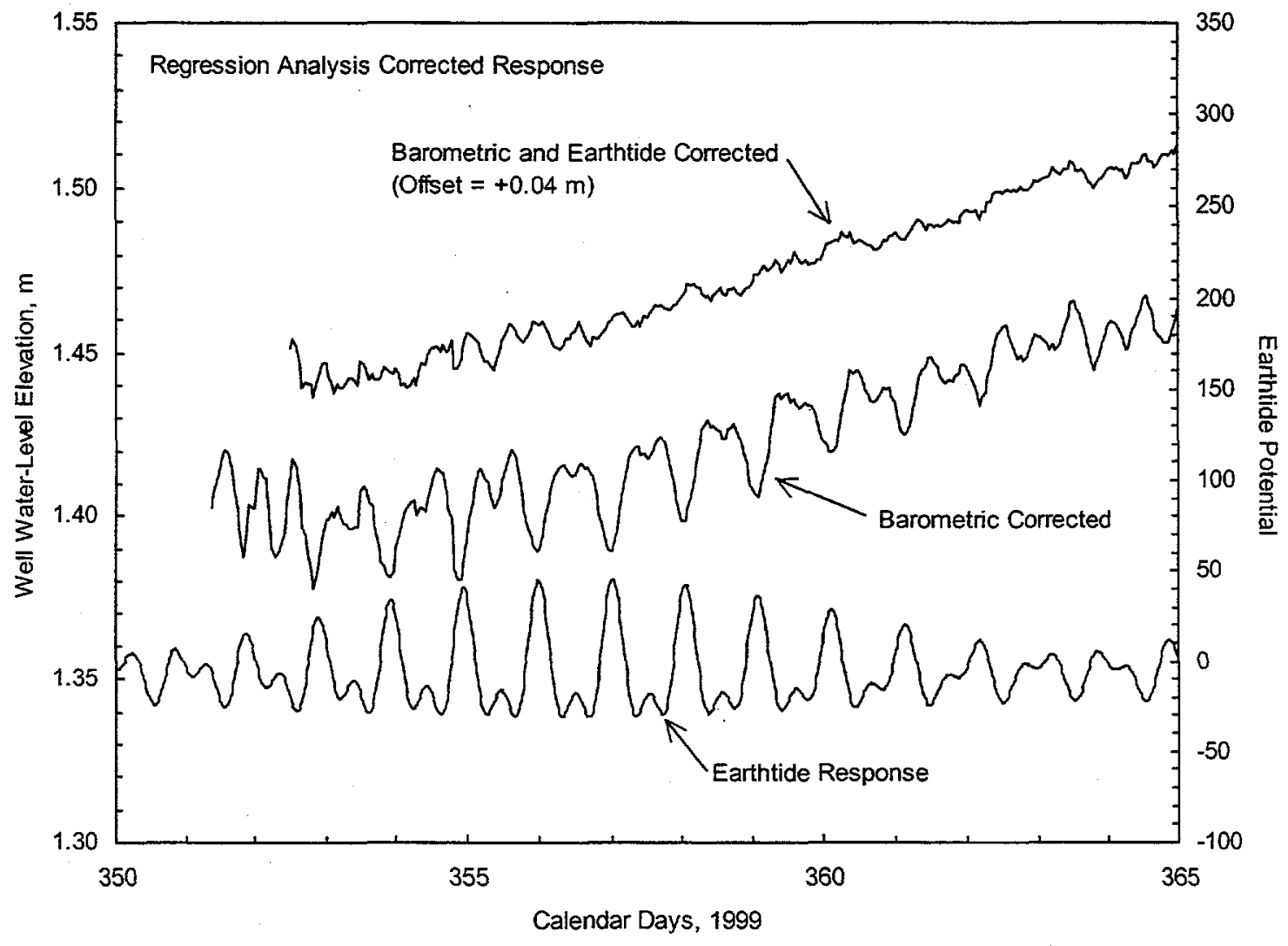

Figure 5.10. Earthtide Potential and Barometric and Earthtide-Corrected Water-Level Elevation Responses for Monitor Well 299-W14-9, December 16 to December 31, 1999 (1999 Calendar Days 351 to 365 )

A number of possible conceptual models may be responsible for the apparent $200-\mathrm{ZP}-1$ hydrologic response observed at well 299-W14-9: 1) pervasive direct leakage through the Ringold Lower Mud Unit, 2) loading phenomena (i.e., resulting from increases and decreases in the overlying unconfined aquifer saturated thickness), 3) distant hydrogeologic communication between the unconfined and confined aquifer systems (i.e., where the lower mud unit is not present), and 4) local hydraulic communication associated with well-seal deficiencies. With additional study, it may be possible to distinguish between which of the conceptual models is responsible for the imposed response evident at well 299-W14-9. 


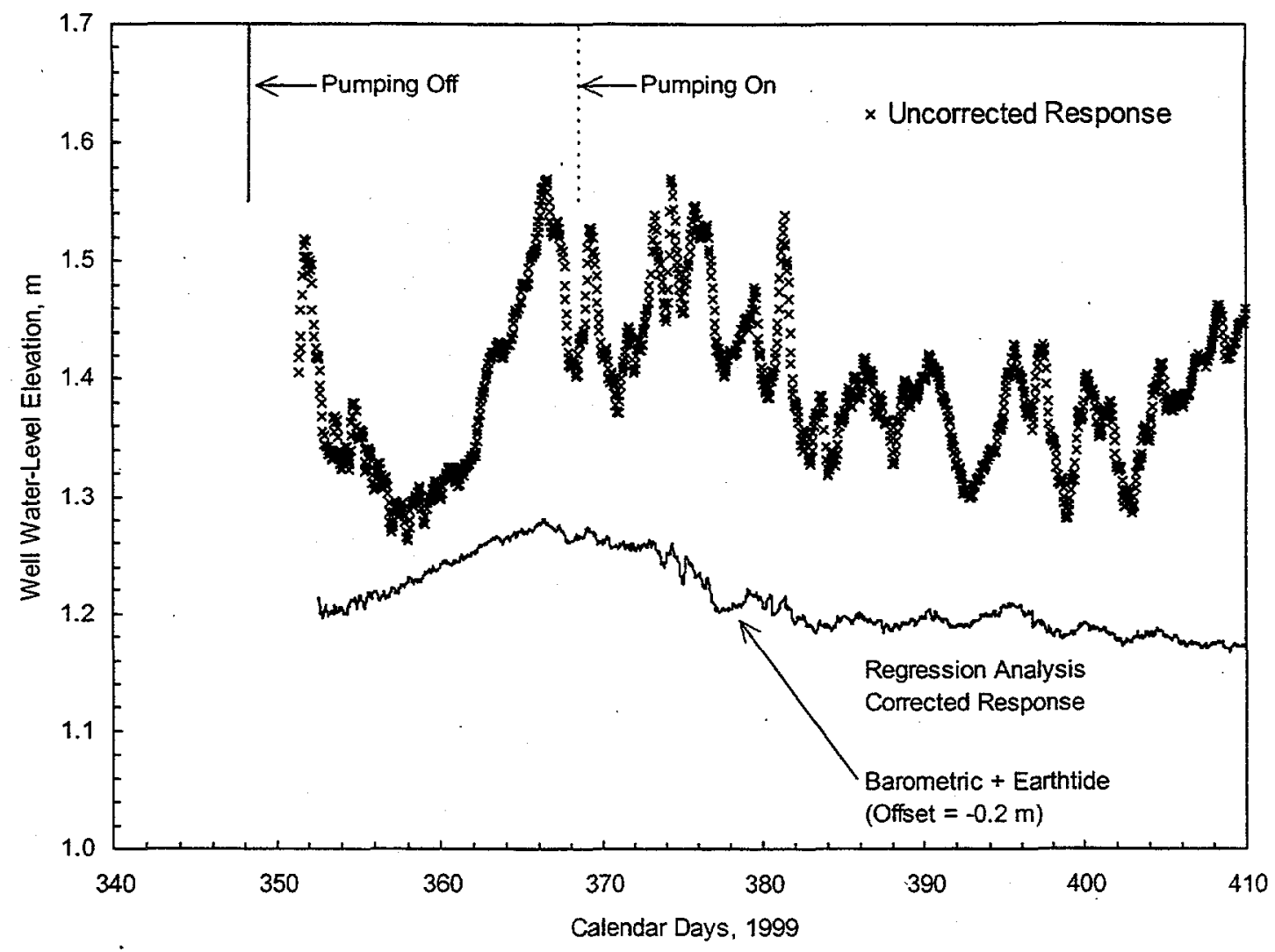

Figure 5.11. Barometric and Earthtide-Corrected Water-Level Elevation Responses for Monitor Well 299-W14-9, December 16, 1999 to February 14, 2000 (1999 Calendar Days 351 to 409) 


\subsection{Conclusions}

Operation of the 200-ZP-1 Operable Unit remedial pump-and-treat system imposes variable hydrologic pressure responses both laterally and vertically (i.e., with depth) over a significant distance within the unconfined aquifer (i.e., $>500 \mathrm{~m}$ for pumping times of 1 month or more). The lateral radius of influence is a function of a number of physical factors and test facility operation characteristics. Important physical factors include aquifer properties (i.e., hydraulic conductivity, vertical anisotropy, specific yield, and aquifer thickness) and well-/aquifer-completion relationships (i.e., partial penetration aspect). Test facility operation characteristics include the location, duration, magnitude, and variability of groundwater extraction and injection within the aquifer. The direct detection of the lateral radius of influence of the pump-and-treat system can be significantly improved by removing external stress effects imposed by barometric pressure fluctuations. These external stress effects can mask the response to the pump-and-treat system at more distant monitor well locations. Results from this investigation indicate that barometric pressure fluctuations were effectively removed from all monitor well water-level records examined using the multiple-regression deconvolution technique.

Operation of the pump-and-treat system also induces a vertical groundwater-flow component within the aquifer, which is reflected by drawdown differences with depth. The vertical flow component results from the downward movement of water that is released as the water table declines in an unconfined aquifer. This is associated with the delayed-yield response that is characteristic of unconfined aquifers. Downward groundwater-flow components imposed by the pump-and-treat system occur primarily within the upper part of the aquifer and diminish with time, becoming negligible for protracted periods of test system operation. Pumping wells that partially penetrate the upper part of the aquifer do not preclude establishment of vertical downward flow within the upper part of the aquifer, but likely diminish the persistence of this effect with time. Additionally, use of partially penetrating pumping wells within the upper part of the aquifer enhances upward vertical flow from the lower part of the aquifer, particularly for areas in proximity to the pumping well.

Specific findings pertaining to barometric response removal, imposed hydrologic influence, and hydraulic property characterization are summarized below:

1. Removal of barometric pressure fluctuations using the multiple-regression deconvolution technique significantly improves the ability to detect and analyze hydrologic stresses (e.g., $0.01 \mathrm{~m}$ ) imposed by the pump-and-treat system on distant monitor well responses.

2. Barometric response pattern analysis for the four unconfined aquifer wells examined (299-W15-1, -7, -11, -31A) indicates a composite model consisting of an unconfined aquifer system with wellbore-storage/skin effects evident during the early time-lag periods.

3. Barometric response pattern analysis and baseline response analysis using the Weeks (1979) analytical method indicate that the area surrounding three of the four wells examined exhibit very similar vadose zone pressure transmission characteristics (i.e., pneumatic diffusivity), while the 
fourth well (299-W15-31A) exhibits transmission characteristics nearly twice as high. All four wells exhibit vadose zone pneumatic diffusivities $\left(0.01\right.$ to $\left.0.03 \mathrm{~m}^{2} / \mathrm{s}\right)$ within the range previously observed at other 200-West Area locations.

4. Operation of the pump-and-treat system imposes variable hydrologic pressure responses both laterally and vertically (i.e., with depth) over a significant distance within the surrounding unconfined aquifer. It is likely that the lateral radius of influence for the facility exceeds $500 \mathrm{~m}$ for facility operation times of 1 month or more.

5. The operation of the pump-and-treat system likely imposes vertical flow conditions that result from the delayed-yield phenomenon, which is characteristic of unconfined aquifers. Vertical flow, though persistent with distance, diminishes with time, becoming negligible for protracted periods of pump-and-treat system operation. For the theoretical example in this investigation, small vertical flow components (i.e., based on drawdown differences $\leq 0.004 \mathrm{~m}$ ) were still evident after 1 year of pumping for radial distances $>100 \mathrm{~m}$ from the pumping well.

6. The hydrologic impact of the pump-and-treat system on the underlying confined aquifer system below the Ringold Lower Mud Unit is largely unknown. However, removal of barometric pressure and earthtide stress effects from well 299-W14-9 water-level record, which monitors this underlying confined aquifer system, reveals a hydrologic response that appears associated with the pump-and-treat shutdown and startup activities. This apparent association was not evident in the uncorrected water-level response.

7. Analysis of the pump-and-treat system during the $\mathrm{Y} 2 \mathrm{~K}$ restart period provided hydraulic property estimates for transmissivity that ranged between 230 and $430 \mathrm{~m}^{2} / \mathrm{d}$ (average $325 \mathrm{~m}^{2} / \mathrm{d}$ ). The calculated average value compares closely with large-scale values of 300 and $327 \mathrm{~m}^{2} / \mathrm{d}$ previously reported in Newcomb and Strand (1953) and Wurstner et al. (1995), respectively, for the unconfined aquifer within the 200-West Area. These previously reported values were based on analyzing the areal growth and decline of the groundwater mound that developed in this area as a result of wastewater disposal activities.

8. Estimates for hydraulic conductivity ranged between 3.5 and $6.6 \mathrm{~m} / \mathrm{d}$ (average $5.0 \mathrm{~m} / \mathrm{d}$ ). The estimated values are within the range previously reported for the unconfined aquifer within the 200 -West Area and are close to the baseline value of $5.2 \mathrm{~m} / \mathrm{d}$ used for this area in previous numerical simulations of sitewide groundwater flow (e.g., Law et al. 1996) and pump-and-treat activities (Freeman-Pollard et al. 1996).

9. The estimates obtained for specific yield, however, $(\approx 0.03)$ appear to be lower than what would be expected (i.e., between 0.05 to 0.25 ) for this hydrogeologic unit. The reason for this apparent discrepancy is not currently understood. This lower-than-expected value, however, is consistent with findings from other unconfined aquifer location investigations where type-curve analysis methods were used (e.g., Mock and Merz 1993; Moench 1994). 
In conclusion, the analysis of areal water-level responses imposed by the 200-ZP-1 pump-and-treat system provides an opportunity for obtaining detailed, large-scale information for a wide range of hydrologic properties (i.e., transmissivity, hydraulic conductivity, vertical and horizontal anisotropy, storativity, and specific yield). Many of these properties cannot be reliably estimated using standard single-well tests or hydrologic tests of short duration. This large-scale hydrologic characterization information can provide valuable input for assessing the performance of the 200-ZP-1 pump-and-treat facility and for predicting contaminant movement in the 200-West Area. The wide variability in pumping and injection rates, while acceptable for the normal operation of the pump-and-treat facility, greatly complicates this hydrologic characterization opportunity. Operating the pump-and-treat system in a more controlled manner over a 2 - or 3-month period would likely provide the best opportunity for obtaining more accurate, large-scale, hydrologic characterization information. 


\subsection{References}

Bourdet DJ, A Ayoub, and YM Pirard. 1989. "Use of pressure derivative in well-test interpretation." SPE Formation Evaluation June 1989:293-302.

Clark WE. 1967. "Computing the barometric efficiency of a well." American Society of Civil Engineers, Joumal of the Hydraulic Division, Proceedings 93(HY4):93-98.

Cooper HH, Jr., and CE Jacob. 1946. "A generalized graphical method for evaluating formation constants and summarizing well-field history." American Geophysical Union, Transactions 27(4):526-534.

DOE/RL. 1993. 200 west groundwater aggregate area management study report. DOE/RL-92-16, Rev: 0, U.S. Department of Energy, Richland Operations Office, Richland, Washington.

DOE/RL. 1998. Fiscal year 1997 annual report for the 100-NR-2, 200-UP-1, and 200-ZP-1 pump and treat operations and operable units. DOE/RL-98-38, Rev. 0, U.S. Department of Energy, Richland Operations Office, Richland, Washington.

DOE/RL. 1999. Fiscal year 1998 annual summary report for the 200-UP-1, 200-ZP1-, and 100-NR-2 pump and treat operations and operable units. DOE/RL-99-02, Rev. 0, U.S. Department of Energy, Richland Operations Office, Richland, Washington.

DOE/RL. 2000. Fiscal year 1999 annual summary report for the 200-UP-1, 200-ZP-1, and 100-NR-2 pump and treat operations and operable units. DOE/RL-99-79, Rev. 0, U.S. Department of Energy, Richland Operations Office, Richland, Washington.

Freeman-Pollard JR, ID Jacques, WJ McMahon, KM Singleton, SA Strope, LC Swanson, and CR Winmueller. 1996. 200-ZP-1 phase II interim remedial measure quarterly report; August-October 1996, BHI-00952-01, Rev. 0, Bechtel Hanford, Inc., Richland, Washington.

Hantush MS. 1964. "Hydraulics of wells." Advances in Hydroscience (VT Chow, ed.) 1:282-433, Academic Press, New York.

Hartman MJ, ed. 1999. Hanford Site groundwater monitoring for fiscal year 1998. PNNL-12086, Pacific Northwest National Laboratory, Richland, Washington.

Hartman MJ, LF Morasch, and WD Webber. 2000. Hanford Site groundwater monitoring for fiscal year 1999. PNNL-13116, Pacific Northwest National Laboratory, Richland, Washington.

Hsieh PA, JD Bredehoeft, and SA Rojstaczer. 1988. "Response of well aquifer systems to earth tides: Problem revisited. Water Resources Research 24(3):468-472. 
Hydrotechnique Associates. 1984. User's manual for the theoretical earth tide generation program, ETIDE. Prepared by Hydratechnique Associates, Berkeley, California for the Basalt Waste Isolation Project, Rockwell Hanford Operations, Richland, Washington.

Law A, S Panday, C Denslow, K Fecht, and A Knepp. 1996. Hanford sitewide groundwater flow and transport model calibration report. BHI-00608, Rev. 1, Bechtel Hanford, Inc., Richland, Washington.

Lindsey KA. 1995. Miocene- to Pliocene-aged suprabasalt sediments of the Hanford Site, south-central Washington. BHI-00184, Bechtel Hanford, Inc., Richland, Washington.

Mock P, and J Merz. 1993. "Observations of delayed gravity response in partially penetrating wells." Ground Water 28(1):11-16

Moench AF. 1994. "Specific yield as determined by type-curve analysis of aquifer-test data." Ground Water 32(6):949-957.

Moench AF. 1997. "Flow to a well of finite diameter in a homogeneous, anisotropic water-table aquifer." Water Resources Research 33(6):1397-1407.

Neuman SP. 1972. "Theory of flow in unconfined aquifers considering delayed response of the water table." Water Resources Research 8(4):1031-1045.

Neuman SP. 1974. "Effect of partial penetration of flow in unconfined aquifer considering delayed gravity response." Water Resources Research 10(2):303-312.

Neuman SP. 1975. "Analysis of pumping test data from anisotropic unconfined aquifers considering delayed gravity response." Water Resources Research 11(2):329-342.

Neuman SP. 1979. "Perspective on 'delayed yield." Water Resources Research 15(4):899-908.

Newcomb RC, and JR Strand. 1953. Geology and ground-water characteristics of the Hanford Reservation of the U.S. Atomic Energy Commission, Washington. Administrative Report WP-8, U.S. Geological Survey, Washington, D.C.

Rasmussen TC, and LA Crawford. 1997. "Identifying and removing barometric pressure effects in confined and unconfined aquifers." Ground Water 35(3):502-511.

Record of Decision (ROD). 1995. Declaration of the record of decision, USDOE Hanford 200 area, Hanford Site, Benton County, Washington (200-ZP-1). State of Washington Department of Ecology, U.S. Environmental Protection Agency, and U.S. Department of Energy, Richland Operations Office, Richland, Washington.

Spane FA, Jr. 1992. Applicability of slug interference tests under Hanford Site test conditions: Analytical assessment and field test evaluation. PNL-8070, Pacific Northwest Laboratory, Richland, Washington. 
Spane FA, Jr. 1993. Selected hydraulic test analysis techniques for constant-rate discharge tests. PNL-8539, Pacific Northwest Laboratory, Richland, Washington.

Spane FA, Jr. 1999. Effects of barometric fluctuations on well water-level measurements and aquifer test data. PNNL-13078, Pacific Northwest National Laboratory, Richland, Washington.

Spane FA, Jr., PD Thorne, and LC Swanson. 1996. "Applicability of slug interference tests for hydraulic characterization of unconfined aquifers: (2) Field test examples." Ground Water 34(5):925-933.

Spane FA, Jr., and SK Wurstner. 1993. "DERIV: A program for calculating pressure derivatives for use in hydraulic test analysis." Ground Water 31(5):814-822.

Swanson LC, VC Rohay, and JM Faurote. 1999. Hydrologic conceptual model for the carbon tetrachloride and uranium/technetium plumes in the 200 West Area: 1944 through 1999 update. BHI-01311, Rev. 0, Bechtel Hanford, Inc., Richland, Washington.

Theis CV. 1935. "The relationship between the lowering of the piezometric surface and the rate and duration of discharge of a well using ground-water storage." Amer. Geophys. Union, Transactions, 2: 519-524; reprinted in Society of Petroleum Engineers, "Pressure Transient Testing Methods.", SPE Reprint Series (14):27-32, Dallas, Texas.

Walton WC. 1960. "Application and limitation of methods used to analyze pumping test data." Water Well Journal, Feb. - March 1960.

Weeks EP. 1979. "Barometric fluctuations in wells tapping deep unconfined aquifers." Water Resources Research 15(5):1167-1176.

Wurstner SK, PD Thorne, MA Chamness, MD Freshley, and MD Williams. 1995. Development of a three-dimensional ground-water model of the Hanford Site unconfined aquifer system: FY 1995 status report. PNL-10886, Pacific Northwest Laboratory, Richland, Washington. 


\section{Appendix}

Multiple-Regression, Model-Predicted, and Barometric Corrected Water-Level Elevation Responses for Monitor Wells 299-W15-7, -11, and -31A 


\section{Appendix}

\section{Multiple-Regression, Model-Predicted, and Barometric Corrected Water-Level Elevation Responses for Monitor Wells 299-W15-7, -11, and -31A}

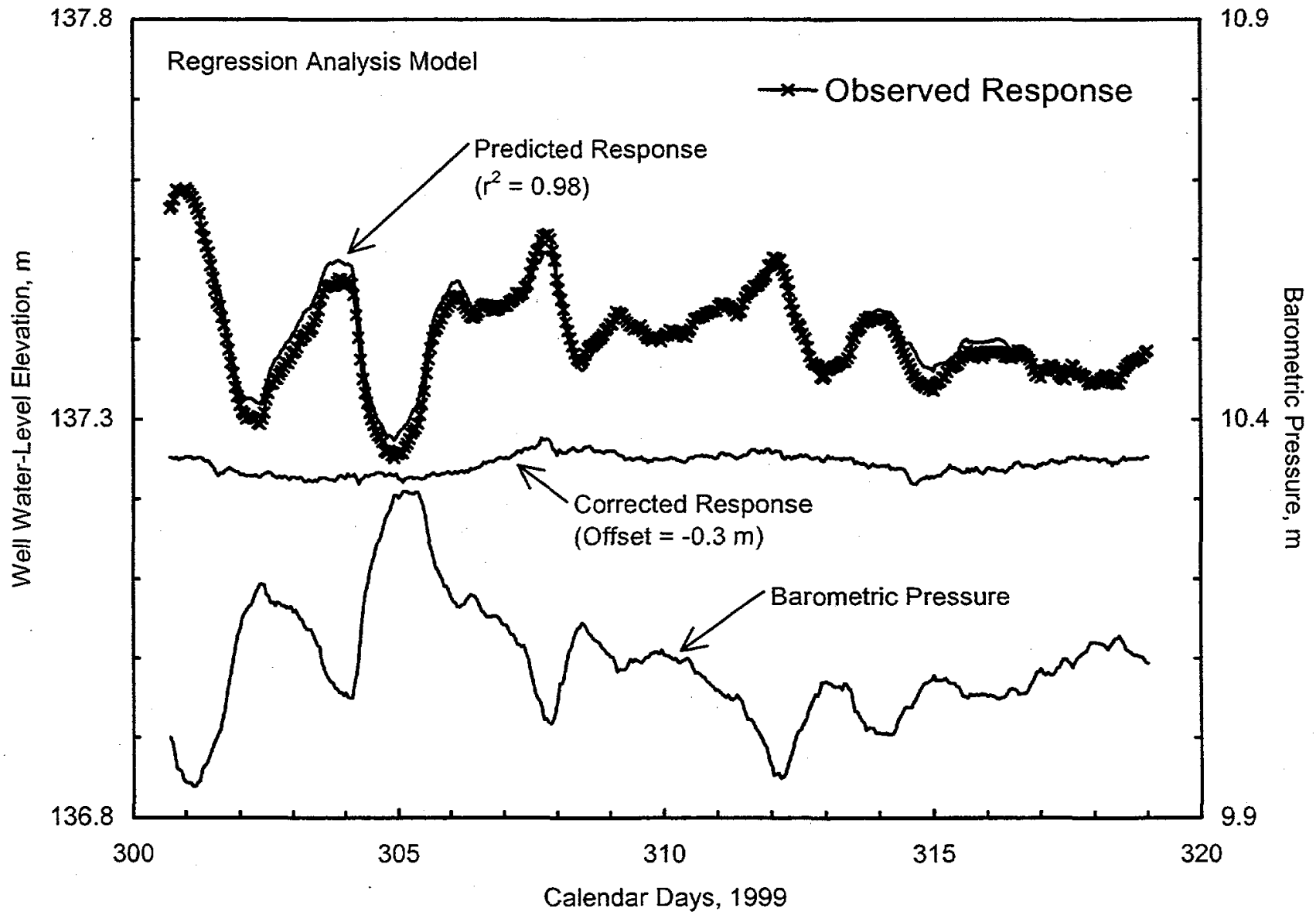

Figure A.1. Multiple-Regression, Model-Predicted, and Barometric Corrected Water-Level Elevation Responses for Well 299-W15-7 


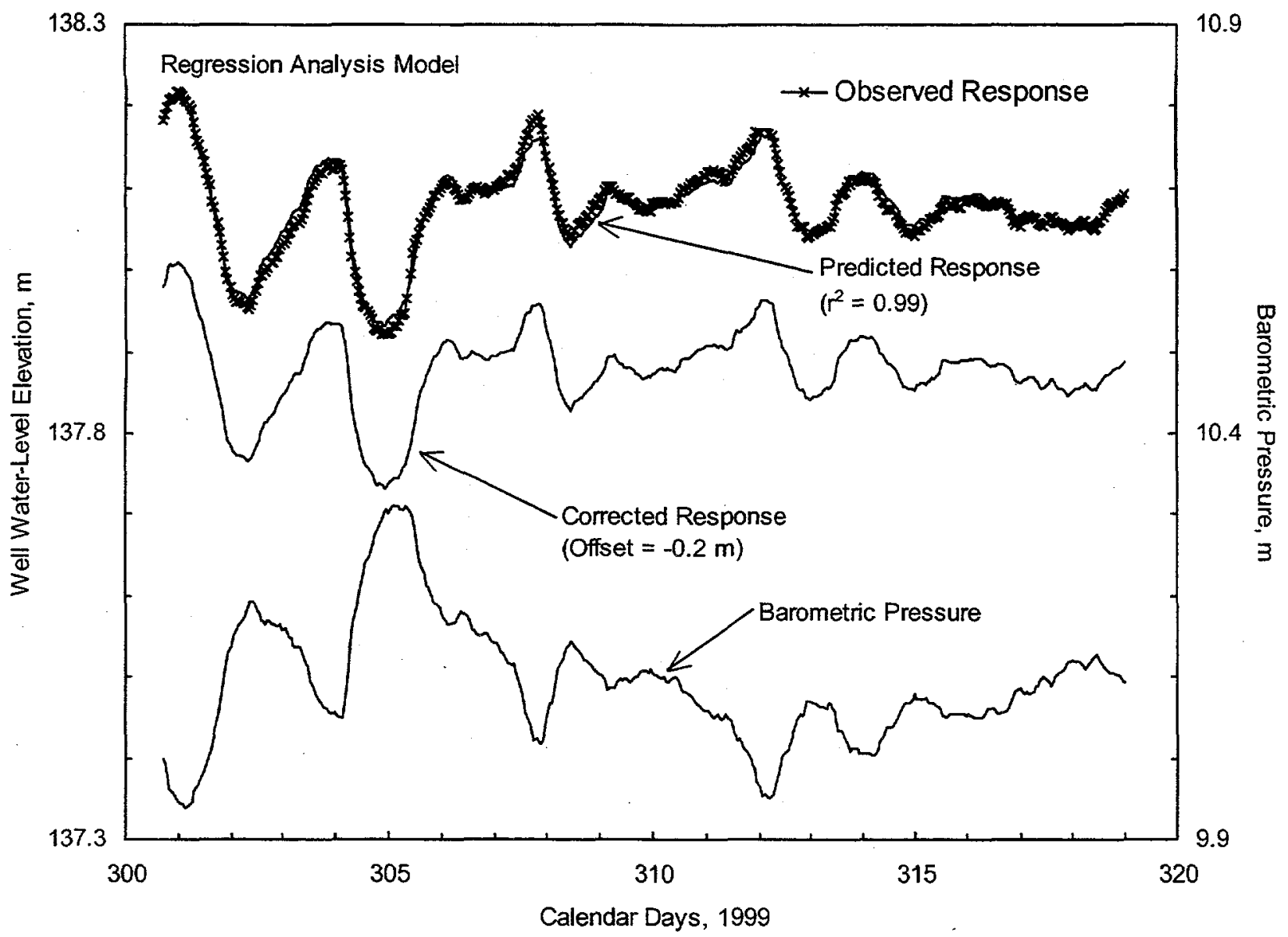

Figure A.2. Multiple-Regression, Model-Predicted, and Barometric Corrected Water-Level Elevation Responses for Well 299-W15-11 


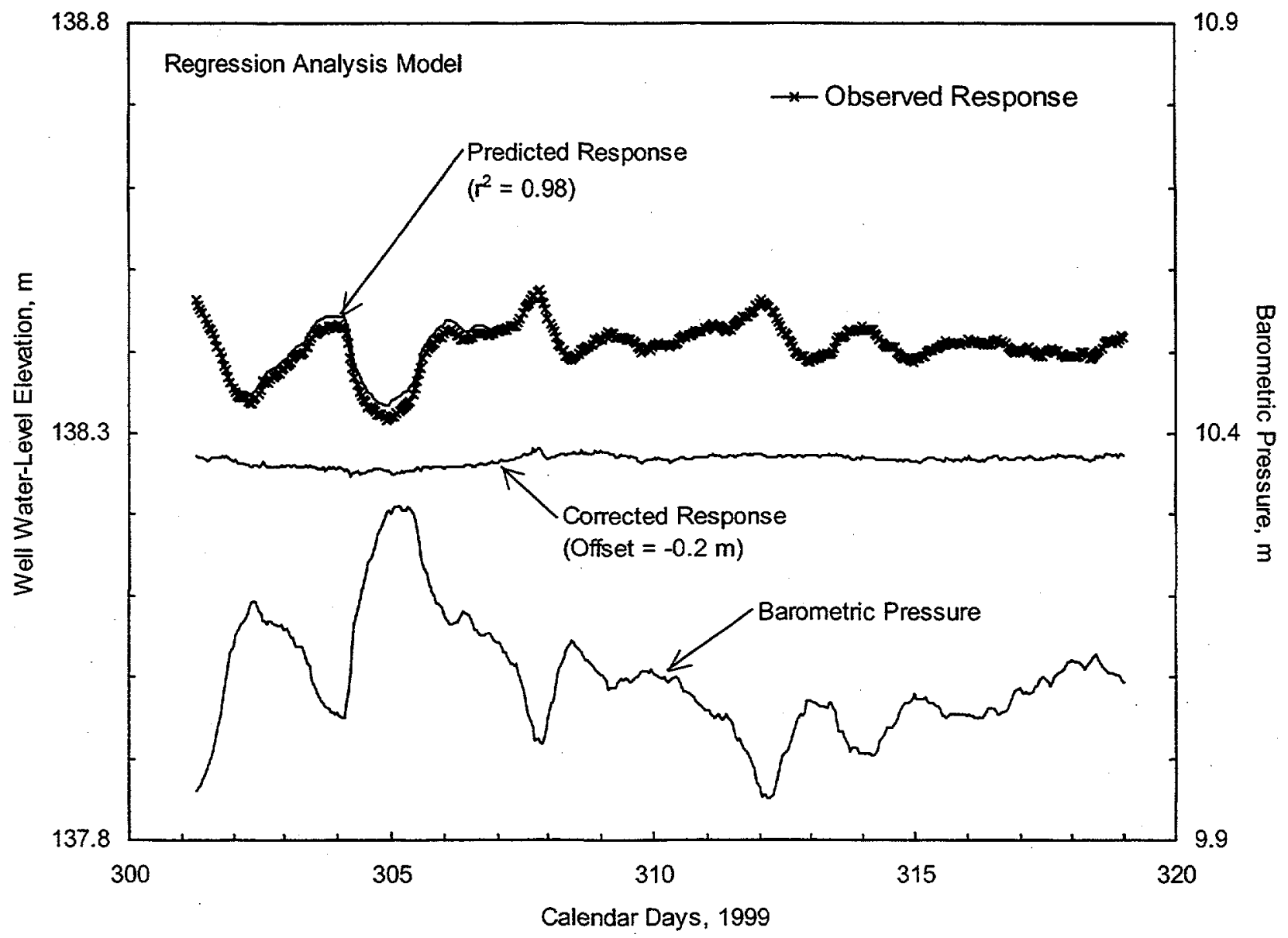

Figure A.3. Multiple-Regression, Model-Predicted, and Barometric Corrected Water-Level Elevation Responses for Well 299-W15-31A 
PNNL-13342

\section{Distribution}

No. of

\section{Copies}

\section{OFFSITE}

M. L. Blazek

State of Oregon Office of Energy

625 Marion Street N.E.

Salem, OR 97310

\section{J. S. Bochmaier}

U.S. Department of Energy

Forrestal Building, EH-412

1000 Independence Avenue, S.W.

Washington, D.C. 20585

J. Butler

Geohydrology Section

Kansas Geological Survey

University of Kansas

Lawrence, KS 66047

2 Confederated Tribes of the Umatilla

Indian Reservation

P.O. Box 638

Pendleton, OR 97801

ATTN: W. Burke

S. Harris

R. A. Danielson

State of Washington Department of Health

2 South $45^{\text {th }}$ Avenue

Yakima, WA 98908

B. W. Drost

Geological Survey

U.S. Department of the Interior

1201 Pacific Avenue, Suite 600

Tacoma, WA 98402

M. K. Harmon

U.S. Department of Energy

Cloverleaf Building, EM-44

19901 Germantown Road

Germantown, MD 20874-1290
No. of

Copies

W. N. Herkelrath

Geological Survey

U.S. Department of the Interior

345 Middlefield Road, MS 496

Menlo Park, CA 94025

2 Idaho National Engineering and Environmental Laboratory

Lockheed Martin Idaho Technology Co.

P.O. Box 1625

Idaho Falls, ID 83415-2107

ATTN: J. M. Hubbell

J. B. Sisson

2 Nez Perce Tribe

Environmental Restoration/Waste

Management

P.O. Box 365

Lapwai, ID 83540-0365

ATTN: S. Sobczyk

P. Sobotta

T. C. Rasmussen

Hydrology and Environmental Systems

Warnell School of Forest Resources

The University of Georgia

Athens, GA 30602-2152

2 Schlumberger HydroGeological

Technologies

6090 Greenwood Plaza Blvd.

Englewood, CO 80111

ATTN: R. Lewis

N. Clayton

2 State of Washington

Department of Health

Division of Radiation Protection

P.O. Box 47827

Olympia, WA 98504-7827

ATTN: D. McBaugh

G. Robertson

Distr.1 
No. of

Copies

3 Wanapum People

Grant County P.U.D.

P.O. Box 878

Ephrata, WA 98823

ATTN: R. Buck

L. Seelatsee

R. Tomanawash

E. Weeks

Geological Survey

U.S. Department of the Interior

Box 25046

Building 53, Room 2910

Denver Federal Center

Lakewood, CO 80225

2 Yakama Indian Nation

Environmental Restoration/Waste

Management Program

2808 Main Street

Yakima, WA 98903

ATTN: R. Jim

W. Rigsby

\section{Foreign}

M. Hagood

Schlumberger

Parkstraat 83

2514 JG The Hague

The Netherlands

4 Westbay Instruments, Inc.

\#115-949 W. Third Street

North Vancouver, British Columbia

Canada V7P 3P7

ATTN: W. Black

D. Larssen

F. Patton

J. Sankey
No. of

Copies

ONSITE

12 DOE Richland Operations Office

H. L. Boston H6-60

B. L. Foley $\quad \mathrm{HO}-12$

M. J. Furman H0-12

R. D. Hildebrand $\quad \mathrm{H} 0-12$

J. G. Morse H0-12

J.P. Sands H0-12

T. A. Shrader H0-12

K. M. Thompson H0-12

A. C. Tortoso H0-12

R. M. Yasek H6-60

Public Reading Room (2) H2-53

4 Bechtel Hanford, Inc.

J. F. Armatrout H0-19

B. H. Ford $\quad \mathrm{H} 0-21$

M. J. Graham H0-09

G. B. Mitchem H0-21

5 CH2M Hill Hanford, Inc.

J. V. Borghese

H0-21

R. L. Jackson H9-03

W. J. McMahon H9-03

V. J. Rohay H0-21

L. C. Swanson H9-02

CH2M Hill Hanford Group
A. J. Knepp
$\mathrm{H} 0-22$

2 State of Washington Department of Ecology

D. Goswami B5-18

A. Huckaby B5-18

3 U.S. Environmental Protection Agency

D. R. Sherwood B5-01 
No. of

Copies

4 Waste Management Federal Services, Inc., Northwest Operations

D. R. Brewington

H1-11

M. G. Gardner

H1-11

D. E. Hollingsworth

H1-11

S. H. Worley

H1-11

4 Waste Management Federal Services of Hanford, Inc.
R. D. Haggard
G1-29
K. J. Lueck
S6-72
P. M. Olson
S6-72
R. W. Szelmeczka
S6-72

69

\section{Pacific Northwest National Laboratory}

J. G. Bush

D. B. Barnett

K6-96

M. P. Bergeron

M. A. Chamness

C. R. Cole

P. E. Dresel

M. J. Fayer

M. D. Freshley

J. S. Fruchter

G. W. Gee

T. J Gilmore

M. J. Hartman

K9-33

K6-81

K6-96
No. of

Copies

F. N. Hodges

K6-81

V. G. Johnson

K6-96

C. T. Kincaid

K9-33

G. V. Last

T. L. Liikala

K6-81

K6-96

J. W. Lindberg

S. P. Luttrell (5)

K6-81

K6-96

J. P. McDonald

K6-96

R. B. Mercer

K6-96

S. M. Narbutovskih

K6-96

D. R. Newcomer

K6-96

S. Orr

K9-33

K6-96

R. E. Peterson

K6-81

K6-96

K.6-96

K6-96

K6-96

K6-96

K6-96

K6-81

K9-33

K6-96

K6-96

K6-96

K9-36

K6-81

K9-36 